\title{
Die finnische Grammatik von Henricus Crugerus.
}

Die älteste im Druck erschienene finnische Grammatik ist bekanntlich die Linguæ Finnicæ brevis institutio von Eschillus Petreus, 1649. Das ist aber nicht der erste Versuch, die finnische Sprache in Regeln zu fassen. In der Fachliteratur ist nämlich von zwei früheren Grammatiken, der von Olaus Sondergelteus und der von Hexricus CrugeRUS berichtet worden. Im Folgenden soll nun über diese, besonders über die zweite, und zwar mit Anführung neuen, bisher übersehenen Materials gehandelt werden.

1. In einem dem Brief vom Kardinal Possevixo an den Kardinal Сомо, datiert in Prag d. 7. XI.1580, beigefügten Schülerverzeichnis des Jesuitenkollegiums zu Olmütz, s. Thersek Schweden und seine Stellung zum heiligen Stuhl II, Augsburg 1839, S. $313 \mathrm{ft}$, wird ein aus Finnland stammender Zögling der Klasse "Physici" OLAus Soxdergelteus genannt und nachher in einer Bemerkung über ihn u. a. noch ausgeführt, dass er mit der Abfassung einer finnischen Grammatik beauftragt worden sei: "Olaus Sondergelteus, Finlandus, 28 annorum, receptus 12 . Oct. $1579 \ldots{ }^{1}$ Quinto, quod ad ipsas catalogi personas attinet, primus in ordine, Olaus, qui erat acerrimus Ecclesiae catholicae persecutor, et minister haereticus, cupit post Philosophiae studia absoluta posse Theolo-

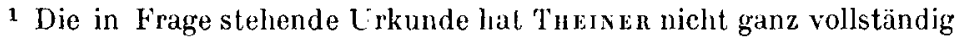
veröffentlicht. Nach einem genauen Abdruck derselben, herausgegeben in dem Werk von Navrátil Jesuité Olomoučli za protireformace I, Brünn 1916, sind die Angaben "Olaus Sondergelteus, Finlandus» durch einen Zusatz Arctopoliensis*, d. h. ein aus Björneborg (Pori) Stammender zu ergänzen (nach Mıкоц Hist. Ark. XXXVl, s. u.). 
giam audire; quae nondum potuit praelegi ordinate in Collegio Olomucensi, rebus ejus Collegii hoc non ferentibus. Huic vero cura data est Finlandicae Grammaticae conscribendae, ut postea item eam in linguam vertatur Catechismus. "1 Der obige Auszug mit einigen Bemerkungen findet sich mit Nennung derselben Quelle bereits bei YrJö KoskrNen Historiallinen Arkisto IV, Helsinki 1874, S. 166; über OlaUs SondergeLTeus (Sundergelteus) siehe ferner ders. Hist. Ark. V, 1876, S. 58 f., Biografinen nimikírja, Helsinki 1879-83, S. 669 (mit Nennung von Hist. Ark. IV, V und ferner von A. G. AhLQvist Hist. Bibl. 1879), LeINBERG Om finske studerande i Jesuitcollegier in Hist. Ark. XI, 1891, S. 173 ff., kurz ohne Quellenangabe SETÄLÄ in einem Aufsatz über finnische Grammatiken in NyK XXIV, Budapest 1894, S. 93 f., zusammenfassend J-S H[EDExgREx] in Carpeldxs Finsk Biografisk Handbok II, Helsingfors 1903; fernerhin LEINBERg Några tillägg etc. in Hist. Ark. XVIII, 1903, S. 362 ff., BIAUdET Om finske studerande i Jesuitcollegier in Hist. Ark. XIX, 1905, S. 179 ff., MrkкoLA Pohjoismaalaisista ja eritoten suomalaisista opiskelijoista Braunsbergin paavillisessa seminaarissa ja Olmützin kollegiossa S. 6 f. in Hist. Ark. XXXVI, 1928, und ders. zusammenfassend in Kansallinen elämäkerrasto V, Porvoo 1934, S. 295. Nach den zur Zeit als glaubwürdig erscheinenden Angaben ist Oraus Soxdergelteus 1551 in Ulvila (Ulfsby) geboren; seine Kinderjahre verbrachte er in Helsinki und Pori (Björneborg), s. LeIvberg Hist. Ark. XI S. 173. In der zuletzt erwähnten Stadt ist er wahrscheinlich auch aufgewachsen, denn er wird nachher im Olmützer Jesuitenkollegium "Arctopoliensis" genannt (s.o. S. 55 Fussnote) und seine Mutter lebte noch 1590-91 dort, s. LeIvberg 1.c.

I Vgl. Theixer l. c. S. ', wo folgendes steht: "L'nter andern vielen und weisen Verordnungen, die Possevin zum Besten der in dieser Anstalt zu erziehenden Jünglinge traf, muss vor allen jene erwähnt werden, welche diesen das Studium der vaterländischen Sprache empfahl und ans Herz legte. So ward Olof, früher lutherischer Prädikant, Finne, und grosser Feind der katholischen Religion, beauftragt, eine Grammatik und einen Katechismus [!, vgl, den lat. Text] in der Sprache seines Vatẹrlandẹs abzufașsen"n, 
S. 173 f. Er war eine Zeitlang lutherischer Pfarrer - wo er dieses Amt bekleidet und wo er seine Ausbildung erhalten hat, ist nicht bekannt -, trat aber dann, wahrscheinlich 1578, zur katholischen Kirche über und wurde 1579 als Schüler in das neugegründete Jesuitenkollegium zu Olmütz aufgenommen, 1580 wurde er daselbst zum Bakkalaureus promoviert, s. LeINBERG 1. c. S. $174 \mathrm{f}$, , und wahrscheinlich in demselben Jahre mit der Abfassung der finnischen Grammatik beauftragt. Am 15. IV. 1581 verliess er das Olmützer Kollegium und ging, dem Rufe des Kardinals Possevixo folgend, an den polnischen Hof und von dort mit Instruktionen des Letzteren versehen als katholischer Missionär nach Schweden und Finnland, s. BIAUdert l. c. S. 183 ff. Einige Jahre später wird sein Name (Olats Sundergeltecs, Suecus [sic!]) in dem Schülerverzeichnis des Braunsberger Jesuitenkollegiums erwähnt, s. LeIxBERG 1. c. S. 175; offenbar hielt er sich hier aber nur eine kurze Zeit auf, s. BIAUder l. c., da hier höhere Kurse fehlten. Wo er schliesslich seine katholischtheologischen Studien trieb und zum Schluss brachte, ist nicht bekannt. Später war er in Estland tätig; in den neunziger Jahren als katholischer Priester in Pärnu, in welcher Eigenschaft er am 15. VI. 1596 ein Viaticum für einen schwedischen Glaubensgenossen ausstellte, s. YrJö Koskrven Hist. Ark. V S. 58 f. und Leinberg Hist. Ark. XI S. 176 f., XVIII S. 364, und etwa 1600 als Propst in Tartu ("Olaus Sundergelteus prepositus Torpatensis, Torpati in Livonia, Finlandus"), s. Lein berg Hist. Ark. XVIII S. 362 f. und BIAUDET Hist. Ark. XIX S. 182 ff. Aus seiner späteren Lebenszeit ist nichts bekannt.

Wie oben angeführt, wurde OLAus SONDERGELTEUs während seines Aufenthalts in dem Kollegium zu Olmütz mit der Abfassung einer finnischen Grammatik beauftragt. In der Annahme, dass er die Grammatik fertiggestellt habe, hat man verschiedenerseits eifrig nach ihr gesucht, s. BIAUDET l. e. S. 186 und Mikkola Hist. Ark. XXXVI, doch ohne jeglichen Erfolg. Nun ist hierbei hervorzuheben, dass nur die Beauftragung als Tatsache feststeht, dagegen aber liegt keinerlei Notiz vor, dass Soxpergelteus den Auftrag, sei es 
auch nur zum Teil, ausgeführt habe; sonst sind wir ja über sein Leben verhältnismässig gut unterrichtet. Daher ist es wohl fraglich, ob die Grammatik überhaupt je geschrieben wurde.

2. So kommen wir zu Hexricus Crugerus, der im Gegensatz $\mathrm{zu}$ Sondergelteus schon als Autor einer finnischen Grammatik erwähnt ist. Unter den von LEIBNIz (1646-1716) hinterlassenen Handschriften in der Königlichen Öffentlichen Bibliothek zu Hannover findet sich ein Konvolut, bezeichnet "Collectanea etymologica" (IV, 469), das u. a. einen Aufsatz über seine allgemeinen sprach wissenschaftlichen Betrachtungen enthält. SETÄLÄ hat 1888 in Hannover den handschriftlichen Nachlass und den Briefwechsel von Leibniz durchgesehen und sich mit dem Aufsatz näher befasst, s. seine Untersuchung Lisiä suomı.-ugr. kielentutk. historiaan in Suomi III, 5, Helsinki 1892, S. 234 ff. ${ }^{1}$ Er hat daraus (§ 11) den unser Thema interessierenden Auszug gemacht: "Grammaticas nostras recensituris fortasse non erunt prætereundi Grammatici linguarum vicinarum. - - - qvibus addiderim Finnicam Henrici Crugeri Aboensis, Livonicam vel fortasse potius Estonicam Henrici Stahlii et Henrici Goesekenii - -

1 Dieser Aufsatz von LEIBNiz ist nach dem J. 1711 verfasst worden, denn er bietet u.a. Ergänzungen zu dem Werk von Eccandes Historia studii etymologici linguæ Germanicæ, Ilannover 1711, wenngleich das Material dazu, wenigstens z. T., schon früher gesammelt worden ist, vgl. bei SetäLÄ l. c. S. 237 ff. das von Leibxiz benutzte Material und den diesbezüglichen Briefwechsel.

Leiвxiz war an etymologischen Untersuchungen, der Verwandtschaft und Klassifikation der Sprachen lebhaft interessiert, s. z. B. seine Collectanea etymologica, illustrationi linguarum, veteris Celticæ, Germanicæ, Gallicæ, aliarumque inservientia. Cum præfatione J o. G e o rg i i E c c a r di, Hannover 1717; Opera omnia, hsg. von L. u d o vi c u s Du tens, t. IV, Genf 1768, p. II SS. 186-98 ("Brevis designatio Meditationum de Originibus Gentium, ductis potissimùm ex indicio linguarum»; erschienen zuerst in Miscellanea Berolinensia I, 1710); Euvres philosophiques de Leibniz, hsg. von $\mathrm{P}$ a u l J a n e t, I, Paris 1900, S. 231 ff. ("Des mots") und (Eurres de Leibniz, hsg. von A. F o u ch er d e C a r e i l, VII, Paris 1875, S. 519 ff. ("Concept einer Denkschrift Leibniz's ïber L'ntersuchung der Sprachen und Beobachtung der Variation des Jagnets im Russischen Reichen); s. auch SetäLi 1. c. 
- -." Im Anschluss daran fährt er 1. c. S. 238 f. folgendermassen fort: "Hier wird also HENRICUs CRUGERUs Aboensis als Verfasser einer finnisehen Gram mat $i k$ genannt. Von der Existenz einer solchen Grammatik gibt es [anderweitig] keine Nachricht, und ebenso wenig weiss man von einem Verfasser namens Grugerus. Doch kann keinesfalls angenommen werden, dass die Nachricht von LEIBNIz aus der Luft gegriffen sei, insbesondere weil dessen andere Angaben, z. B. von den nebenstehend erwähnten estnischen Grammatiken, richtig sind. Merkwürdig nur ist, dass die Person selbst völlig in Dunkel gehüllt ist." Danach führt SEtäLÄ zwei Personen an, die als Verfasser in Frage kommen dürften: 1. nach R. HAUsen Utdrag ur Åbo Domkyrkas Räkenskaper 1553-1637 S. 147 Henricus Johannis CrugeRUs, der am 19. IV. 1591 in Turku ( $\AA$ bo) beerdigt wurde (da sein Begräbnis gebührenfrei war, musste er entweder Geistlicher oder Lehrer gewesen sein); 2. nach STRANDBERG [ $\AA$ bo Stifts] Herdaminne I S. 113 Henricus Crugerus, der 164352 Kaplan zu Naantali (Nådendal) und Raisio (Reso) war. Er schliesst mit den Worten: "Natürlich kann darüber nichts Gewisses ausgesagt werden. Vorläufig wissen wir auch nicht, ob diese Grammatik je gedruekt worden ist und auf welchem Wege sie in die Hände von LEIBNiz gelangt ist." In NyK XXIV, wo SETäLÄ S. 94 abermals auf die Frage kurz Bezug nimmt, äussert er sich dahin, dass jene Grammatik wahrscheinlich $\mathrm{im}$ 17. Jh. geschrieben worden und nun verschollen sei; also entscheidet er sich hier für den Kaplan Henricus Crugerus als Verfasser. ${ }^{2}$

Indessen verhält es sich mit der finnischen Grammatik von Henricus Crugerus Aboensis weit günstiger, als Setälä angenommen hat. Sie ist etwa um ein halbes Jahrhundert frü-

1 Von Setälä wird 1. c. S. 239 Fussnote 2 nach Lagus Ảbo Akademis studentmatrikel å nyo upprättad S. 288 ferner noch ein "KRoGERUs He vric. Vib. p. 222, Vib. $307: 1698$ d. 16 Junii» angeführt, der aber wegen des Namens und des Heimatortes nicht in Betracht gezogen wird.

2 Die Ausführungen Seтäläs werden kurz von Julius Kroнn Suomalaisen kirjallisuuden vaiheet, Helsinki 1897, S. 75 Fussnote referiert. Daselbst kurz über O. SUndergelteus] nach LeINBERG Hist. Ark. XI. 
her, als LEIBNIz seinen soeben angeführten Aufsatz geschrieben hat, in der Grammatica Danica von ErICUs PontoppIDANUs, Kopenhagen $1668^{1}$, nicht nur erwähnt, sondern es sind aus ihr auch eine Reihe von Angaben mitgeteilt worden. ${ }^{2}$ Ferner wird sie in den Werken Peder Syvs, eines anderen dänischen Grammatikers, eines Zeitgenossen PONTOPPIDANs erwähnt und zwei Stellen aus ihr in Kürze wiedergegeben. Dadurch wird ihre einstige Existenz ausser Zweifel gesetzt, und noch mehr, man kann sich auf Grund dieser Angaben eine ungefähre Vorstellung von ihr machen. Bevor wir weiter gehen, sollen über PoxtopPIDax und sein Werk, das nunmehr die Hauptquelle für die verschollene Grammatik ist, kurz einige Daten mitgeteilt werden.

3. Erik Pontoppidan wurde 1616 in Süd-Broby auf Fyn geboren (nach seinem Geburtsort B r o b y latinisiert PontopPIDANus, woraus im Dänischen PoNTopPIdax). Er besuchte die Lateinschule und das Gymnasium in Odense, studierte 1635-38 in Kopenhagen Theologie, in der er sich ebenso wie durch seine Sprachkenntnisse hervortat. Danach wirkte er einige Jahre in Kopenhagen als Hauslehrer und begab sich 1641 mit einem königlichen Stipendium auf eine Studienreise nach Holland und Frankreich. Im J. 1643 zurückgekehrt, erlangte er die Magisterwürde und lebte nachher wieder mehrere Jahre in Kopenhagen als Hauslehrer und Privatdozent, während er sich gleichzeitig seinen Studien an der Universität und seiner schriftstellerischen Tätigkeit widmete. 1649 wurde er Schlosspfarrer auf Antvorskov und Hospitalsprediger in Slagelse, 1665 Pfarrer zu Køge, zugleich Propst für den Kreis Ramsø und 1673 Bischof in Trondhjem, wo er 1678 starb. Literarisch war er auf mehreren Gebieten tätig: er schrieb Gedichte (meistens lateinisch), ein Schauspiel, Werke geistlichen und sprachwissenschaftlichen Inhalts; von den letzteren ist bis auf die oben erwähnte Grammatik kaum etwas im Druck erschienen. Mit dieser Grammatik hat er aber ein

1 Der genaue Titel lautet: Erici Erici Pontoppidani Grammatica Danica. Hauniæ, Typis Christiani Veringii Acad. Typogr. Anno CID IDCLXVIII.

2 Darauf hat mich Frl, mag. art. ELLEX OLSEX aufmerksam gemacht. 
Werk geschaffen, das seine übrige Produktion überragt und ihm einen bleibenden Platz in der dänischen Geistesgeschichte gesichert hat. Über sein Leben und Wirken siehe das Nähere (mit Literaturangaben) H. EHRExcRox-MÜLLER Forfatterlexikon omfattende Danmark, Norge ng Island indtil 1814 VI, Kobenhavn 1929, S. 317 ff. und bri MariUs Kristexsen (Vilh. Bang) in Povl Engeistofts Dansk biografisk Leksikon XVIII, København 1940, S. 456 ff., über seine Grammatik insbesondere bei N. M. Petersex Bidrag til den danske Literaturs Historie III,2. Udgavé, Kjobenhavn 1868, S. 361 ff., R. Paulli in Carl S. Petersens og Vilhelm Andersens Illustreret dansk Litteraturhistorie I, København 1929, S. 870 ff. und Henrik Bertelsen Danske Grammatikere fra Midten af det syttende til Midten af det attende Aarhundrede VI, København 1929, s. 35 ff. $^{1}$

In diesem Zusammenhang sind noch zwei Männer zu erwähnen, deren Bekanntschaft PoNToppidans sprachwissensehaftliche Tätigkeit fördernd beeinflusst hat. Das sind Rektor RAVN und der bereits erwähnte Pastor Syv. Hierüber lesen wir bei Paulli l. c. S. 875 folgendes: "Da Pontoppidan havde fuldendt sin Grammatik, fik den Lov til at ligge en Snes Aar i hans Skuffe, medens hans Liv gled ind i den gejstlige Bane. 1649 var nemlig hans Tilværelse som fri Litterat til Ende, da han udnævntes til Slotspræst paa Antvorskov og Hospitalsprast i Slagelse. I denne By sad som Rektor Hans Mikkelsen Ravn, med hvem han da kom i nær Forbindelse, og i hvis Meninger om Modersmaalets Stilling og Kultivering (S. 516517) han jo ogsaa maa have samstemt hjærteligt. En Nabo, med hvem han i lige saa høj Grad har haft fælles Interesser, fik han, da han 1665 forflyttedes til Koge og derved kom til

1 In Trondjem hat Poxtoppidan sich auch mit dem Lappischen befasst. In seinem Nachlass wird eine lappische Übersetzung des Katechismus und ein lappisches Wörterverzeichnis erwähnt, s. EHREncronMüller 1. c. S. 321 und Kristensen 1. c. S. 458. Das Wörterverzeichnis ist in der Königlichen Bibliothek zu Kopenhagen in Povroppidaxs handschriftlichem Nachlass, Thott $15054^{\circ}$, enthalten und umfasst zwei Seiten (Bl. 92a-b) in ziemlich unlesbarem Zustand. Die Katechismusubersetzung habe ich nicht zu Gesicht bekommen. 
Hellested-Præsten Peder Syvs Egn. Her sluttedes varmt Venskab, og sproglige Drøftelser kom i Gang. Pontoppidan fik sit gamle Manuskript frem, gjorde Tilføjelser deri under Indflydelse af $\mathrm{Syv}$, og det synes ikke urimeligt at antage, at dennes Tilskyndelse eller det smittende Exempel af hans allerede paabegyndte sproglige Forfatterskab har bevæget Pontoppidan til at lade sit Værk udkomme i 1668.» PONTOPPIDAN und SYV sind jedoch schon früher miteinander in Fühlung gewesen, bevor der erstere nach Koge kam. Das sehen wir aus einer Fussnote in Syvs Nogle betenkninger om det Cimbriske Sprog, Kiöbenh. 1663, S. 30, wo berichtet wird, dass er von PoNTOPPIDAN Informationen über eine handschriftliche dänische Grammatik erhalten hat: "Grammatica, begyndt af $\mathfrak{M}$. $\mathfrak{B a n s} \mathfrak{R a f n}$ [RAvN] fullofonteliger ifreven paa $\mathfrak{a} a$ tin af Stefan Spodsbierg fom jeg haver jeet/og fom mig er fagot/af M. Erif Pontoppidan." Das sehen wir ferner noch deutlicher daraus, dass daselbst $\mathrm{S}$. 32 die finnische Grammatik von Henrtcus Crugerus, allerdings anonym, genannt wird und S. 30, ohne $Z$ weifel aus dieser (die Quelle ist nicht angeführt), eine Angabe über die fi. Kasus mitgeteilt wird (s. § 6); diese Nachrichten hat er ohne Zweifel von Pontoppidar erhalten. Pontoppidan und Syv standen offenbar damals (vor 1663) wie auch in späterer Zeit (u. a. über die dän. Orthographie) im Briefwechsel miteinander, vgl. hierzu Syvs 1685 erschienene Den Danske Sprog-Kunst S. 51: "Bel haver D. Erif Pontoppioan varet mig imod $i$ noget..../ ja vi ogiaa jiden ofte have indbyrbis baabe talet og fifrevet hinanden til om Sfriverigtighed/oaj. hovr paa hans Breve endnu findes hos mig."

Die Grammatik von PoxtopPIdax ist ein verhältnismässig umfangreiches Werk von $638 \mathrm{~S} .8^{\circ}$ (klein) $=$ XXXVIII S. (Titelblatt, Widmung, Vorwort und Ehrenverse) + II + 542 S. (Grammatik und lateinische grammatikalische Ausdrücke mit dänischen Übersetzungen) + LVI S. (verschiedene Indexe und Errata) ${ }^{1}$; die eigentliche Grammatik (II + 533 S.) ist in drei Teile eingeteilt: Observationes orthogra-

1 Mit römischen Ziffern sind die unpaginierten Seiten bezeichnet. 
phicæ (= Orthographie und eine Art Lautlehre), Observationes etymologica (= Formenlehre und Wortbildung) und Observationes syntactica. Im Neudruck als 2. Bd. der Sammlung Danske Grammatikere von Henrik Bertelsen, København 1917. Ferner findet sich in der Königlichen Bibliothek zu Kopenhagen eine Handschrift (Thott 463 S. $8^{\circ}$ ) von 127 Blättern, eine Vorarbeit zu der gedruckten Grammatik; hierüber ausführlich BeRTELsEx Danske Grammatikere VI S. 35 ff., vgl. auch unten $\S 7,1$.

Das Werk ist, wie schon erwähnt, 1668 im Druck erschienen, ist aber mehr als zwei Jahrzehnte früher geschrieben worden, offenbar zu der Zeit, als der Verfasser nach seiner Auslandsreise ohne feste Anstellung in Kopenhagen lebte (s. o.), in der Zwischenzeit ist es freilich umgearbeitet bzw. erweitert worden ${ }^{\perp}$, vgl. das Vorwort (Præfatio), wo wir folgendes lesen: "Ingenuis tuis oculis tandem legenda exhibetur Grammatica DANICA, ante viginti annos, \& qvod excurrit, conjeripta, \& fubinde demum, qvatenus præ gravioribus ftudiis atqve catenatis delegati officii laboribus fieri licuit, recognita \& aucta, non tamen numeris Juis abjoluta." So hat er während der Umarbeitung OLaus Wormus' Specimen lexici runici, Hafniæ 1650, RUNoLPHUS Jonas' Grammaticæ Islandicæ rudimenta, Hafniæ 1651, und Johannes WaIdis' Grammatica linguæ Anglicanæ, Oxoniæ 1653, für sein Werk verwertet.

Für seine Aufgabe hat PontopPidan sich gründlich vorbereitet, indem er sich eine gute Kenntnis der grammatischen Literatur erwarb. Im Vorwort werden über hundert Grammatiker angeführt ": "Grammaticam Hebrcam fcripferunt..., \& ex noftratibus Cunradus Aflacus, Nicolaus Petræus, Severinus

1 Allem Anscheine nach ist dabei die soeben genannte Handschrift entstanden. Die Handschrift in der ersten Fassung sowie jene zu dem gedruckten Werk sind verloren gegangen, vgl. $\$ 7,1$.

${ }^{2}$ Im Folgenden werden von mir der Kürze halber nur die Autoren angeführt, die Bezug auf die vorliegende Untersuchung haben und fernerhin erwähnt werden; sowie diejenigen, die Bezug auf Dänemark haben, um dem Leser eine Vorstellung davon zu geben, mit welchen Sprachen man sich in Dänemark zu jener Zeit beschäftigte. In allen anderen Fällen werden lediglich die Sprachen erwähnt. 
Petræus Calinburgius etc.; Chaldaicam..., Syriacam..., Syro-Chaldeam..., ex Danis Hermannus Nicolar, qui ideam lingvarum Aramearum dedit; Arabicam...; Perficam...; Ethiopicam...; Egyptiacam..., Armenicam..., Armenicam \& Ethiopicam ..., Turcicam...; Gracam..., Severinus Petræus \& Johannes Petræus Fratres Calundia-Dani \&c.; Latinam . . ., Philippus Melan[ch]thon ${ }^{1}$, . . ., Gerhardus Voffius ${ }^{2}$, \& ex Danis Joannes Jerfinus atqve Thomas Bangius etc.; Italicam...; Gallicam ... \& Daniel Matras Profesfor in Dania Soranus, etc.; Hifpanicam... \& Carolus Rodriguez Matritenfis, Lingvarum Hifpanicæ[,] Gallicæ \& Italicæ in Academia Sorana Profesfor etc.; Gallicam \& Hifpanicam ...; Cambro-Britannicam ...; Anglicam ..., \& Johannes Wallis Latine ${ }^{3}, \ldots$; Germanicam Albertus Oelingerus Argentinenfis ${ }^{4}$, Johannes Clajus Hirtzbergenfis ${ }^{5}$, Juftus Georgius Schottelius ${ }^{6}$ etc.; Polonicam Jeremias Roterus Glogenfis ${ }^{7} . . .$, Japonicam..., Brafilicam..., Malaicam...,

1 Melanchthons lateinische Grammatik war das hauptsächlichste Muster der ersten deutschen Grammatiken, hierzu Jelııx k Geschichte der neuhochdeutschen Grammatik I, Heidelberg 1913, S. 66.

2 G. J. Vossius war der bedeutendste Grammatiker des 17. Jh., s. Jellinek 1.c. S. 24; mit ihm kam Pontoppidan während seiner Auslandsreise 1641 in persönliche Berührung, s. Paulli l. c. S. 870.

3 Grammatica linguæ Anglicanæ, Oxoniæ 1653.

4 Vnderricht der Hoch Teutschen Spraach: Grammatica seu institutio veræ Germanicæ linguæ, Argentorati 1573 (1574); von mir benutzt im Neudruck, hsg. von Willy $\mathrm{S}$ ch e e l als IV. Bd. der Sammlung Ältere deutsche Grammatiken in Neudrucken, Halle a. S. 1897.

5 Grammatica Germanicæ linguæ, Lipsiæ 1578 (spätere Auflagen: $1587,1592,1604,1610,1617,1625,1651,1677,1689,1720$ ); von mir herangezogen die Auflage von 1617 und der Neudruck, NNach dem ältesten Druck von 1578 mit den Varianten der übrigen Ausgaben» hsg. von Fried ri ch We id ling als II. Bd. der in der vorhergehenden Fussnote erwähnten Sammlung, Strassburg 1894. Nach der Orthographie der aus Crajus entlehnten Belege zu urteilen, hat Pontoppidan offenbar die Auflage von 1617 oder die von 1625 benutzt.

- Teutsche Sprachkunst, Braunschweig 1641, und Ausfürliche Arbeit von der Teutschen HaubtSprache, Braunschweig 1663, in welcher die ersten drei Bücher als 3. Auflage der Sprachkunst zu betrachten sind.

7 Schlüssel zur Polnischen und Teutschen Sprach, Breslaw 1616; vgl. unten $\S 7,3 d$. 
Livonicam [Eftonicam] Henricus Stahl ${ }^{1}$, Iflandicam Runolph. Jonas Islandus ${ }^{2}$, ac Finnicam Henricus Grugerus Aboenfi[s] etc." Wie es scheint, hat PontopPIDAN mindestens einen guten Teil von den Grammatiken der von ihm genannten Autoren durchgearbeitet. Von besonderem Interesse musste für ihn das Studium neusprachlicher Grammatiken sein, da er an ihnen Vorbilder fand, wie der Weg von der damals herrschenden lateinischen Grammatik in eine lebende Sprache zu bahnen sei. Bei der Abfassung seines Werkes hat ihm neben der lateinischen zunächst die, allerdings unter dem Einfluss jener stehende, deutsche Grammatik als Vorbild gedient, vgl. hierzu Paula 1. c. S. 870 ff.

Eine Quellenanalyse der Grammatik von Pontoppidnx ist nicht geliefert worden; deshalb muss ich meinerseits darauf eingehen, soweit es für diese Untersuchung unentbehrlich ist, s. $\S 5$.

PontopPIDans Grammatik ist ein wissenschaftliches Werk, verfolgt aber zugleich praktische Zwecke. Sie bietet vor allem ein überaus reiches Material aus dem Dänischen mit Berücksichtigung der Dialekte (vornehmlich des fynschen Dialekts), infolgedessen sie noch heute von Wert ist; dann werden (nicht gleichmässig durch das ganze Werk) die übrigen skandinavischen Sprachen, besonders das Isländische, berücksichtigt, ferner Hebräisch, Griechisch, Latein, Jentsch, Englisch, Französisch und andere Sprachen zum Vergleich herangezogen. Letzterem Umstand verdanken wir es auch, dass einige Bruchst ücke der finnischen Grammatik von Hexricus Crugerus uns erhalten geblieben sind.

Ausser der Grammatik von Crugerus hat Pontoppidan noch eine andere Quelle für das Finnische benutzt. Das ist Orbis Arctoi imprimisque regni Sueciæ descriptio von AxDreas BUREUs (BURE), erschienen zuerst in Stockholm 1626 als Zusatz zu seiner Karte: Orbis Arctoi nova et accurata delineatio ${ }^{3}$; dann selbständig in Wittenberg $1631,24^{\circ}$; des weite-

1 Anführung zu der Esthnischen Sprach, Revall 1637.

2 Grammaticæ Islandicæ rudimenta, Hafniæ 1651.

3 Im Neudruck: Orbis Arctoi ... delineatio. Auctore Andrea Bureo, Sueco. 1626. Edited by Herman Richter..., Part I: Text (Introduc- 
ren mit Auslassung des norwegischen und dänischen Teiles und verändertem Titel: Regni Suecix geographica \& politica descriptio als 1. Kap. (SS. 1-72) in dem Werk von HeNRICUS SoterUs Suecia, siue de Suecorum regis dominiis et opibus, Lugd. Batav. 1631, $16^{\circ}$, desgleichen in der ebenda 1633 erschienenen 2. Auflage (SS. 1-70). ${ }^{2}$ PontopPIDAN führt diese Quelle nach SoTERUs und unter dessen Namen an. Sie ist dreimal benutzt und jedesmal erwähnt worden (s. Auszüge 3,9 und 12); welche von den beiden Auflagen herangezogen worden ist, lässt sich nicht ermittehn, da die Seitenangaben fehlen, und da die beiden Auflagen miteinander verglichen nur geringe Abweichungen (in der Orthographie, Interpunk-

tion, Text in Latin and Translation into English, Notes and 8 Maps in Phototype...), Lund 1936. Meddelanden från Lunds Universitets Geografiska Institution. Avhandlingar. III.

1 Das Werk in deutscher Übersetzung (sowohl der Name des Soterus als auch der des Bureus sind nicht erwähnt; auch der Übersetzer - wohl M. Lungwitrus, s. gleich unten - hat sich nicht genannt): Respublica regni Sueciæ, Das ist: Kurtze jedoch eigentliche Beschreibung desz Königreichs Schweden ..., Leipzig 1632, $4^{\circ}$ (auf der letzten Seite: Zwickaw, Gedruckt bey Melchior Göpnern, ... 1632; XVI + 222 s.); der von Bureus stammende Teil: Ausführliche Beschreibung Des Königreichs Schweden umfasst die Seiten 1-48. Dieselbe Übersetzung (etwas genauer), aber mit Umstellung einzelner Teile bzw. Auslassung einiger Stellen und Einschaltung des Textes aus anderen Werken erschien, ebenfalls anonym, als Appendix Des Dreyfachen Schwedischen LorbeerKrantzes \&. Ersten Theils ..., Leipzig 1632, 40 (auf der letzten Seite: Zwickaw, Gedruckt bey Melchior Göpnern,... 1633; XVI + 398 S.); der auf Buneus zurückgehende Teil, gleichfalls mit Auslassungen und Einschaltungen auf den Seiten $16-18,22-23,25,33-35,38-39,40$, 52 , umfasst die Seiten 1-52. Der Verfasser dieser Kompilation ist offenbar M. Lungwitius, der auch das Ilauplwerk: Dreyfacher Schwedischer LorBeer Krantz 1. T., Leipzig 1632 (2. T. 1632 bzw. 1633 und 3. T. 1. Buch 1633,2 . und 3 . Buch 1634) "Aus war- vnd glaubhafften Hiftorien, Vrkunden vnd Berichten mit Jonderm Fleifz trewlich zuJammen" gebracht hat. Ricin ten scheint sich 1. c. S. 47 über die deutschen Ausgaben (er erwähnt nur die zweite) nicht ganz im klaren zu sein; über die in Rinteln 1634 und 1639 erschienenen $d$. Übersetzungen desselben Werkes (nicht vollständig) siehe bei ihm daselbst.

Bei Richter über Andreas Bureus S. VH ff. und Henricus Soterus $\mathrm{S}$. 47. Siehe über A. Bureus auch E. Vennberg in Bertil Bö̈тныч' Svenskt hiografiskt lexikon VI, Stockholn 1926, S. 704 ff. 
tion u. desgl.) zeigen ${ }^{1}$; zudem hat PontopPIDAN in der Interpunktion und der Orthographie (z.B. v statt u) einige Veränderungen vorgenommen. Crugerus wird dagegen ausser im Vorwort (s. o.) und in dem Autorenindex in der eigentlichen Grammatik nur einmal erwähnt, wo er unmittelbar nach Soterus [BUREUs] zitiert wird (s. Auszug 3). Falls die finnischen Belege in allen übrigen Stellen (Auszüge 1-2, 4-8, 10-11, 13-14) ebenfalls von CrugErus stammen sollten, wie man schon aus dem Grunde schliessen möchte, dass weder im Zusammenhang mit ihnen noch anderwärts eine weitere Quelle genannt wird, ist er im ganzen 12-mal von PoxtopPIDAN herangezogen worden, hierzu eingehender unten $\S 5$.

4. Nun sollen aus Pontoppidans Grammatik die Stellen, in denen das finnische Material vorliegt, der Reihe nach angeführt werden, und zwar mit dem Kontext, um zu zeigen, in welchem Zusammenhang es herangezogen ist; das ist in einigen Fällen für weitere Auseinandersetzungen nicht ohne Belang. Die fi. Wörter, die u. a. lexikalisch, semasiologisch und orthographisch einiges Interesse beanspruchen, werden dabei mit Heranziehung der mir zur Zeit zugänglichen Literatur in Fussnoten erläutert; auch auf ihre Etymologien meistens handelt es sich hierbei um schwedische Lehnwörter - wird Rücksicht genommen, weil diese Frage von Crugkrus bzw. Pontoppidan aufgeworfen und weil dies ab und zu in semasiologischer Hinsicht erforderlich ist. Wegen der $\mathbf{A b}$ kürzungen siehe das Verzeichnis an Schluss dieser Untersuchung.

Bemerkt sei noch, dass in Anführungsstrichen ("...") die Quelle möglichst genau wiedergegeben wird mit Ausuahme der Abkürzungen (z.B. - $\dot{q} \mathbf{\beta}=-q v e,-q ;=-q u e$ und $-\bar{u}=-u m$ in lat. Wörtern), die aufgelöst und voll gedruckt werden. Eine gewisse Schwierigkeit bereiten bei PontopPIDan die Zeichen

1 Die sich auf die finnische Sprache beziehende Stelle ist von A. AHLQvist Bidrag till Finska språkforskningens historia före Porthan, Helsingfors 1854, S. 3 ff. nach der Auflage von 1633 angeführt. Möglicherweise ist diese Auflage auch von PonToppidan benutzt worden (vgl. §6). Wie dem auch sei, wird hier die 1. Auflage (1631) herangezogen. 
$\mathfrak{a}$ und $\mathfrak{a}$ bzw. $\mathfrak{u}$ und $\mathfrak{\mathfrak { l }}$, die in einigen Fällen nicht leicht $\mathrm{zu}$ unterscheiden sind. Ausserhalb der Anführungsstriche werden die fi. Belege in Fettdruck - so zunächst in Fussnoten wiedergegeben, wobei $\mathfrak{a}(\mathfrak{a})$ bzw. $\ddot{a}, \mathfrak{u}(\mathfrak{h})$ und $\mathfrak{o}$ durch $\ddot{a}, \ddot{u}$ und $\ddot{o}$ ersetzt werden; in schw. Belegen wird $\mathfrak{d}$ bzw. $\mathfrak{a}$ durch $\dot{a}$ ersetzt.

1.S. 53 (Obfervationes orthographicæ) "[60.]. . Dies Saturni, Islandis $\mathfrak{L a u g u r} \mathfrak{D} \mathfrak{a g u r} /$ Finnonibus $\mathfrak{L a u b a n t a j}[=a \mathfrak{i}]^{1} /$ Svecis Logeroag/nobis Loveroag/ita appellari putatur, qrod veteres Ethnici eo die Je laverint, løpede vel løgede Sig . ..

2. S. 57 f. (Obf. orth.) "63. Voces, qvæ in cotidiano Jermone, præfertim à plebe, raptim pronunciando in unam contrahuntur, non ita Jcribendæ, ut jellicfe pro jeg vil icfe / vittucfe pro vilt bu icfe / fantucke pro fanot ou icfe / villicfe pro ville $i$ icfe / du talicke pro taler icfe / jiffenteen pro jee hoilfen een / jiffe pro jee hoilfe. Şvicken handel pro huilfen en hanbel / and jind pro anben finde / ut mu rin-

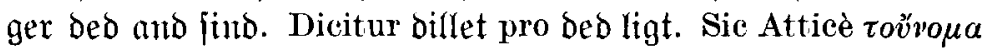

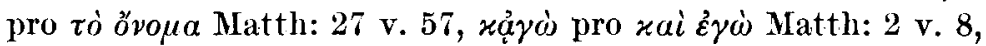

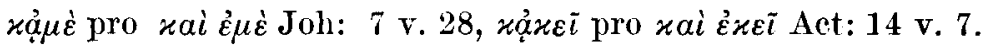
$\& 22$ v. 10. Ac Gallicè dicitur, ficut $\&$ tandem feribi coepit, Aftheure, qvòd aliàs fcribitur à ce te heure. Finnones dicunt cuinga-s Janot pro cuinga finä fanot qvid [quomodo] tu dicis? cungas menet pro cunga finä menet qvorfum tu vadis? $\eta^{2}$

I Zu Lauvantaj [-ai] 'Dies Saturni' vgl. VRVoc. 6 Lauwantai 'Dies Sabbathi vel Saturni, Lögerdagh', Petraus D 8a Lauwandai 'dies Saturni', Flor. 6 Lauwantai 'Dies Saturni, Lögerdag', Jusl. Lauwandai id., Renv, lauvantai od. lauvontai 'dies saturni, sonnabend (schw. lördag)', Lönnr. lauvantai, dial. lauvanta, lauvantaki 'lördag' = lauvan-, lauvon-, Gen. von *lauka, *lauko an. laug 'lavacrum' + tai, taki an. dagr, aschw. Sö̀nkw. dagher, s. SEт̈̈L̈̈ Verz. in FUF XIII S. 400 und 455 .

${ }^{2} \mathrm{Zu}-\mathrm{s}$ in cuinga-s und cungas s. $\$ 7,3 \mathrm{~d}$; cunga $=$ kunka (dial.) $<\mathrm{ku-}$ hunka. Die komprimierte Illativform kunka, in unbetonter Stellung aus kuhunka von kuka 'wer; welcher' (gleichwie jonka aus johonka von joka 'welcher, der' und minkä aus mihinkä von mikä 'was; welcher'), findet sich stellenweise in IIäme (s. RAPOLA SKKH I S. 195) und in Satakunta (s. I кокA ASMÄH I S. 201 und auch Osansuv LMÄH II S. 91 Fussnote); in Südwestfinnland ist kunka in den heutigen Dialekten nicht gebucht (beachte jedoch z. B. nach J. G. Torvonen Tutkimus 
ORTHOERAPHICA. so

rum vocum, qvà à pradictis literis vel à duabus, pluribusve confonancibus incipiunt: fed priores confonantes femper elidunt, ut pro Grex dicant Rex, pro Gracus Ratus, pro Spes Pes, pro Prodere Rodere, proftrepere repere \&c. probonus ponus, pro Dominus Tominus, pro guberno Cuperno, pro Filius vvilims \&c. Ideoq́ve Nobiles, Mercatores \& Sacerdotes, Ruftıci etian diciores, curant, ut corum filii ab incunabulis Svecicam difcant lingvam, eạque ratione eos ad aliarum lingvarum propriecates, pronunciationemq́ve fefe accommodareaflvefaciunt, ut teftatur Henricus Socerus in Svecia defcriptione. Henricus verò Crugerus A boenfis in Grammatica Finnica manufcripta hac afferc: Nulla vernacula dictio incipit ab his literis B, D, G, F, Z, ab his enim initium babentes à Svecis funt in u/um traducte. Dicimus pro Qjárgmeftare pormeftari, pro Dargare porvari, pro do: mare Tuomari, pro Doom $T$ uomio, pro Dalar taalari, pro glas klaji, pro fix vixi. unica extat noftratium dictio ab Finit:

iturn

Beilage 1. Schluss des ersten Zitats aus Hexricus Soterus' [ANdreas Bureus'] Sueciæ descriptio und Anfang des Zitats aus Henricus Crugerus' Grammatik in Pontoppidans Grammatica Danica.

3. S. 58 ff. (Obf. orth.) "64. Apud nos dux imò tres Confonantes conjunguntur in una fyllaba enuncianda, vocefq́ve inchoant, ut Bleeg / blander / bluner / bruun / bruger / breber / brager / oriffer / brommer / dveler / flag / flagrer / flyer / 


\section{0}

OBSERVATIONBS

ambabens faoherma hallon/ quam Ta* vaftenfes vabherma pronuncianc. In lingua Finnica rarisfima d duabus confonantzbus incipientia extant vocabula. Гаvaftenfibus à $C R$ hæc pauciffima extant, ut crappe nola lignea, cratti lar, craaccu fupellex culinaris, crwbu fovea circa fornacem converfi cineris, crencu sedile uni fedenti. His Aboenfes \& in cjusdem finibus babitantes quadam alia addunt, ut pleicu creta, truski (fam* maco) ranunculus, plufu (candela cerea ) vat lius/ plaiccu, (bleina) macula, crapu cancer, prijmi (murfina) rempusjentandi, práámi opflag/trontticau. lis oleris diflectı. Laicorum vitiwss est nativum in dictionibus a duabus confosantibus incipientibus pronunciandis omittere priorem confonantem, ut dicant pro SFoofoo / pro Slagh lagh/ pro Sldt Idr/ pro Epinna pinna. Sic in fequentibus witatis dictionibus S/equenti conjond abforbetur propria tamen terminali liters refervata, ut pro Groop tuoppi/ pro Etool tuoli/pro ftola coulu/ pro feal foli/proffrota lúutto/proftápcaappi/

pro

Beilage 2. Fortsetzung des Zitats aus Henricus Crugerus' Gramma. tik in Pontoppidans Grammatica Danica.

tfrna / jultefer / from / frnder / glam / glaede / glenmer / gneger / graad / grceder / flemmer / hutepper / fluler / fram / frufer / plager / praler / pruter / queger / quinde / flag / fliber / flummer / imager / jmorer / juar / inager / iquatter / trang / tryffer / treder / ipreder / iprader / iprutter / iplinto / iplitte / 
ORTHOGRAPHICA.

0

proffrijn frijni / proftuus tuubi / pro fpiclo pelli/pro fpegel peili. Trius ex ulpbabeto elementorum F. L. R. nullus apud gentem Brafilienfens est ufus: mini. mè abjurda quorundam animadverfone factum id effe divinitus, è quòd Fide, Le. ge, Rege, careant. Sebaftianus Schroterus Geograph. tom. 2, 1. 4. c. 27.

65. Notæ \& diftinctiones orthographicx funt Comma, colon, femicolon, periodus feu punctum, fignum interrogationis, fignum admirationis, \& exclamationis, Parenthefis, Dixrefis, Diaftafis, Hyphen, Circumflexus (Acucum \& gravem, quum probatore ufu haud fcribantur, non adfcribimus, qvamvis quibusdam vocibus ad diftinctionem .accommodi videantur) A poftrophus, ut in verfibus.

6\%. Comma diftinguit nomina, verba \& adverbia, quando plura ponuncur, qvaincer fedifferunt, \& partem, non integram fententiam autperiodum, abColvit , ejusq̣ve noza eft parvus femicirculus (,) vel virgula (/).Colon ufurpatur in fententia qvidem inte-

gra

Beilage 3. Schluss des Zitats aus Henricus Crugerus' Grammatik in Pontoppidans Grammatica Danica.

itriffe / itrunffer \&c. Feliciores ergo fumus Finnonibus, qvi in t ota Jua lingva non tantùm carent literà $F$, fed etiamnullam dictionem habent incipientem à $\mathrm{B} D \mathrm{G}$ vel duabus confonantibus. Qræ res Finnones ad difcendum alias lingvas inhabiles facit, nifi hoc vitium ab ineunte etate arte corrigatur. Si enim in 
pueritia non addidicerint aliam lingvam, adultiores facti non poffunt difcere pronunciationem earum vocum, qvæ à prædictis literis vel à duabus, pluribusve confonantibus incipiunt[ur]: $\int e d$ priores confonantes femper elidunt, ut pro Grex dicant Rex, pro Gratus Ratus, pro Spes Pes, pro Prodere Rodere, pro Jtrepere repere \&c. pro[Pro] bonus [dicunt] ponus, pro Dominus Tominus, pro guberno Cuperno, pro Filius vvilius \&c. Ideoq́ve Nobiles, Mereatores \& Sacerdotes, RuJtici etiam ditiores, curant, ut eorum filii ab incunabulis Svecicam difcant lingram, eấq ve ratione eos ad aliarum lingvarum proprietates, pronunciationemq́ve fefe accommodare a $\iint \mathrm{ve}$ faciunt, ut teftatur Henricus Soterus [ANDreas Bureus] in Sveciæ deferiptione. ${ }^{1}$ Henricus verò Crugerus Aboenlis in

IIalikon kielestä S. 40 in Suomi III, 2, Helsinki 1888, in Hal i k ko kunkkas mit kunkka- aus kuhunkahan- und jonkkus mit jonkku-aus johonkuhun- sowie nach OJAnsuU 1. c. in E $\mathrm{Eraj}$ o $\mathrm{ki}$ ionkkun aus iohoqkuhun), wohl aber in der alten finnischen Schriftsprache, so bei Agricola, dessen Sprache vorwiegend West-bzw. Südwestfinnisch ist: cunga ( cuhungas) und bei den südwestlichen Autoren: Martri cunga (sowie ionga $\sim$ iohonga und mingä, mingen $\sim$ mihingän), Ju usTEN cunga ( kuhunga), Finno (SUomalainen) cunga und Jemmink Cunga, cungan (s. OJansuu l. c. S. 95 ff. und Rapola l. c.). Zu cungas 'qvorfum tu' vgl. in VRVoc. FPColl. Bl. I 6a Cungas und bei Petreus Bl. D 5 b cungas Agricola (nach OJAnsuU LMÄH I S. 179 und II S. 95) NT Matth. XXV 24 und Bibel 1642 Mos. 1. XXVIII 15 cuhungas id.

'Vgl. Bureus Regni Sueciæ... descriptio in Soterus' Suecia 1631 S. 56 f.: "Linguam Finnones peculiarem habent, à reliquis Scanzianorum populorum linguis plane diverfam, quæ cum aliquot habeat proprietates, reliquis Europæis linguis non communes, eas hic obiter recenfere libuit. Primo enim in tota Jua lingua carent litera $F$. neque ullam habent dictionem, quæ incipitur à $B$. D. vel $G$. vel à duabus confonantibus. Quæ res Finnones ad difcendum alias linguas inhabiles facit, nifi hoc vitium ab ineunte ætate arte corrigatur. Si enim in pueritia non addidicerint aliam linguam, adultiores facti non poffunt difcere pronunciationem earum vocum quæ à prædictis literis, vel à duabus pluribufve confonantibus incipiuntur: Jed priores confonantes femper elidunt, ut pro Grex dicant Rex, pro Gratus, Ratus, pro spes, pes, prodere, rodere, ftrepere, repere, \&c. Pro bonus dicunt ponus, pro dominus, tominus, pro guberno, cuperno, pro filius vvilius. Ideoque nobiles, mercatores \& facerdotes, ruftici etiam ditiores curant, ut eorum filii ab incunabulis Svecicam difcant linguam, eaque ratione eos ad aliarum linguarum proprietates pronunciationemque fese accommodare affuefaciunt." 
Grammatica Finnica manufcripta hæc affert: Nulla vernacula dictio incipit ab his literis $\mathrm{B}, \mathrm{D}, \mathrm{G}, \mathrm{F}, \mathrm{Z}$, ab his enim initium habentes à Svecis funt in ufum traducte. Dicimus pro $\mathfrak{B a ́} \mathfrak{i g}=$ mejtare pormeftari ${ }^{1}$, pro Bargare porvari ${ }^{2}$, pro domare Tuomari $^{3}$, pro boom Tuomio ${ }^{4}$, pro balax taalari ${ }^{5}$, pro gla klafi

1 Zu pormestari 'Bårgmestare' vgl. Agr. Burgme ${ }^{\prime}$ arien (Gen. Pl.), Borgme $t$ tarit (Nom. Pl.), LuUngo borme $t$ tarit, Bibel 1642 Borgme tari (nach Streng), VRVoc. 63 Borgmäftari 'Conful, Borgmäftare', Flor. 71 BorgmeJtari id., Jusl. Bormäftari id., Renv. pormestari (borgmestari) 'consul, Bürgermeister (schw. Borgmästare)', Lös $\mathbf{R}$. pormestari (borgmestari) 'borgmästare' 〜 nschw. borgmästare 'Bürgermeister', aschw. SöDERW. borghamästare usw., von mnd. borgmêster, s. STRENG NRLS S. 159 und wegen des schw. Wortes HellQuist SvEOb. ${ }^{2}$ s. v.

b o r g m äs t a re.

${ }^{2}$ Zu porvari 'Bảrgare' vgl. Agr. Porghari, Borghari, Burgharit (Nom. Pl.), Bibel 1642 Borgari (nach Streng), Petreus Bl. C 4a Borgari: ofa Borgareift 'pars civium', Flor. 71 Borwari 'Civis, Borgare', Jusl. Borwari id., Renv. porvari, porkari (borgari) 'incola urbis, juris oppidani, municeps, Bürger (schw. borgare)', LönnR. porvari (borgari) 'borgare' nschw. borgare 'Bürger', aschw. Sönenw. borghare, von mnd. od. fries. borgere, s. Setälä Verz. in FUF XIII S. 428, Strexg NRLS S. 160 und wegen des schw. Wortes IIELLuist SvEOb. ${ }^{2}$ s. v. b o rgare.

3 Zu Tuomari 'domare' vgl. Petreus Bl. C 7b duomarixens (Translat. Sg. mit dem Possessivsuffix der 3. P.), VRVoc. 63, Flor. 68, JusL. Duomari 'judex, domare', Resv. tuomari (duomari) 'judex publicus max. territorialis, Richter (schw: domare)', Lönvr. tuomari (duomari) 'domare, domhafvande, lagskipare' an. dómari, aschw. Söve rw. domare, s. SETÄL Ï Verz. in FUF XIII S. 462.

4 Zu Tuomio 'doom' vgl Schrod. 23 Duomio 'Iudicium, Doom, das Gerichte', Flor. 69 'Judicium, Jententia, Dom', Jusl. duomio'judicium, Jententia judicialis, dom', Resv. tuomio (duomio) 'judicium publicum, sententia judicis, Urtheilsspruch, Rechtsspruch (schw. dom)', Löns. tuomio (duomio) 'dom, domslut, afgörande utslag (päätös); fördömelse'; vom Verbalstamm tuomi-: Inf. tuomita 'judicare' $\sim$ got. domjan 'urteilen', an. dœma (s. Setälä Verz. in FUF XIII S. 462), dieses von got. doms 'Urteil', an. dómr, schw. dom; zur Etymologie der germ. Wörter s. Falk-Torp NDEWb. s. vv. $d o m$ und $d$ o $m$ m e, Hellquist SvEOb. ${ }^{2}$ s. vv. do $\mathrm{m}$ und $\mathrm{d}$ ö $\mathrm{m}$ a und Feist GEWb. ${ }^{3} \mathrm{~s}$. v. d o $\mathrm{m} \mathrm{s}$.

5 Zu taalari 'dalar' vgl. Schrod. 27 Talari 'Thalerus, Daler, ein Thaler', Petreus Bl. G 6b dalaringos (Illat. Sg. mit den Partikeln -go [ - -ko] und-s), Fror. 73 Dalari 'Thalerus, En Daler', Jusı. Daalleri, talari 'thalerus, daller', Renv. taalari, taaleri, taalleri, taalteri (daleri) 'thalerus, numus, Thaler (schw. daler)', Löxn.taalari, taaleri, talari, dial. 
$\left[c l a \int i\right]^{1}$, pro fix vixi [vixi $]^{2}$. Unica extat noftratium dictio ab $\mathbf{F}$ initium habens fabherna hallon / qvam Tavajten Jes varherma pronumciant $^{3}$. In lingva Finnica raris fima à duabus con fonantibus incipientia extant vocabula. Tavajtenfibus à CR hæc pauciffima extant, ut crappu nola lignea ${ }^{4}$, cratti lar ${ }^{5}$, crauccu

taalleri, taalteri (daleri) 'daler' nschw. daler, über nd. daler von nlhd. Taler, Verkürzung aus Joachimstaler (die ersten Taler wurden in Böhmen aus dem Silber von Joachimstal von 1519 an geprägt, in Schweden die ersten Taler von 1534 an), s. Streng NRLS S. 221, wegen schw. Wortes Falk-Torp NDEWb., Helcourst SvEOb. ${ }^{2}$ und sachlich Svensk upplagsbok s. v. da le r.

$1 \mathrm{Zu}$ klafi [cl-] 'glas' vgl. Agr. Clafi (nach Streng), Schrod. 5 Clafi 'Vitrum, Glas, Glajz', 36 Glaji 'Calix vitreus, Glaas, das Glajz', VRVoc. 15 clafi: Juoma clafi 'Calix vitreus, Dryckeglaas', Wijna claji 'Vitrum vinarium, winglaas', Flon. 26 Clasi 'Vitrum, Glaas', Jusl. 'vitrum, glas', Renv. klasi, lasi (glasi) 'vitrum, fenestra vitrea, poculum vitreum, Glas, Glasfenster, Trinkglas (schw. glas)', Lönn r. lasi, klasi (glasi) 'glas; glasfönster; dricksglas; glasflaska' nschw. glas 'Glas', aschw. Sönerw. glas 'glas, glaskärl', von mnd. glas, s. Streng NRLS S. 95 und wegen des schw. Wortes Heclquist SvEOb. ${ }^{2}$ s. v. glas.

${ }^{2}$ Zu vixi 'fix' vgl. Lönnr, viksi 'qvick (kerkeä, veiterä)' $\sim$ nschw. fix 'fest; flink, rasch', über nlıd. fix 'fest; schnell, rasch' von frz. fixe (= lat. fixus 'fest'), s. wegen des schw. und d. Wortes FALk-Torp NDFWb. s. v. f i k s und Ku UGE DEWb. ${ }^{11}$ s. v. fi $\mathbf{x}$.

3 Zu fadherma, 'Tav. vadherma 'hallon' vgl. Schrod. 54 Faderma 'Mora Idæa, Hållon, die Himbeer', VIRVoc. 97 Faderma: Fadermapen $\int a s$ 'Rubus, Brombäreträä', Flor. 19 Faderma 'Morum rubi idai, Hallon', Rerv. Faaderma, vaaderma, vaaterma 'rubus idæus, Himbeere', Lön r. faaderma, faderma, fadelma, vaderma, vadelma, valerma, varelma, vaaderma, vaaterma 'hallon'; einheimisches Wort mit dial. $f$ - statt $\vartheta_{-}$, aufgekommen im südwestl. Finnland in der Gegend, wo infolge vieler schw. Lehnwörter anlaut. $f$ geläufig geworden war, von dort dann weiter verbreitet; zu dieser Frage und zur Verbreitung der Wortform mit $f$ - s. Ojansu LMÄH I S. 19, Rapola KSi-Dift. S. 266, SKKII I S. 96 und I коцА ASM ÄH I SS. 228, 246, 273.

- Zu crappu 'nola lignea' vgl. Jusc. Rappu 'crotalum ligneum, träSkälla', Lönnr. rappu 'träskälla', estN Verf. krapp Gen. krapi 'hölzerne Herdenschelle', WIED. EWb. ${ }^{2}$ krapp Gen. krapi (rapp) 'Viehglocke (hölzerne), (D) Klopfbrett, (fig.) Klätscher, Klätscherin; Klotz; Netzanker (Stein, in einer Ejsenstange mit zwei Armen)'; einheimisch, onomatopoetisch.

6 Zu cratti 'lar' vgl. Agr. Cratti (nach Streng), Petraus Tabella Cratti 'Lar', Revv. kratti 'genius mythol., mythol. Schatzhüter (schw. skratt)', I.öN R. '(myth.) i jorden nedgömda skatters beskyddare (aarni) 
Jupellex culinaris ${ }^{1}$, crwhu fovea circa fornacem converfi cineris ${ }^{2}$, crencu [krenccu] sedile uni Jedenti ${ }^{3}$. His Aboen Jes \&

(schw. skratt)', est. WIED. EWb ${ }^{2}$. kratt Gen. krati (ratt) 'ein Geist (von welchem manche abergläubische Vorstellungen im Schwange gehen, z. B. dass er Reichtum gebe, den Kühen dje Milch aussauge, Butter und Milch verderbe)', estN Verf. kratt 'Kobold (Schatzträger)' schw. dial. Rrerz skrate 'ande, spöke, tomtgubbe', skratten 'hin onde', åker-skratt 'åkerspöke, fogelskrämma på åkern', aschw. SöDERw. skratte 'skratte, tomte', s. SEт̈̈LA Verz. in FUF XIII S. 390, Streng NRLS S. 75 und zum schw. Wort Hellquist SvEOb. ${ }^{2}$ s.v. skrat tabor re.

1 Zu craaccu 'fupellex culinaris' vgl. Petraus Bl. A 1 Kraacu 'inftrumentum culinare, cui lebetes imponuntur', Jusi. Craacu 'bacca ericæ, kråkbär', RENv. kraaku od. kraakku 'stipes I. vectis cum unco, ollis igni suspendendis serviens, Kesselhebel, -träger (schw. krảka)', kraakun marja 'empetrum nigrum (al. vareksen marja), Felsenstrauchbeere (schw. kråkbär)', LönNr. kraakku, kraaku 'grythängare, stolpe vid spiseln med vidfästad grythängare af trä (af jern hahlot); kråkbär (empetrum nigrum)', vareksen kraakku, kraakun marja, harakan kraaku 'kråkbär', raakku 'grythållare, hvari grytan hänger öfver elden (kraakku)' nschw. kråka' 'Krähe', aschw. SödERw. kraka 'kråka', dial. RıETz kråk-trä 'en inrättning, hvarpå en gryta hänges öfver elden i spisen', finnl.-schw. VEND. lerăko etc. 'svängbar järnslå i spiseln för att hänga grytan på', s. zum schw. Wort Ifellquist SvEOb. ${ }^{2}$ s. v. $\mathbf{k r} \mathbf{r} \mathbf{k}$.

$2 \mathrm{Zu}$ crwhu 'fovea circa fornacem conver $\int \mathrm{i}$ cineris' vgl. Renv. kruuhu od. kruuvu 'fovea ante fornacem, in qua prunæ colliguntur (schw. grufva)', kupari-kruuhu 'ærifodina, Grube', LönnR. kruuhu 'glödgrop framför ugn (liesi); grufva (kaivanto)', kuparikruuhu 'koppargrufva (schw.)' nschw. gruva 'Grube, Bergwerk', aschw. Sön Enw. gruva 'grufva', dial. RıETz gruva 'eldstad framför ugnen; stället i spisen der askan ligger, det innersta af spisen, askgrop framför ugnen', finnl.-schw. VEND. gruso, gruo, gruvu etc. 'framför ugnen eller spisen befintlig grop, hvari kolen samlas; den del af spiseln där elden flammar', von mnd. grûve 'Vertiefung, Grube', s. zum schw. Wort Falk-Torp NDEWb. s. v. grue und Hellquist SvEOb. ${ }^{2}$ s. v. gru va.

3 Zu crencu [krenccu]' Jedile uni Jedenti' vgl. RENv. krenkku, renkku 'sella longior quadrupes, vierfüssige Bank', LönnR. krenkku 'pall, långstol med fyra fötter, ugnsbänk', renkku 'fyrfotad bänk, pall (krenkku, jakku, palli) ' schw. dial. RIETz kränka 'en pall med 3 eller 4 pinnar under; liten stol utan ryggstycke; ställning för tunnor, såar' (auch fi. krenkku angeführt), finnl.-schw. VEND. krängko, kränk etc. 'karmlös, icke fyrkantig stol eller bänck, ofta använd såsom underlag för kar, såar o.s. v.', s. zum schw. Wort FALK-ToRP NDEWb, und Torp NNEOb, s. v, k r a $k$, 
in ejusdem finibus habitantes qvadam alia addunt, ut pleicu creta ${ }^{1}$, truski (Jammaco) ranunculus ${ }^{2}$, plufu (candela cerea) vax lius $^{3} /$ plaiccu, (bleina) macula ${ }^{4}$, crapu cancer ${ }^{5}$, prijmi

1 Zu pleicu 'creta' vgl. Schrod. I Pleicku [-jeu?] 'Creta. Klijta, Kreide', VRVoc. 10 Pleicu 'Creta, Krijta', Jusl. 'creta, krijta', Renv. pleiku 'creta, Kreide', Lönnr. 'salpeter; krita' scliw. dial. Rietz bleka 'kalkjord; sjölugn, stiltje', finnl,-schw. VExD, bläiko, bläiku etc. 'havslugn, stiltje', aschw. Sö̀ E Rw. bleka 'kalk, krita', dän. blege 'Kalk, Kreide', s. Streng NRLS S. 158 und wegen des schw. Wortes FalkTorp NDEWb.s. v. b l e g und Hellquist SvEOB. ${ }^{2}$ s. v. B l e k i n g(e).

2a truski 'ranunculus', sonst nicht gebucht, $\sim$ schw. dial. RiETz tóssk, tråsk etc. 'källfrö, randig groda: Rana temporaria', finnl.-schw. Vend. trosk 'mindre groda, källfrö'; etymol. identisch mit trosk od. torsk 'Mundschwamm', welches ebenfalls ins Finnische entlehnt ist und hier als turska, torsku, truska erscheint, s. Бет $\ddot{L}$ Ä FUF II S. 152 If. und Verz. in .FUF XIII S. 463; zur Etymologie des schw. Wortes s. Falk-Torp NDEWb. s. v. t ro $\mathrm{s}$ e II und Hellquist SvEOb. ${ }^{2} \mathrm{~s}$. v. torsk 2.

$2 \mathrm{~b}$ Als Synonym von truski angeführtes Jammaco, Rexv. sammakko 'rana max. temporaria, Frosch', ist einheimisch, s. hierzu z. B. SetäLä FUF II S. 146 ff.

3 Zu plufu 'candela cerea, vax lius' vgl. Agr. Plujia (Part. Pl.), plufut (Nom. Pl.) (nach Streng), Lönnr. plusu 'fett och rödlett person', plusi 'stort julljus af talg, inneslutet i luftstrupen af ett nötkreatur' nschw. bloss 'Fackel', aschw. Söperw. blus (blos) 'bloss', s. Streng NRLS S. 158, wegen des schw. Wortes FaLk-Torp NDEWb.s. v. b l u s und ItelLquist SvEOb. ${ }^{2}$ s. v. blos s.

$4 \mathrm{Zu}$ plaiccu 'bleina [ = schw. dial. und aschw. Sön Enw. blena, s. hierzu ТАм м Etym. svensk ordbok I, Úppsala 1890—1905, s. v. b l e m m a], macula' vgl. LöNxr. plaikku 'stor fläck, bar fläck i besådd åker (laikku)' laikku 'fläck (plaikku), flamma', est. WiED. EWb.' laik Gen. laigu '(grosser) Fleck, Lappen'; falls einheimisch, wie wahrscheinlich, so ist $p l$ - (statt $l$-) sekundär, unter dem Einfluss der so anlautenden Lehnwörter und onomat. Wörter entstanden, wofür es in westfi. Dialekten viele Beispiele gibt, s. hierzu OJAxsuU I MÄH I S. $18 \mathrm{f}$. und Nay va v. FieandT Kaksi konsonanttia sanan alussa suomen kielessä S. 17 in Suomi IV, 5.

5 Zu crapu 'cancer'vgl. Agr. Crapu (nach Streng), Schrod. 60 Krapo [Crapu] 'Cancer, Kräweta, Krabba, der Krebs', Flor. 18 Crapu 'Cancer, Krabba, Kräfweta', Jusl.' cancer, krabba, kräfta', Révv. krapu, rapu 'cancer, Krebs (schw. krabba)', Lönn r. 'kräfta, krabba' nschw. krabba 'Krabbe', aschw. Söperw. krabba, krabbe, s. Serälä Verz. in FUF XIII S. 436, Streng NRIS S. 181 und zur Etymologie des schw. Wortes HeLLQuist SvEOb. ${ }^{2} \mathrm{~s}^{\cdot}$ v. k r a b b a. 
(murfina) tempus jentandi ${ }^{1}$, práámi opjlag ${ }^{2} /$ tronti caulis

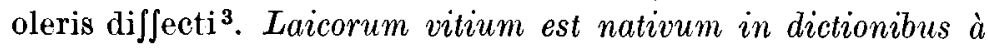
duabus confonantibus incipientibus pronunciandis omittere priorem confonantem, ut dicant pro Sfoo foo / pro Slagh lagh / pro Slár láx / pro Spinna pinna. Sic in Jeqventibus

1a prijmi 'tempus jentandi [Frühstückszeit]', in dieser Bedeutung sonst nicht gebucht, aschw. SöDERw. prim (priim) 'nymåne; den förste timmen på dagen el. kl. 6 f. m., den andre af s. k. kanoniske timmarne; äfven det som lästes el. sjöngs vid den gudstjenst som hölls vid denna tid', von mlat. prima (sc. hora od. luna), das in fi.-schw. mittelalt. Urkunden nach Намманsтröм Glossarium till Finlands och Sveriges latinska medeltidsurkunder, Helsingfors 1925, S. 205 'prim, morgonbön i tidegudstjänsten' bedeutet; zu dem schw. Wort s. HeLLQuist SvEOb. ${ }^{2}$ s. v. p ri m. In der fi. alten Schriftsprache ist es bei Agr. Ps. Bl. B 3b in der Form Prijm 'Prim, Morgengebet, Frühmesse' belegt: iofta Nocturnit / Prijm ia Sexti Aina luetin ia weifatin 'woraus die Nokturnen, die Prim und die Sext immer gelesen und gesungen wurden', s. STreng NRLS S.164, wo dieses, wohl mit Recht, als eine literarische Entlehnung bezeichnet, aber unrichtig mit 'aamumessun aika [die Zeit der Frühmesse]' übersetzt wird.

1b Zu murkina, als Synonym des vorhergenannten Wortes angeführt, vgl. VRVoc. 28 Murkina 'Jentacula, Daghward, Morgonward', Fron. 14 'Prandium, Morgonward, middagzmåhltijd', JusL. 'cibus antemeridianus, morgonward', Renv. murkina 'jentaculum, Frühstück' (Sav. 'cœna meridiana, Mittagsmahl'), Lönnr. 'frukost, middag (olika på skilda orter); måltid' got. maúrgins 'Morgen', an. morginn, morgunn $<{ }^{*}$ murgina-, s. SETÄlä Verz. in FUF XIII S. 414 und zu dem germ. Wort Feist GEWb. ${ }^{3}$ s. v. $m$ a úr gin $\mathrm{s}$.

${ }^{2}$ Zu präämi 'opflag [Aufschlag = Verzierung an Kleidungsstücken]' vgl. Bibel 1642 präämit (Nom. Pl.) (nach Streng), Flor. 22 Brämi 'Fimbria, Klädefåll, bräm-krufering' nschw. DaLın bräm 'med pelsverk eller dyrbart tyg beprydd bred kant på kläder', von mnd. brem $(e)=$ mhd. brem, nhd. dial. Bräm und Bram 'Rand, Kante', s. STRENg NRLSS. 169, wo Bibel 1642 präämi 'reunakoriste [Verbrämung]' als literarische Entlehnung aufgefasst wird, was wegen pr(nicht br-) wohl nicht richtig ist; zu dem schw. Wort s. FalK-Torp NDEWb. s. v. b ræm und HeLlQUist SvEOb. ${ }^{2}$ s. v. b r äm.

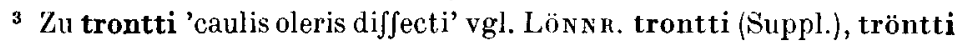
'qvarlefva af en afbruten växt eller qvistadt träd, stump', OJANsuU LM ̈̈H I S. 20 A h l a i n e n ströntti '[se,] mikä on kulunut kovin lyhyeksi' $\sim$ schw. dial. RıETz strunt 'kort halm; yttersta ändan (struten) af en ryssja', strunt-halm 'småhalm, halm som gått genom ett tröskverk', von mnd. strunt, s, zum schw. Wort Hellquist SvEOb. ${ }^{2}$ s. v. strunt. 
ufitatis dictionibus $\mathbf{S}$ Jeqventi confona abjorbetur propria tamen terminali litera reservata, ut pro Stoop tuoppi ${ }^{1} /$ pro Stool

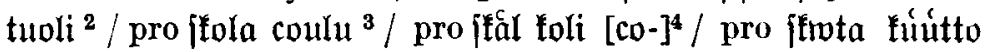

1 Zu tuoppi 'Stoop' vgl. Agr. Stopin (Akk. Sg.), Luungo Stuoppi, Bibel 1642 Stuoppi, Stopia (Part. Sg.) (nach Streng), Schrod. 38 Tuoppi 'Poculum, Stoop, das Trinckgefchirr', VRVoc. ${ }_{5} 5$ Stopi: AhdasJuu Stopi 'Poculum angufti oris, Stoop fom är trångl offwan til', JusL. Tuoppi 'vas potus minus: dimidium canthari, stop', Renv. tuoppi (tooppi, touppi) 'sextarius congii l. dimidium canthari, mensura liquidorum; poculum, potorium, Mass flüssiger Waaren, halbe Kanne, Trinkgefäss (schw. stop)', Lönn. tuoppi 'stop (mått l. dryckeskärl), halfkanna' nschw. DALıN stop 'rymdmått för våta varor, som håller hälften af en kanna; ett slags drickskärl af detta innehåll', aschw. SönE Rw. stop (stoop, stopp) 'stop, ett slags cylindriskt dryckeskär']; stop ss. måttkärl el. mått (för våta varor)', von mnd. stôp 'Becher, ein gewisses Mass', s. Streng NRLS S. 241 f,, zu dem schw. Wort Falk-Torp NDEWb. s. v. støp und Hellquist SvEOb. ${ }^{2}$ s. v. s to p.

2 Zu tuoli 'Stool' vgl. Agr. Stole, Stoli, Jtoolilla (Adess. Sg.) (nach Streng), VRVoc. 57 jtuoli: Saarnaftuoli 'Suggeftus, PredikeJtool', Jusc. Tuoli 'Jedile, Jtol', Renv. tuoli (tooli) 'sella, sedile, Stuhl (schw. stol)', Lön n R. tuoli (dial. tooli) 'stol' 〜 nschw. stol 'Stuhl', aschw. SönERw. stol (stoll, stool, stooll) 'stol, i sht stol i kyrka el. gudstjenstrum' usw., s. Setälä Verz. in FUF XIII S. 462, Streng NRLS S. 241 und wegen des schw. Wortes Heququist SvEOb. ${ }^{2}$ s. v. s tol.

$3 \mathrm{Zu}$ coulu 'fkola' vgl. Agr. Scoulut (Nom. Pl.), Schoulus (Iness. Sg.), Scholu-: Scholutupijn (Illat. Pl.) (nach Streng), VRVoc. 69 Schoulu 'Ludus literarius, Scholeftugha', Fror. 39 'Schola, ludus literarius, Schola, Scholftufwa', Just. Coulu 'Jchola, Schola', Revv. koulu 'schola, Schule', Lön r. 'skola, undervisningsanstalt, läroverk' 〜 nschw. skola 'Schule', aschw. Söd ERw. skole (schole) 'föreläsning, föredrag; skola, undervisningsanstalt, läroverk', an. skóli usw., von mlat. schola, s. Setäl ä Verz. in FUF XIII S. 389, Streng NRLS S. 73 f., wegen des schw. Wortes FALk-TorP NDEWb. s. v. skole und Hellquist SvEOb. ${ }^{2}$ s. v. skola.

4 Zu koli [co-] 'Jkål'vgl. VRVoc. 44 Jkoli: Wicht Jkoli 'Bilanx, Wichtfkåål', Renv. kooli 'skål', Lönnr. kooli 'skål, litet fat' nschw. Dalin skål 'kärl af rund form, större eller mindre, ursprungligen begagnadt att derur äta supamat eller att dricka; bägare eller glas (ford. skål), fyldt med någon dryck, och som tömmes under välgångsönskning för någon dervid nämd person etc.; benämning på vissa ting, som mer eller mindre likna en skål (vågskål, vigtskål); (skepp.) ett på ena sidan urhålkadt trästycke, som till förstärkning fastspikas eller surras vid ett svagt eller bräckt rundhult', aschw. SöDERw. skal (skaal, skaall) 'skål; fylld skål el. bägare som drickes', zu dem schw. Wort s. FALK-TonP NDEWb. s.v. $s \mathrm{k}$ a a l und IIELLQuist SvEOb. ${ }^{2}$ s. v. s k ål. 


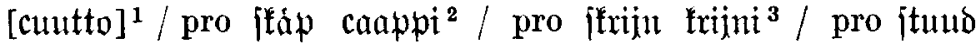
tuubi $[-\delta \text { hiq }]^{4} /$ pro fpield pelli ${ }^{5} /$ pro [pegel peili ${ }^{6}$...."

1 Zu küütto [cuut-] 'Jkwta' vgl. Flor. 115 Skuto 'Navicula, Lijtet fkep, Jkuta', Marsinıs Hodegus Finnicus 95 Cuutot: Hahdet vel Cuutot tulewat Suomejta 'skutorna komma ifrån Finland', Renv. kuutto 'navis species onerariæ, Schüte (schw. skuta)', Lönnr. kuutto 'skuta, skojt (fartyg)', Dimin. kuuttonen 'båt' nschw. Dalin skuta 'hvarje mindre fartyg, som enḍast är ämnadt till flod-, insjö- eller kustfart', aschw. Sönerw. skuta 'ett slags mindre fartyg, skuta', zu dem schw. Wort s. Falk-Torp NDEWb. s. v. s k u de und Hellquist SvEOb. ${ }^{2}$ s. v. s k u ta.

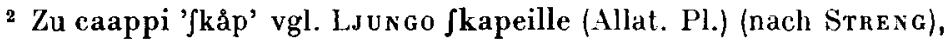
Schrod. 38 Capi 'Penuarium, Skåp, das Schapff', VRVoc. 40 Caappi 'Promtuarium, Skååp', Flor. 29 'Promptuarium, Maat fkåp', JusL. 'promtuarium, fkåp', Renv. kaappi 'promptuarium clausum, in quo pecunia, cibus etc. servantur, Schrank (schw. skåp)', LönnR. 'skåj) — nschw. skåp 'Schrank, Spind', aschw. Söperw. skap (skaap) 'skåp', von mnd. schap, s. STrENG NRSL S. 45 , zu dem schw. Wort FALK-TORP NDEWb. s. v. s $k$ a b und HeLlQuist SvEOb. ${ }^{2}$ s. v. sk å p.

3 Zu krijni 'fkrijn' vgl. Schrod. 38 Krijni 'Scrinium, Skrijn, das Käftlein', VRVoc. 46 Crijni 'Scrinium, Skrijn', Resv. kriini, riini 'skrin', LöN R. kriini 'skrin' nschw. skrin 'Kasten, Kästchen', aschw. SöD ERW. skrin (skriin) 'skrin, särsk. skrin hvari helgons aflefvor förvaras, relikskrin', von mlat. scrinium, s. Stres g NRLS S. 76, zu dem schw. Wort Falk-Torp NDEWb. und Hellquist SvEOb. ${ }^{2}$ s. v. skrin.

1 tuudi [-dhi?) 'Jtuud', sonst nicht gebucht, aschw. Sön ERw. stup (stodh usw.) 'stolpe, stod, pelare, kolonn; stöd, det hvarpå ngt hvilar; (bild.) stöd, hjälp, bistånd', zur Etymologie des schw. Wortes s. FALK'Torp NDEWb. s. v. stot te und HellQuist SvEOb. ${ }^{2}$ s. v. s töd.

$5 \mathrm{Zu}$ pelli 'fpield' vgl. Schnod. 35 Spelli 'Lamina foci, Spiäll, ein Schufzblech im Camin', Jusc. Pelli 'lamina camini, Jpiäll', Renv. pelli od. pelti 'operculum camini, Schornsteinsschliesse (schw. spjell)', klasi-pelli 'lamina vitri, Glasscheibe', Lönnr. pelli 'spjell, plàt', pelti 'bleckspjell, plăt (pelli)' nschw. spjäll 'Ofenklappe', s. SetäLï Verz. in FUF XIII S. 424, Streng NRLS S. 148, wegen des schw. Wortes FalKTorp NDEWb. s. v. s p jeld und Hellquist SvEOb. ${ }^{2}$ s. v. s p jäll.

- Zu peili 'Jpegel' vgl. Agr. Speili, Speijlixi (Translat. Sg.), Bibel 1642 Speilit (Nom. Pl.) (nach Streng), Schrod. 38 Peili 'Speculum, Spegel, der Spiegel', VRVoc. 47, Flor. 23 Speili, Jusl. Peili, Speili 'fpeculum, Spegel', Rerv. peili 'speculum vitreum, Spiegel (schw. spegel)', Lönnr. 'spegel' nschw. spegel 'Spiegel', aschw. SöDERw. speghil (speghel usw.) 'spegel; föresyn, mönster; exempel, varnagel', von mnd. spêgel, s. Setülä Verz. in FUF XIII S. 423, Streng NRLS S. 147 f., wegen des schw. Wortes Falk-Torp NDEWh. s. v. s jeil und Heriquist SvEOb. ${ }^{2}$ s. v. s pegel. 
4. S. 79 f. (Obf. orth. Cognatio Literarum) »10. $\mathfrak{A} \mathfrak{u} \& \$$ cognationem habent. $\mathfrak{A} \mathfrak{u}$ Runicum \& Islandicum Jonat ut noftrum $\$$. Olim Jeribebatur aul cerevijia (jam ol) / anxe fecuris (jam ore) / aurn aqvila, (jam orn)/atteftante Edda Islandorum, part. 2 de Var. rer. appellat. .. . Finnis Jauma Sont Jutura ${ }^{1}$, nauta need bos ${ }^{2}$ \&c."

5. S. 81 f. (ObJ. orth. Cognatio Literarum) »11. $\mathscr{B} \& \mathfrak{B}$ conJonantes, utpote labiolabiales, Junt cognatæ. Dicimus: blabd= rer pladorer nugor; Blummer plummter pruna; lube lippe labrum, labium. A flceber flipper. Dicitur nobis $\mathfrak{B i f c o p}$ pro $\mathfrak{B i f c o p / ~}$

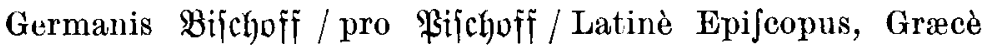

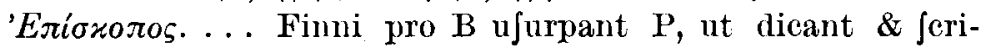
bant pro Borvari poriari Bárgare / Borger / civis ${ }^{3}$; pro barta parta bart / barba ; pro Bijpa pispa Bijp ${ }^{5}$ \&c.»

1 Zu Jauma 'futura' vgl. Sch nod. 30 Sauma 'Sutura, Sööm, der Saum', Flor. 106 'Sutura, Sömm', Jusl. 'futura, Jöm', Renv. sauma 'sutura e. c. vestium, commissura e.c. duorum assium, junctura trabium in parjete l. nave etc., Naht, Fuge', löss r. 'fog, fogning, söm; infalsning, nät; sutur (bot.)' an. saumr, s. SETÄLÄ Verz. in FL'F XIII S. 449, wegen des germ. Wortes Falk-Tonp XUEWb. s. v. so in und IIELLQuist SvEOb. 2 s. v. s ö m 1.

2 Zu nauta 'bos' vgl. Schrod. 56 Nauta 'Bos, Nööt, der Ochs oder die Kiuh', VRVoc. 85, Flor. 95 'Bos, Nööt', Jusl. 'bos, nöt, fää', Renv. nauta 'bos, pecus, jumentum, Rindvieh (schw. nöt)', Lön n. 'nötkreatur, nöt, fä, djur' $\sim$ an. naut, s. Setälä Verz. in FUF XIII S. 416 , wegen des germ. Wortes Falk-Torp NDEWb. s. v. n a u t und HelaQuist SvEOb. ${ }^{2}$ s. v. n öt 2.

3 Zu porvari civis' s. o. S. 73 Fussnote 2.

4 Zu parta 'barba' vgl. Schrod. 11 Parta 'Barba, Skägg, der Bart', VRVoc. 12 'Barba, Skegg', Flor. 9 'Barba, Skägg', Jusl. 'barba, fkägg', Renv. parta 'barba, Bart', Lönnr. 'skägg' an. bard, ags. beard < *barda-; das Wort kann auch balt. bzw. russ. Ursprungs sein, s. ТномSEN FBB S. 162 (= Samlede Afhandlinger IV S. 277), Falk-Tonp NDEWb. s. v. bar t, Setälä Verz. in FUF XIII S. 423 und Mikkola MSFOu. LXXV S. 52.

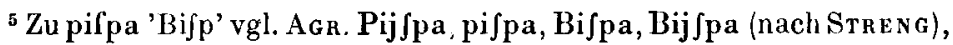
Schrod. 13 Pifpa 'Epifcopus, Bifcop, Bifp, der Bifchoff', VRVoc.

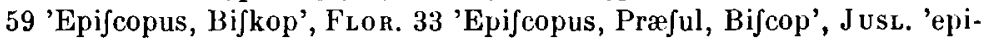
Jcopus, bifkop', RENv. pispa od. piispa 'episcopus, præsul sacerdotum, Bischof', Lönsr. piispa od. pispa 'biskop' $\sim$ nschw. bisp, aschw. SÖDERW. bisp, in proklitischer Stellung vor Namen aus biskop, S. SETäLä Verz. in FUF XIII S. 427, Strang NRLS S. $153 \mathrm{f}$. und wegen des schw. Wortes IInlqueist SyEOb. ${ }^{2}$ s. v. bisko p. 
6. S. $83 \mathrm{f}$. (Obf. orth. Cognatio Literarum) "14. D \& $\&$ confonantes lingvodentales Juperæ fimul cognationem habent. Dicimus labder latter / bed bette / goed got / intad ntet /

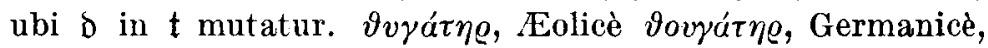
ut \& Perficè, Dochter / Danicè botter / Finnonicè Tytär ${ }^{1}$. . . "

7. S. 86 f. (Obj. orth. Cognatio Literarum) "16. F etiam \& $\mathfrak{B}$ literæ, ut labiales labiodentales, cognatæ Junt. Germani v ut $\mathfrak{f}$ fere pronunciantes dicunt voget/vogt/Saxones vaget/ nos foget / qvafi vocat, Advocatus, Adminiftrator, Gubernator. In hiftoria Theoderici Veronenfis: Der ebil voget vou Berne.... Qvoniam Finni literam i rejiciunt, illamq́ve vocabulis á [à] Svecis mutuò acceptis excludunt, cognatumq́ve

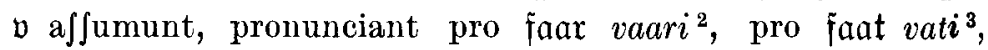
pro fange vangi ${ }^{4}$, pro falff ralski ${ }^{5}$."

1 Zu Tytär 'dotter' vgl. Schron. 16 Tytär 'Filia, Dotter, die Tochter', VRVoc. 66 'Filia, Dotter', Flor. 62 'Filia, gnata, Dotter', Jusc. 'filia, dotter', Revv. tytär 'filia, puella, Tochter, Mädchen', LönNr. 'dotter, flicka' lit. dukter-, s. 'Тномек FBB S. 267 f. (= Samlede Afh. IV S. 286).

${ }^{2} \mathrm{Zu}$ vaari 'faar' vgl.', Agr. waarj, Faarj, Pict. farillens (Allat. Sg. mit dem Possessivsuffix der 3. P.) (nach Streng), Jusl. Faari 'pater, fader', Renv. vaari 'pater, avus, senex reverendus, Vater, Grossvater, Greis (schw. far)', Lönnk. 'far, farfar l. morfar; gammal far (ukko)' $\sim$ nschw., aschw. SAOb. far 'Vater', aus fader in unbetonter Stellung, s. STRFNc: NRLS S. 252 und wegen des schw. Wortes Hellquist SvEOb. ${ }^{2}$ s. v. f a d e r.

3 Zu vati 'faat' vgl. Agr. Fatin (Gen. Sg.), LuUngo fatit (Nom. Pl.) (nach Streng), Schrod. 26 Fati 'Dolium, Faat, das Fajz', 38 'Patina, Faat, das Fasz', VRVoc. 45 'Scutella, Faat', Flor. 29 'patina, Faat', Jusl. Fati, Wati 'patina fat', Renv. vati (fati) 'patina, Schüssel (schw. fat)', Lönnr. vati (fati) 'fat; (sjöt.) fastage' nschw. fat 'Schüssel, Untertasse; Fass', aschw. Sön E rw. fat 'fat, i sht ss bordkärl; fat, större slutet kärl (laggkärl) hvari en handelsvara är innesluten; äfven ss mått; klädesplagg', S. Setälä Verz. in FUF XiII S. 469, Streng NRLS S. 255 f., wegen des schw. Wortes Falk-Torp NDEWb. s. v. fad und Hellquist SvEOb. ${ }^{2}$ s. v. f a $t$.

$4 \mathrm{Zu}$ vangi 'fange' vgl. Agr. Fanghit (Nom. Pl.), fangien (Gen. Pl.) (nach Streng), Schrod. 15 Fangi 'Captivus, Fånge, Gefangen', Flor. 70 'Captivus, Fånge', Jusc. Fangi, wangi id., Renv. vanki (fangi) 'captivus 1. captus in bello, vinctus 1. carceri inclusus e. c. maleficus, Gefangener (schw. fånge)', LöN N R. vanki (fanki) 'fånge, häktad person' -

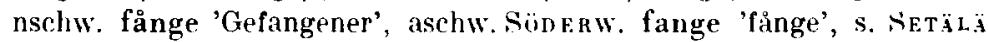


8. S. 88 f. (Obf. orth. Cognatio Literarum) »17. (G) confonans lingvodentalis infera exterior cognationem habet cum $\sqrt[5]{5} \mathfrak{\mathbb { R }} \& \mathfrak{Q}$ confonantibus lingvodentalibus inferis interioribus. A brager orectig/eenbrectig; à vaager vact / à jager jact / à nego negatum necter; ab aag ecte / ecter / ectejfab / . . Finni, qrum G non admittant, ut dictiones incipiat, pro glafi dicunt klafi [cl-]1, pro gulda culda ${ }^{2}$. Tänäpän culda huomena mulda. $\mathfrak{F}$ bag guld / $\mathrm{i}$ morgen muld."

9. S. 120 f. (ObJervationes etymologicæ. Accidentia Nominis. I. Genus) »1. Genus eft triplex; 1. Polyconum, cujus nota eft articulus En / item Dend / \& pronomen benone / ut en / beno / benone mand / quinde / bog / imò etiam En in fine; ut manden / quinden / bogen. 2. Neutrum, cujus nota articulus Et / item Ded / Dette / ut Et / Ded / Dette ongr / huus / boerd / imo (5t in fine, ut dyret / huufet / boerdet / \& dicitur Neutrum, qvòd nec Jit polyconum, nec Commune. 3. Commune, qvod nominibus polycœni \& Neutrius generis competit, nt En halt mand / et halt lant / en ffaldet pande / et flaldet hovet / bend vilde mand / bed wilde byyr. Nos igitur noftra habemus Genera. At Finnones in totâ Juâ lingvâ nulla omnino obfervant genera, fed unicum tantùm habent articulum $S E$, qvi utriqve fexui, ommibusq́ve generibus attribuitur, ut $S e$ mes [mies] hic vir, Se vvarmo [waimo] vel Naine [-nen] hac

Verz. in FUF XIII S. 467, STRENG NRLS S. $254 \mathrm{f}$. und wegen des schw. Wortes HellQuist SvEOb. ${ }^{2}$ s. v. f ång.

5 Zu valski 'falfk' vgl. Agr. faljki (nach Streng), Renv. falski, valski 'falsus, fallax, mendax, dolosus, adulterinus, e.c. pe:unia, falsch', Lönnr. valski (falski) 'falsk, bedräglig, opålitlig' $\sim$ nschw. falsk 'falsch', achw. Sön ERw. falsker 'falsk, bedräglig, svekfull; falsk, icke verklig, understucken, oäkta; falsk, osann, osannfärdig', dän. falsk, von mnd. valsch, s. Streng NRLS S. 19, wegen des schw. Wortes Falk-Torp NDEWb. und Hellquist SvEOb. ${ }^{2}$ s. v. f a l s k.

$1 \mathrm{Zu} \mathrm{kla \int i}$ [cl-] s. o. S. 74 Fussnote 1.

2 Zu culda 'guld' vgl. Schrod. 6 Culda 'Aurum, Guld, das Goldh', 25 'Aureus, Guld, Gullen, der Goldgülden', VRVoc. 102 'Aurum, Guld', Petraus Tabella 'Aurum', Flor. 93 'Aurum, Gull', Jusl. 'aurum, gull', Renv. kulta 'aurum, Gold (schw. guld)', Lön NR. 'guld' $\sim$ got. gulp, s. SETäLä Verz. in FUF XIII S. 392, wegen des germ. Wortes Feist GEWb. ${ }^{3}$ s. v. gull' und IIelquvist SvEOb. ${ }^{2}$ s. v. g il 1 d. 
mulier, Se Aelehin ${ }^{1}$ [Eläin] hoc animal, ideoq́que nifi Svecicam vel aliam in juventute didicerint lingvam, difficillimè in aliis lingvis difcunt objervare difcretionem jexus \& generum, eamq́ve aut prorfus omittunt, aut inconvenientem apponunt. Qvæ tamen iftius lingvæ proprietas maximo eft adjumento extraneis Finnonicam lingvam addi jcentibus, qvò citiùs eam

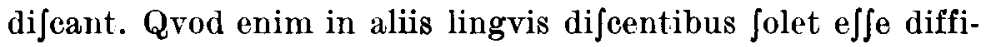
cillimum, in ea prorfus omittitur. Henricus Soterus [ANDREas Bureus] in Sveciæ defcriptione. $\|^{2}$

1 Da dieses Wort bei Pontoppidan undeutlich ausgedruckt ist, so hat BERTELSEN es unrichtig gelesen, und in seinem Neudruck (Danske Grammatikere II S. 105) erscheint es in einer ganz entstellten Form: Aslebin.

2 Vgl. Bureus l. c. S. 57 f. (Fortsetzung von S. 72 Fussnote 1): wSecundo in tota Jua lingua, nulla omnino objervant genera, fed unicum tantum habent articulum je, qui utrique fexui, omnibufque generibus

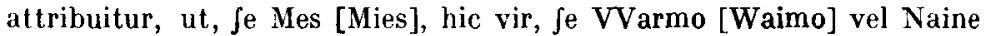
[-nen], hæc mulier, fe Aelehin [Eläin], hoc animal. Ideoque nifi Svecicam vel aliam in juventute didicerint linguam, difficillime in aliis linguis difcunt objervare difcretionem fexus \& generum, eamque aut pror $\int u s$ omittunt, aut inconvenientem apponunt. Quæ tamen iftius linguæ proprietas, maximo eft adjumento extraneis Finnonicam linguam addifcentibus, quo citius eam difcant. Quod enim in aliis linguis difcentibus

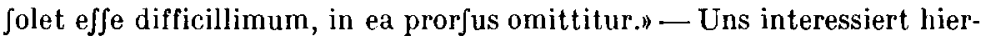
hei vor allem die Stelle, wo die fi. Wörter vorliegen. Sie lautet in der Auflage von 1633 des Soterus'schen Werkes ganz gleich: S. 55 "... le, . ., ut, Je Mes, hic vir, Je VVarmo vel Naine, hæc mulier, fe Aelehin, hoc animal." Die fehlerhafte Form vvarmo bei Pon top PID an stammt von Soterus her. In dem Bureus'schen Originalwerk 1626 erscheint dieses Wort richtig (Waimo), vgl. die betreffende Stelle in dem von Richten hrsg. Neudruck (s. o. S. 65 Fussnote 3) S. 14: ". . Se, . ., ut, se Mes, hic vir, se Waimo vel Naine, hæc mulier, se Elehin, hoc animal»; vgl. diese Stelle auch in der 1631 in Wittenberg erschienenen Descriptio von BuREus (hier sind in fi. Wörtern wieder andere Fehler untergelaufen) Bl. K 4a: ^. . . SE, ..., ut Se Mes, hic Vir, fe Wamio [Waimo] vel Nanie [Naine], hæc mulier, fe Elehin, hoc animal." Bei Scннореrus Lexicon Latino-Scondicum 1637, Vorrede ("Ad Lectoremn), ist die in Frage stehende Stelle, wie folgt, abgedruckt (er hat ohne Zweifel das Originalwerk von Bureus benutzt), dabei Mes in mies korrigiert, aber das nicht weniger fehlerhafte Alehin so gelassen oder, genauer, als âlehin wiedergegehen: .... Se /... ut: Semies / ille vir; Se waimo vel naine / hac mulier; Ge ålebin / hoc animal." Während es mit Waimo so steht, erscheint das bei Bureus vorliegende $A$ Iehin (als Älehin zu lesen) bei Sotenus und nach ihm bei Pontoppinan als Aelehin, andrerseits hai 
10. S. 198 ff. (Obf. etym. Accidentia Nominis. VI. Species) "1. Nomina alia Junt primitiva, ut Gud / mand; alia Derivata, ut Gubelig/mandig.

2. Derivata Junt Gentilia, Pofse Ssiva, Deminutiva, Denominativa, \& Verbalia.

5. Deminutiva Junt, qræ defignant deminutionem primi-

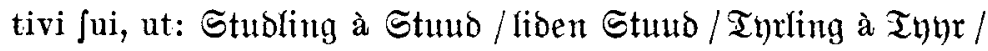
Basnge à vaang / liben vaang / dulle / bullife à bue / liben bue $/ \ldots$ Nomina qvædam propria etiam deminuuntur, ut apud Germanos. E. g. Annife ab $\mathfrak{A n n e}$ / liben $\mathfrak{A n n e ~ / ~ M a r i f e ~ a ̀ ~}$ Marie/liden Marie elder liben Maren/Thadife à Thale . . . liben Thale / Thrinife à Thrine / liben Thrine / Sillife à Sille / liben Sille / . . Finnonibus terminantur Deminutiva in inen / ut Rinbuinen avicula, à linou avis, firiainen libellus à tirja liber, veibzinen cultellus à neidzi culter, poicainen puerulus à poica puer.,1

11. S. 244 ff. (Obf. etym. Accidentia Nominis. VI. Species) "10. Adjectivorum terminationes.

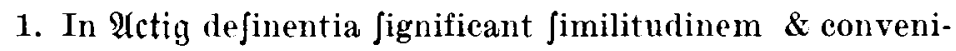
entiam, ...

5. In $\mathfrak{Q} \mathscr{\mathfrak { S }}$ definentia fignificant inopiam \& privationem, ut:

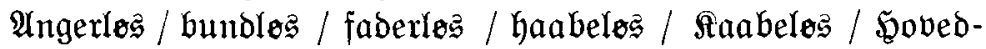
loś / livles / pengeles / Sandjeles / trolos \&c,[.] Qvemadmodum Germanica in loiz/ut jchabloiz/ Gottloiz/ jorgloiz / tunitloiz / trewololz / machtloiz / frafftlojz \&c., \& Finnonica in toin \& tóin, ut: Neuvotoin [-vot-] raablos / lapfitoin barnles / rahatoin pengelos / voimatoin macteşlos / Paidhatoin

Schroderus Vorrede als ålehin (vgl. sein Lexicon!); eine solche Form ist indessen im Finnischen nirgends belegt, wohl aber eläin (so auch in den ältesten Wörterbüchern: Schrod. 55 Eläin 'Animal, Diwr, Das Thier', VRVoc. 84 'Animal, Diwr', Flor. 94 'Animal, ett Diur'), ferner elän, älän, eläjäin, eläjän usw., s. OJAxsuU LMÄH I S. 204 f., RAPOLA KSi-Dift. S. 277 und SKKH I S. 287.

1 Siehe hierzu $\$ 7,3 \mathrm{~d}$. 
Gfjorteles / Isátóin fáderlas / aititón [åi-] moderles / kenod-

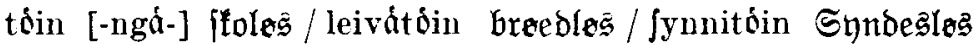
\&C.»1

12. S. 333 f. (ObJ. etym. De Præpofitione) "Prapofi[t]io eft orationis pars invariabilis, qvæ aliis vocibus præponitur ad aliqram circumftantiam denotandam.

Prapofitiones dicuntur à præponendo, qvia aliis vocibus præponi folent. Sed apud Finnones potiùs dicendæ Poftpofitiones, qvum in eorum lingvâ poftponantur, ut teftatur Henricus Soterus [ANDREas Burecs] in Sveciæ defcriptione his verbis: Vocuke, qva in aliis lingvis à preponendo prepofitiones vocantur, in Finnonica lingva femper poftponuntur.» ${ }^{2}$

13. S. 397 f. (Obf. syntacticæ. Syntaxis Nominum) "... $\mathfrak{A n r m i}=\mathfrak{\Re n u b e}$ vel $\mathfrak{\Re n r m i f f e = f m u d e ; [ . ] ~ D i c i m u s ~ r u l g a r i t e r ~}$

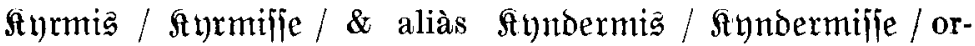

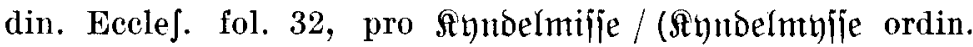
fol. 35), Islandis $\mathfrak{f t y n d i l m e f i ́ a ~ / ~ m i s s a ~ c a n d e l a r u m , ~ a ̀ ~} \mathfrak{A y n d e l}$ candela (Finnis kynttila [-lä bzw, -lád] ${ }^{3}, \&$ idem eft, qvod Iyjemefíe/Germanicè Riechtmes/Gallicè La chandeleufe, Anglicè Kandelmes. ...»

14. S. 493 f. (ObJ. synt. Syntaxis Præpofitionum)"1. Qræ-

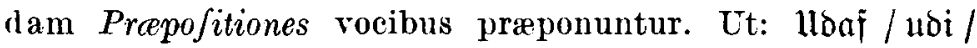
formedelit / Fremt / Fremfor / Snben / Sndenfor / ubenjor / ovenfor / Medenfor/Mkaerhos. E. g. Mrlot got er noaf Gub.

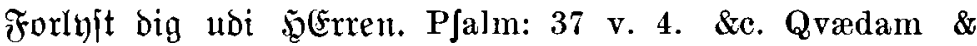
præponuntur \& poftponuntur. Ut: $\mathfrak{A} \mathfrak{j} / \mathfrak{A} \mathfrak{n} / \mathfrak{b a g} / \mathfrak{b i} /$ bort $/$ efter / for / forbi / . . ud / ved / under. E. g. Jeg affladbe

1 Siehe hierzu $\S 7,3 \mathrm{~d}$.

2 Vgl. Bureus l. c. S. 58 (Fortsetzung von S. 83 Fussnote 2): Tertia ejus proprietas e $\mathrm{t}$, quod voculæ qvæ in aliis linguis à præponendo præpofitiones vocantur, in Finnonica lingua femper poftponuntur."

3 Zu kynttila [-lä] 'candela' vgl. Scн nod. 37 Kyntilä 'Candela, Liws, Keitz [Kertz]', VRVoc. 44. 'Candela, Liws', F lor. 28 'Candela, Lius', JusL. Kynttilä od. kynttylä 'candela, lius', Rexv. kynttilä od. kynttylä 'candela, Talglicht (peregr.)', Lönnr. kynttilä, kynttylä 'ljus; kyndelsmessa' an. kyndil 'Kerze, Licht', norw. und schw. dial. kyndel 'Fackel, Flamme', s. SetäLÄ Verz. in FUF XIII S. 396, wegen der nord. Wörter FALK-Torp NDEWb. s. v. k y n d e ls in es s e und Helqquist SvEOb. ${ }^{2}$ s. v. k y $\mathrm{n} d \mathrm{els} \mathrm{m}$ äs $\mathrm{s}$ a. 


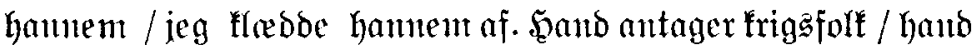
tager frigăfolf an.... Dent / jom wil fjobe / fand icke vare penge foruden \&c. Vide obJervationes Etymologicas de Prapofitionibus. Finnones dicunt Menen ulos \& ulos menen, ylśs noufen \& Noufen ylós. Sed notandum hîe, qvòd verbis imperativi modi Præpofitiones potiùs poftponantur. Ut: Ctat op/gat ud/løb hea / tager bort eders unde ibrat fra mine ojen. EJa: 1 v. 16. Ita Finnones: Mene ulos gaf ud/ Noufe ylis ftat op.»1.

Anschliessend sollen aus PEDER Srvs Werken die Stellen angeführt werden, wo das Finnische erwähnt ist, und zwar in fortlaufender Numeration der Auszüge.

15. Nogle betenkninger om det Cimbriske Sprog, Kiöbenlh. 1663 (im Neudruck bei BERTELSEN Danske Grammatikere I, Kobenhavn 1915, S. 75-272) S. 29 f.:»... Goos de Siner bejtaae aldo pordene af cen itafuelie; joos llugerne ere be mreget lange.2 Andre bevege iffe vordene $i$ abjfillige entolfer [in der Fussnote: Cajus] men jaetter eet Slaeloord [in der Fussnote: Articulus] for ved / [om be நebrcer. Anore hafue mange /

1 Zu den fi. Belegen s. $\S 7,3$ d und e.

2 Woher diese Nachricht über das Ungarische stammt, ist nicht angegeben worden. An IIand z. B. des Georgius HenischuUs' 'Thesaurus linguæ et sapientiæ Germanicæ, Augustæ Vindel. 1616 oder Ам в оsius Calepinus' Dictionarium decem bzw. undecim linguarum (Ungarisch darin zum ersten Male in der Auflage von 1585, Lyon; s. Melich NyK XXXVI, Budapest 1906, S. 43 ff.) konnte er selbst eine oberflächliche Vorstellung von dem Ungarischen erhalten. Erst später, in dem interfoliierten Exemplar seines Werkes (s. unten $\S 6$ ) fühırt Syv S. 107 die Grammatik von Albertus Molnír an: Gram. Ungarica. Hanovia 1650 [?1550]. 8. Avtore Alberto Molnar." Ob SYv selbst die Grammatik (Novæ grammaticæ Ungaricæ... libri duo, Ilanoviæ 1610) gesehen hat, ist fraglich; von ihr gibt es nämlich keine weitere Auflage, der von ToLdy hsg. Neudruck 1866 (s. gleich unten) allerdings nicht mitgerechnet - die Jahreszahl 1650 ist somit unrichtig -, vgl. Francisces Toldy Corpus grammaticorum linguae Hungaricae veterum, Pesthini 1866, S. XI, C. Horváth A régi magyar irodalom története, Budapest 1899, S. 442 und J. Pintér Magyar irodalomtörténete III, Budapest 1931, S. 242, vor allem aber József SzıNvy i Magyar írók élete és munkái IX, Budapest 1903, sp. 162. 
andere fan Endeliex. De Fimner hafpe tolf ${ }^{1} /$ bores genteenligt tre / bog bet tilforn hafbe fleere [in der Fussnote: Worm. in Addit. ad Lit. R. p. 38. L.].»²

16. Daselbst S. 32: "... Suvilfet iffe fando erlanges/uben vi jaa vel jom andre folf befatte vort iprog i vifje regle. Seijer Rarl Den Store jureev jelo een Tydfl Grammatifa/ ber fproget var entoda barbariff/og gaf Monederne og Min-

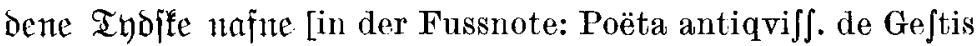
Car. Magni, per R. Reinec. Helm. 1594. L.]. Den Rubjifice (Srantmatife findes jo traft $i$ deris eget iprog ${ }^{3} /$ men dend Finniffe haandjtxefuen?[.] $]^{4} \ldots$

17. Daselbst S. 140: "De Finner have riim/beftaaende $i$ otte itavelier/og fallede Runoi/maa ifee efter vore $\Re u=$ iter. $11^{5}$

18. Jaselbst (Nachtrag) S. 196 (Zusatz zu S. 27, Zeile 17): "De Fimmer hajue iffe: $\mathfrak{F}$. elfer noget ourd/fon begunter af B. D. G. elfer to medindende/vam. A. Bureus Defer. Svec. 56. S. (2.) $)^{6}$

19. Den Danske Sprog-Kunst eller Grammatika, Kiøbenhafn 1685 (im Neudruck bei BerTelsen Danske Grammatikere III, København 1919, S. 147-250) S. 103 f.: " $2(t$ nogle giore $\mathfrak{R}$ arvarende og 1 fuldomme tio eentis $\mathrm{f}$ enfoldig og $\mathfrak{M}_{\mathfrak{n} n g} \mathfrak{f o l b i g} \mathfrak{I} \mathfrak{a l}$ [in der Fussnote: Dicunt: Præens Indicativi modi habet Numerum Sing. \& Plur. Similem. Sic Imperfecta.] ex mod andre Tungemals maneer (thi entogiaa be Barbarife. Finner / og Lapperne / fomme af bent / giøre forjtel her paa.)

1 Siehe hierzu $\S 6$ und $\S 7,3 \mathrm{c}$.

2 Statt "Addit. ad Lit. R." soll sein: "Addit. ad Monumenta Danican.

3 Es handelt sich um eine kirchenslavische Grammatik; die erste Grammatik der russischen Sprache ist die 1755 in Sanktpeterburg erschienene Rossijskaja grammatika von Michajl Lomonosov.

4 Siehe hierzu $\S 6$.

5 Siehe hierzu $\S 6$.

6 Siehe hierzu $\S 6$. Diese Stelle ist in Syvs Wiedergabe von einem anderen dänischen Grammatiker, HENRICH GERNER in seiner Orthographia Danica, Kiøbenhafn 1679 (im Neudruck bei Bertelsen Danske Grammatikere III, København 1919, S. 11-146) S. 60 kurz ange-

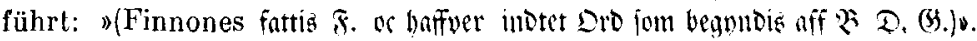


[in der Fussnote: Gram. Fin. Mfc. Crugeri. ${ }^{1}$ J. Schefferi Inpland c. $16 .{ }^{2}$ ]."

5. Das Finnische ist, wie wir gesehen haben, in PoxtopPIDANs Grammatik an 14 Stellen herangezogen, und nur an 3 Stellen mit Quellenangaben. An einer dieser 3 Stellen (Auszug 3) sind Sotercs [Bureus] und Crugerus nacheinander zitiert worden, an zwei anderen (Auszüge 9 und 12) Soterus [Bureus] allein. Wenn wir die drei Zitate aus Soterus [BURecs] ${ }^{3}$ näher ins Auge fassen, sehen wir, dass Pontoppidax sich ziemlich genau an den Originaltext gehalten und ihm gegenüber (s. o. die entsprechenden Fussnoten) lediglich einige unwesentliche Änderungen vorgenommen, z. B. im lateinischen Text einige Wörter in Kursivschrift und statt kleiner Anfangsbuchstaben grosse bzw. umgekehrt statt grosser kleine gesetzt hat; die wenigen fi. Wörter hat er genau so wiedergegeben, wie er sie bei Soterus vorgefunden hat (s. Auszug 9 und die dazu gehörige Fussnote). Jasselbe lässt sich mutatis mutandis auch von den auf andere Sprachen bezüglichen Zitaten behaupten; bei den sprachlichen Belegen sind Schreibbzw. Druckfehler nicht sehr zahlreich, vgl.im Folgenden (S. 89 Fussnote 2) meine Berichtigungen in eckigen Klammern. Daher haben wir allen Grund anzunehmen, dass dies auch von dem anf CRugerus zurückgehenden Zitat: "Nulla vernacula dictio incipit $a b$ his literis $\mathrm{B}, \mathrm{D}, \mathrm{G}, \mathrm{F}, \mathrm{Z}$, ab his enim initium habentes à Srecis funt in ufum traducte. Dicimus pro $\mathfrak{B a ́ n g}=$

1 Siehe hierzu $\S 6$.

2 Syv führt ab und zu Büchertitel in dänischen C̈bersetzungen an. So ist es auch der Fall mit "Schefferi Saplant". Er hat offenbar die Originalausgabe (nicht etwa die englische Ubersetzung) dieses Werkes: Lapponia, Francofurti 16:3 (auf dem Frontispiz steht die Jahreszahl 1674) benutzt, denn in dem interfoliierten Exemplar seiner Nogle betenkningar etc. S. 474 wird diese Ausgabe erwähnt: "Defcriptio Lapponiæ Sc[h]efferi Francof. [16]74. 4.". Ferner ist zu bemerken, dass in dem Werk von Schefferus über die lappische Sprache (mit Rücksicht auf die finnische) in dem 15. Kap. gehandelt wird, nicht aber in dem 16., wie bei $\mathrm{Sy} v$ angeführt.

${ }^{3}$ Mit diesen drei Zitaten ist eigentlich alles erschöpft, was BurEus über die fi. Sp rach e berichtet hat. Denn eine weitere Bemerkung bei ihm, s. Soт rus Suecia 1631 S. 58, bezieht sich nur auf den Versbau der fi. Volkslieder; sie wird unten $\$ 6$ angeführt. 
meitare pormeftari,... pro ipield pelfi / pro ppegel peifi" (Auszug 3) gilt bzw. von den fi. Belegen ohne Quellenangaben (sie stammen ebenfalls von Crugerus, wie wir gleich sehen werden).

Das Zitat bringt einen langen, über den Anlaut handelnden Abschnitt. Es enthält in ganzen 33 Wörter: pormeftari, porvari, Tuomari, Tuomio, taalari, klafi [cl-], vixi, fadherma Tav. vadherma, Tav. crappu, Tav. cratti, Tav. craaccu, Tav. crwhu, Tav. crencu [krenccu], pleicu, truski, Jammaco, plufu, plaiccu, crapu, prijmi, murkina, präämi, trontti, tuoppi, tuoli, coulu, koli [co-], küütt o [cuutto], caappi, krijni, tuudi [-dhi?], pelli und peili. An den übrigen 11 Stellen (Auszüge $1-2,4-8,10-11,13-14)$ sind die fì. Belege, wie erwähnt, ohne Quellenangaben angeführt. Es handelt sich um einzelne Wörter, einige Sätze (darunter ein Sprichwort) und zwei Ableitungsgruppen: Lauvantaj [-ai] 'Dies Saturni' (1) ${ }^{\mathbf{1}}$; cuinga-s Janot? pro cuinga Jinä Janot? 'qvid [quomodo] tu dicis?', cungas menet? pro cunga finä menet? 'qvor $\int u m$ tu vadis?' (2); Jauma 'Jutura', nauta 'bos' (4); porvari 'civis',

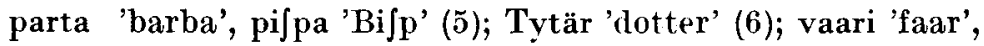
vati 'faat', vangi 'fange', valski 'fallk' (7); klaji [cl-] 'glas', culda 'guld', Tänäpän culda huomena mulda 'I dag guld, i morgen muld' (8); Linduinen 'avicula' von lindu 'avis', Kirjainen 'libellus' von kirja 'liber', veidzinen 'eultellus' von veidzi 'culter', poicainen 'puerulus' von poica 'puer' (10); Neuvötoin [-vot-] 'raadløs', lapfitoin 'barnløs', rahatoin 'pengeløs', voimatoin 'mactesløs', Paidhatoin 'Skjorteløs', Isätöin 'faderløs', aititöin [äi-] 'moderløs', kenoätöin [-ngä-] 'Jkoløs', leivätöin 'brøedløs', fynnitöin 'Syndesløs' (11); kynttila [-lä] 'candela' (13); Menen ulos \& ulos menen ['ich gehe hinaus'], ylös noufen \& Noufen ylös ['ich stehe auf'], Mene ulos! 'gak ud!', Noufe ylös! 'ftat op!' (14). Offenbar stammen diese ebenfalls aus Crugerus' Grammatik. ${ }^{2}$ Poxtoppidaxs Aus-

1 Die neben den fi. Belegen stehenden Ziffern in runden Klammern oder auch ohne dieselben beziehen sich auf die Auszüge.

2 Der Umstand, dass die Quelle bei ihnen nicht angeführt ist, widerspricht dem noch nicht. Bei den aus Grammatiken und Wörterbüchern entlehnten einzelnen Wörtern, Sätzen, Wort- und Formengruppen wird 
drucksweise, deren er sich in gewissen Fällen hinsichtlich des Finnischen bedient, schliesst, wie es scheint, die Kenntnis anderer Quellen ausser Crugerus (und Soterus [Bureus]) aus. Beachte bei ihm vor allem die Stelle, die über die Ersetzung des $b$ - durch $p$ - handelt: "Finni pro B uJurpant $\mathbf{P}$, ut dicant \& fcribant pro Borvari porvari Bargare / Borger / civis; pro barta parta bart/barba; pro Bifpa pifpa Bifp \&c." (Auszug

bei Pontoppidan auch sonst die Quelle, allerdings von besonderen Fällen abgesehen (s. gleich unten), in der Regel nicht angegeben. Vgl. z. B. betreffs der i s lä $n d$ i s c h e $n$ Belege - im Folgenden werden in rurıden Klammern neben Seitenangaben Wort- bzw. Formengruppen und Sätze angeführt, einzelne Wörter dagegen nicht; in eckigen Klammern stehen hier wie sonst meine Berichtigungen und Zusätze - SS. 35 f. ("... Utimur autem nos litera $\mathfrak{S}$ in principio ... \& præponimus $\mathfrak{S}$. Islandi etiam $\mathfrak{Z} / \mathfrak{M} / \mathfrak{R}$ præpofitô $\mathfrak{Q}$ a ppirant [es folgen Beispiele nach Jonas' Gramm. Isl. rud.], ut hlad platea [Jonas S. 23], hfiovo vox, Jonus [23], blaatur rifus [3, 42], blione obedientia [57], bunffue [-11t] culter [27], bneppe qvantum brachiorum complexu contineri potest [31 ... amplexu includi poteft], hnauf labor [34], bnacfe occiput [56], brigd triftitia [11], broffil corvus [22 braffu, 25 jorain], braf res contempta [34], brante sputum [56], brutur aries [27], breibur nidus [29], brofí raftrum [8] \&c.m), 42, 48, 50 ("..., Islandi in quibusdam vocibus propter fonum exprimendum ultimam duplicant confonantem, ut flagg apluftre, vexillum navis [Jonas $S$. 33 Vexillum navium], nagg rixa [33], wlagg fupellex [33], $\mathfrak{c g g}$ ovum, acies [33, 52 Ovum], orega / grugg fex [20,33], bregg imber [33], rood vox [Quelle?] \&c.川), 53, 79 ("... Island s fcribunt haut mes]is [Jonas S. 36 Autumnus], naud calamitas [4 Calamitas, 12 Malum], naut bos [36], traut confidientia, refugium [aus Wormius' Specimen lex. run. S. 128], bratte panis [braut, Jonas S. 23 brant]. ciute mors [56], au tamen pronunciant ut noftrum ..1), 323, 357 (obe. deinn non rogatus [Jonas S. 167], ofiet nefas [167], oxrlegur improbus [78]), 376 f. (mantorn homuncio, piltfnin puerulus [Quelle?; vgl. Jonas S. 98: "hinen / ut Bagge Faugaforn / hev beyform \&c.v]), 397; betreffs der d e u t s c h e n Belege SS. 18, 23,24, 30 (baben, loben, leben, geben), 31 abbamen (atmijeben usw.), 35, 38, 39, 41, 42, 4', 45, 46, $47,48,52,54,75,76,77,79,80,81,82$ (baben, loben, leben, geben, treiben, bleiben, ictreiben, ucroerten [offenbar aus Chajus' Gramm. Germ., s. Neudr. S. 94 ff.; von Pontoppidan benutzt die Auflage von 1617 oder die von 1625, s. o. S. 64 Fussn. 5]), 83, 84, 85, 86, 87, 88, 89, 90, 91, 91 f. ( 5 confonans Lingvopalatina mobilis, \& 3 lingvalis duplex, in $\mathfrak{D} \&$ ? literas Lingvodentales Juperas vertuntur... Sic inferiores Germani bloct / @lot / beet / butel / bat / fetel / tal / tellen / tht / tinn / tucht / twe /

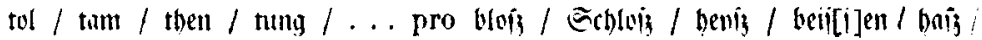


5); desgleichen die Stellen über die Ersetzung des $f$-durch $v$ - und des $g$ - durch $k$-: "Qvoniam Finni literam $f$ rejiciunt, illamq́ve rocabulis à Svecis mutuò acceptis excludunt, cognatumq́ve $\mathfrak{v}$ a fsumunt, pronunciant pro faar vaari, pro faat vati, pro fange rangi, pro falff valski» (Auszug 7) und "Finni, quum G non admittant, ut dictiones incipiat, pro glafi dicunt klafi, pro gulda culda...." (Auszug 8). Vgl. hierzu im Auszug 3 dic

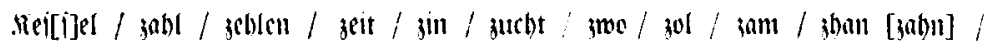
jung / ut loqvuntur Juperiores Germani .. . [die meisten von diesen sowie SS. $39,48,76 \mathrm{f} ., 79,81,83,84,84 \mathrm{f} ., 85,86,87,88,376$ und 378 angeführten nd. Wörter nobst ihren hd. Entsprechungen stammen wahrscheinlich aus ANDr. Hecviguus' Etymologiæ, sive origines dictionum Germanicarum - von mir herangezogen die 1611 in Frankfurt erschienene Auflage - - wo die nd. Wörter nach den hd. Entsprechungen nachzuschlagen sind]), $102 \mathrm{ff}$. ("Nomina propria perfonarum, vel funt domeftica,... Vel peregrina... A Germanica, ut jentif/ qvafi gocimreich..." [benutzt wahrscheinlich Scноттеlius' Ausführliche Arbeit lib. V]), 200 (Rlınife, Marife usw., s. Auszug 10; [aus einer mir unbekannten Quelle]), 244, 258 (icb)ielbit / Alt:jelbit / mir-jelbit / ibrfelbit / erfelbit / fiesielbit [aus Clasus, s. Neudr. S. 67; bei den unmittelbar darnach angeführten engl. Belegen: Mylelf, thy felf [my Jelf, thy Jelf], our Jelves usw. wird die Quelle, Waluis Gramm. linguæ Angl, angegeben, bei den darauf folgenden fr. Belegen: Moyme/me usw. wieder nicht]), 268, 269, 327, 341, 342, 346, 347, 348, 359, 364, $378,427,443,444$ (Da bab ich meine eigne luft an, einem nebmen mas fein ciagen gemejt, nutt jem[em] cigen[lichen] humen nenien [aus Basilius Faber Soranus' Thesaurus eruditionis scholastice, benutzt wahrscheinlich die Auflage von 1654, s. s. v. peculi a liter: Da hat (c) meine eigne ooer fondertiche Elut an und s. v. proprius: Einem mebmen / was jein elgen gewejt, mit jeinem cigenlicben Yamen nenmen; PonTOPPIDAN hat 1 . a. in dem ersten Satz zwei Wörter ausgelassen und in dem dritten zwei Wörter verändert, oder aber, was wahrscheinlicher ist, falsch abgeschrieben), 470 (Biolgen macbr jorgen / iorgen macbt alt

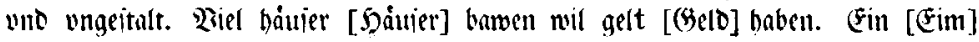
iedan trawen iit nicht gut cenn nieman[t] meiz [weik] eins andern mut [aus

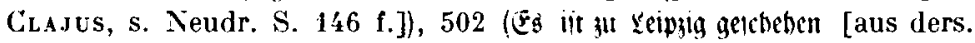
Quelle; bei Clasus, s. Neudr. S. 153, allerdings: Es ijt łl Viorthaujen ueicheben: von Pontoppidan ist ?orthautien durch einen in weiten Kreisen bekannten Ortsnamen, Eeipzig, ersetzt worden]), 508 (Deimes jobns jobns balben [aus Crajus, s. Neudr. S. 160: Deinez Sobng bal, ben]); betreffs der englis chen Belege SS. 38, 89, 261 (thelame, thefame man [offenbar aus WALLis' Gramm. linguæ Ang]. S. 89: the jame, the lame man]), 398, 443, 444 (my own house, your own lands, 
diesbezüglichen Ausführungen von Btreus und Crugerus. Hätte Pontoppidan noch andere Quellen für das Finnische gekannt und benutzt (bei Schroderus z. B. Duomio, Glafi Clafi, Fati, in VRVoc. Borgmäftari, Duomari und bei Petrefeus Borgari, duomari), so hätte er sich kaum dieses Wortlautes bedient; beachte besonders: "Finni pro B ufurpant $\mathrm{P}$, ut dicant \& $\mathrm{ccribant} \ldots$ (Sperrung von mir). Ferner

Alexanders own fword [aus WaLtis S. 90]). Alle diese Verfasser (Jonas, Wormius, Clajus, Helvigius, Schottelius, Faber und Wallis) sind bei Pontoppidan bei anderen Gelegenheiten erwähnt, nicht aber, wie engangs hervorgehoben, in Verbindung mit diesen Belegen.

Erwähnt wird dagegen die $Q$ uelle: a) Bei den zum Beweis angeführten Belegen oder bei denen mit einer beigefügten Erklärung bzw. Erläuterung, z. B. SS. 214 f. ("... Sarfiebing Saxcopia, vetuftifsima civitas Lolandiæ à conditore Sare dicta, vel à Sar forfice, ...

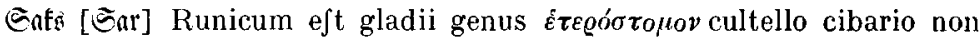
admodùm difsimile. Sar verò modernis Islandis cultrum nauticum \& pifcatorium majorem, qvo pifces exenterare folent, denotat. Claris\}. Worm. in Specimine Lexici Runici.» [S. 111 f.]), 324 f. ("Dicimus, ut hoc adfcribam, af arild / Jur. Cimbr. 1. 1 c. 46, Chron. nobilifs. Hvitfeld. part. 3 pag. m. 393, 400, \& aff aride tid / PJalm. 74 v. 12 Bibl. Reg. edit. A. MDL \& A. MDCXXXIII, Ordinat. Ecclefiaft. fol. XLIV, LXIX, LXX, Jur. Cimbr. l. 1 c. 56, Chron. Itvitf. part. 9 pag. m. 1456, o: af gummel tib / af fordum tio / af alders / Recess. gloriofisf. CHR IST: IV. lib. 1 c. 4. artic. $5 \dot{4}$, à tempore vetufto \& ab hominum memoria remoto, quafi af amotid vel aarefibs tid / alde enim idem qrod vetuftas, fenectus, ... Ellie Gothis \& Islandis fenectus, Jenium, tefte Snorrone Sturlæ Edd. p. 2, \& Runolph. Grammat. Island. pag. 54 [57], ....), 367 ("Voces ficte, vel ex aliis deductæ \& variatæ, quibus animantia accerfimus vel convocamus, ut: $\mathfrak{F}$ lo vox, qvâ eqvas \& pullos

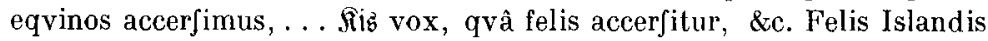
dicitur Sija. Gramm. Island. Runolphi p. 8.»), 368 (»Angli Jcribunt bawe habeo, live vivo, give dono, Joh. Wallis Grammat. Anglic. c. 1. Sect. 1. in veteri Pfalterio apud Arnoldum Wachtendonckium vifo Lipfio Legenti occurrebat liva vita Cent. 3 Epift. Lipfii ad Belgas epift. 44»).

b) Bei seltenen Wörtern bzw. Ausdrücken, z. B. SS. 365 f. ("... Эo Dut eft etiam exclamantis vox, ... qvod occurrit Jerem. 12 v. 6, exponit Lutherus per interjectionem exclamationis jetter / Vers. Sax. per Inodute / Refen. per godut / ut etiam habetur in Bibl. Regiis. Vide, fi placet, lib: 3. Encolpod. Helvaderi fol: 262.»), 498 ("..., Tamar Indus id eft Dactylus Indus Barbaris, Germanis verò Tamarinden \& Saur Dattel vocatus, ut docet Joannes Lonicerus in c. 125 I. 1. Pedanii Diofcoridis, vel qvafi Iummeluae / ut cenfuit D. Petrus Clinkbergius, 
sprechen dafür folgende Gründe: a) Die Belege sind zum grössten Teil (so alle Sätze und die beiden Ableitungsgruppen) der Art, dass sie wohl nur einer Grammatik entnommen sein dürften: cuinga-s Janot? pro cuinga Jinä Janot? 'qvid [quomodo] tu dicis?', cungas menet? pro cunga Jinä menet? 'qvorfum tu vadis?' (2) der Laut-bzw. Formenlehre (in diesem Fall dem Kap. über die Personalpronomina); die Diminutiva Linduinen 'avicula' von lindu 'avis' usw. (10) und die Karitivadjektiva Neuvötoin [-vot-] 'raadløs', lapJitoin 'barnløs' usw. (11) der Wortbildungslehre; Menen ulos \& ulos menen ['ich gehe hinaus'], Mene ulos! 'gak ud!', ylös noufen \& NouJen ylös ['ich stehe auf'], Noufe ylös! 'Stat op!' (14) der Syntax, und zwar einem Kapitel über die Präpositionen ${ }^{\mathbf{1}}$;

...), 499 ("Dominica judica, nobis Sixre Gonday/... in Germania appellatur Der icharartze Eontng. Videatur Nathanaël Tilefius Euangel. annivers. analys. t. 1. p. 552, \& Valer. Herbergerus Poftill. pag. 273.»).

c) Bei Anführung von Fxzerpten aus der Bibel, den Bibelübersetzungen und anderen Schriften (z. B. gr. und lat. Klassikern), z. B. SS. 39 〈"Sic dicitur \& fcribitur biel quaji unica vox efjet pro i bel (qvomodo in Islandicis Bibliis Exod. 20. occurrit: Pu ffalt ecf $i$ bel Ela \&c.,

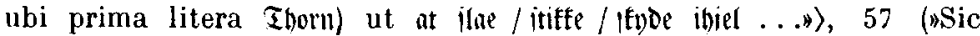

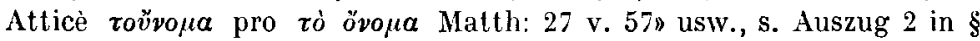

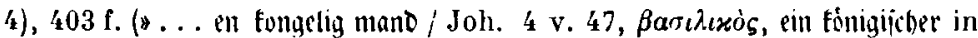
Bibl. Luth...., in lingvæ Saxonicæ Bibliis Lubecæ editis ein fónigeid amptman...., Pfleger Luthero, Foged Resenio, Rentmeiiter oder tajtuer in not. Bibl. Noriberg. Luc. 8 v. 311$), 495$ ("... Sic Germani: Fr 309 leine fleider aus. 1 Sam: 19 v. 24. Da ianden die Ybarieer who boben Wrieiter fnechte auij. Joh. 7 v. 32 . Siejer nimbt die jünder an. Luc: 15 v. 2").

d) In in extenso gebrachten Stellen, vgl. oben die Zitate aus Soterus [BurEus] (Auszüge 3,9 und 12 in $\$ 4$ ).

e) Bei Anführung einer fremden Auffassung (nicht immer), z. B. SS. 23 quidam volunt efse diphthongum, compofitam scilicet ex D \& $\mathbb{E}$ / \& forjan qvia Clajus i (ut in nowig) diphthongis annumerat. Sed $\mathbb{E}$ / qvod non planè jonat ut of / eodem jure inter vocales numerari poteft, qvo g) / qvod eft $\mathfrak{u}$ exile.... Sic eft o tenue \& exile ac qvafi obtufum, nec v numero vocalium excluditur, qvoniam $\mathfrak{i}$ (ut in muiten [2Bijte]) Clajo Diphthongus eft ...”[vgl. Clajus, Neudr. S. 11]〉, 355 〈"ll (à Germanico vn/qvod defcendit à præpofitione obn/qvæ

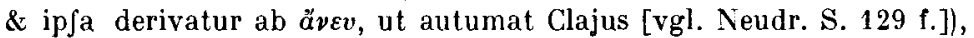
fignificat privationem, ...

${ }^{1}$ Sie sind bei Pontoppidan dort untergebracht und waren es auch wahrscheinlich in seiner Quelle; vgl. jedoch hierzu $\$ 7,3 \mathrm{e}$. 
beachte auch das Sprichwort Tänäpän culda huomena mulda 'I dag guld, i morgen muld' (8) mit zwei Temporaladverbien im Essiv (Lokativ) Tänäpän 'I dag' und huomena 'i morgen', welches aus der Formenlehre, einem Kapitel über die Deklination oder über die Adverbia stammen mag. ${ }^{1}$ b) Sie erscheinen in einer einheitlichen Orthographie (beachte besonders $v$ statt des damals allgemein üblichen $w$, s. Beispiele unter c), dürften also alle auf eine gemeinsame Quelle zurückgehen. c) Sie stimmen hinsichtlich der Orthographie nicht nur untereinander, sondern auch, was für uns besonders wichtig ist, mit jenen Wörtern des authentisch verbürgten Zitats aus Crugerus (Auszug 3) überein, beachte z. B. klaji [cl-] (8) und klafi [cl-] (3), kynttila [-lä] (13) und trontti (3) mit tt nach $\mathbf{n}$ und last, not least das $\mathbf{v}$ einerseits in Lauvantaj [-ai] (1), porvari (5), vaari, vati, vangi, valski (i), veidzinen von veidzi (10), Neuvötoin [-vot-], voimatoin, leivätöin (11) und andererseits porvari, vixi, vadherma (3). d) Wie wir soeben gesehen haben, findet sich in 5 und 8 je ein Wort, das in der gleichen Schreibart in 3 auftritt: porvari ( 5 und 3 ) mit dem für Crugerus charakteristischen $\mathbf{v}$ (s. unter b-c und $\$ 7$, $3 \mathrm{~b}$ das über Crugerus' Orthographie Gesagte) und klafi ( 8 und 3) mit k- statt c-, vgl. culda (8), crappu, cratti, crwhu usw. (3) gegenüber krijni (3), Kirjainen von kirja (10), kenoätöin [-ngä-] (11), worüber ausführlicher in $\$ 7,3$ besprochen wird. In klafi lässt sich k- kaum als Druckfehler ansprechen, denn das Wort liegt, wie soeben gesagt, in derselben Gestalt an zwei verschiedenen Stellen vor: eher handelt es sich hierbei um einen Schreibfehler, der, wie es scheint, in dem Abschnitt über den Anlaut (Auszug 3) entstanden ist und entweder von Pontoppidan oder vielleicht schon von CRUgerus herrührt. Das Wort klaji sowie porvari ist dann von PonTopPIDAN in anderem Zusammenhang noch einmal angeführt worden.

1 Das ist vom Standpunkt der modernen Grammatik aus; in jener Zeit war es üblich, Sprichwörter und Verse über eine Grammatik zu verstreuen, und so kann dieses Sprichwort ebenso gut aus der Lautlehre ("Orthographia) stammen. Zu der Frage, an welchen Stellen diese Belege in der Grammatik, die für Pontoppidan als Quelle gedient hat, vorlagen, vgl. auch $\S 7,3$. 
Die übrigen wenigen Belege, einzelne Wörter: Jauma, nauta (4), parta, pifpa (5), Tytär (6) und culda (8) lassen sich in Ermangelung von Kriterien nicht mit Sicherheit an Crugkrus' Grammatik anknüpfen, wenn auch nichts dagegen spricht, dass sie gleichfalls aus ihr stammen können; übrigens ist das Wort culda (8) zugleich in dem Sprichwort Tänäpän culda huomena mulda (8) enthalten und kann diesem entnommen sein.

Um über die Herkunft der bei PontopPIDax ohne Quellenangaben angeführten fi. Belege möglichst zur vollen Sicherheit zu gelangen, sollen sie noch von einem anderen Standpunkt aus ins Auge gefasst werden. ${ }^{1} \mathrm{Zu}$ der Zeit, et wa $1643-46$,

1 Pontoppidan hat, wie es scheint, mitunter auch Belege angeführt. die in den von ihm erwähnten Quellen nicht zu finden sind und somit anderswoher herangezogen sein müssen. So die S. 200 vorliegenden deutschen Diminutiva: Annife, Marife usw. (s. Auszug 10 in $\$$ 4); sie sind weder bei den in der Præfatio (s. \$3) aufgezählten derzeitigen deutschen Grammatikern (Oelingerus, Clajus und Schottelius) noch anderen (z. B. Albertus) belegt, auch nicht in sonstigen (von Portoppidan erwähnten) deutschen Werken. Von den S. 246 angeführten deutschen

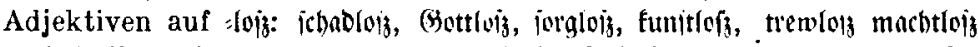
und frafftloi (s. Auszug 11 in $\S 4$ ) ist bei Oelingerus Vnderricht der Hoch Teutschen Spraach S. 79 (= Neudr. S. 56) nur jorglols gebucht; bei Scнotтelius erscheinen sie zwar fast vollzählig (fehlt: hunitloiz), aber in abweichender Orthographie und z. T. auch in abweichender Gestalt: Teutsche Sprachkunst 1641 S. 357 f.: ichadelos, gottloś, lorgenlos oder porgloś, trewlos, Machtlos und frafftlos; Ausführliche Arbeit 1663 S. 426 ff.: jebadelog, (Sottlos, Eorgenlos, Il tulus, Machtlog und Irnftlus, also auch Schotredius kommt hierbei als Quelle (wenigstens als einzige Quelle) nicht in Betracht. In den derzeitigen grösseren Wörterbüchern, welche Pontoppidas benutzt haben könnte, treten sie nirgends vollzählig auf (allerdings bin ich nicht im stande gewesen, alle Auflagen dieser meistens oft wieder gedruckten Werke nachzusehen). So sind bei Petrus Dasypodics Dictionarium Latinogermanicum et vice versa Germanicolatinum (von mir herangezogen die 1537 in Strassburg erschienene Arflage) belegt: Schadlo/s 'Indemnis', Gotlois [Gottloij] 'Atheos, Impius' (vgl. Bl. 15a: "Atheos, (Gottloigu), Trewlols 'Perfidus', Frafittois 'Languidus, Eneruus, Eneruis' (fehlen: joruloiz, funitloiz und machtloiz); Johannes Frisius Tigurinus Dictionarium Latinogermanicum (hier benutzt die 1568 in Zürich ersch. Auflage): ichadluiz 'Indemnis', (Gottlois 'Atheos, Impius', Sorglois 'Incuriofus', fiunjtlois 'Iners', trcümloiz 'Infidus, Perfidus', frafiftoiz 'In- 
als PontopPIDan seine Grammatik aller Wahrscheinlichkeit nach ausarbeitete (s. § 3), hätte er (ausser BuREus und CRUGERUS) ferner Schroderus Lexicon Latino-Scondicum 1637 und [Anonymus] Variarum rerum vocabula 1644 nebst Formulæ puerilium colloquiorum als Anhang benutzen können; späterhin, als er sie umarbeitete und ergänzte (s. $\$ 3$ ), ausserdem noch Petraus Lingux Finnica brevis institutio 1649. Von den in Frage stehenden fi. Belegen ist nun aber kein einziger Satz (s. Auszüge 2, 8, 14) in den genannten Schriften gebucht ${ }^{1}$, auch keines von den Karitivadjektiva auf -toin, -töin $(11)^{2}$, von den Diminutiva auf -inen (10) findet sich nur

firmus, Impotens' (nach den lateinischen Wörtern nachzuschlagen; fehlt: macbtlóf); Josua Marler (Pictorius) Die Teütsch spraach Dictionarium Germanicolatinum, Tiguri 1561 (die einzige Auflage): Echaoloi; 'Sofpes', Gottloiz 'Atheos, Impius, Incredulus, Infidelis', Eorgloiz 'Incuriofus, Curæ expers, Negligens' usw., Sunitloij 'Iners', Tren̈loiz 'Infidus, Perfidus', frafftloiz 'Debilis, Debilitatus' usw. (fehlf: machtloiz); Ambrosius Calepinus Dictionarium undecim linguarum (von mir benutzt die 1616 in Basel ersch. Auflage): (Gottloiz 'Impius', iorgloiz 'Incuriofus', stunitloiz 'Iners', Trewloiz 'Perfidus', machtloi 'Infirmus', trafftloj: 'Infirmus, Languidus' (nach den lat. Wörtern nachzuschlagen; fehlt: (cbudloij); Basilius Faber Soranus Thesaurus eruditionis scholasticæ, Lipsiæ 1593: Ecbadvij 'Indemnis' 〜 -log 'Jartus tectus', (Sottlog̀ 'Impius, Profanus', Iremlos 'Perfidus', Mrafftlog 'Enervis', frafítlog werben 'Concidere \& deficere', traffitlos nucbon 'enervare, infirmare, Exarmare'; dasselbe Werk, Iipsiæ 1654: Ectadolĩ 'Indemnis' -los 'Jartus tectus', Gottlolj 'Impius, Profanus', Trenloij 'Perfidus', trewloj 'Enervis', Irafítlojì muchen 'Infirmare, enervare' trafftlos machen 'Exarmare' (nach den lat. Wörtern nachzuschlagen; in beiden Auflagen

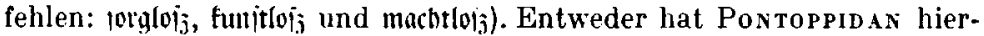
bei mehrere Quellen benutzt - nur Basilius FABER ist von ihm erwähnt worden, dessen Thesaurus aber nicht eben ausgiebig ist und somit nicht allein als Quelle gedient haben kann (wenn benutzt, so die Auflage von 1654) - oder eine weitere Quelle herangezogen.

1 Beachte jedoch in VRVoc. FPColl. BI. I 1b Cuule, nou Je ylös! 'Ilör

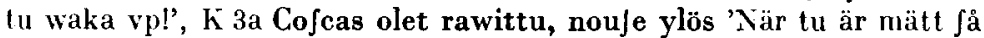
ftat vp', I 6a Cungas nyt menet? 'Iwart går tu nu?'

2 Wohl gibt es aber in VRVoc. eine ganze Reihe anderer zu dieser Gruppe gehörenden Adjektiva: S. 6 Onnetoin päiwä 'Dies infauftus', 11 Päätöin ['capite carens']: Päätöin ruumis 'Truncus', 23 Cunniatoin 'Infamis', 25 carwatoin 'Glabrum', 88 Carwatoin lindu 'Avis implumis', 
bei Petraus Bl. A 6b Kirjainen und poicainen ${ }^{1}$, die Bl. D $5 \mathrm{~b}-6 \mathrm{a}$ nebst den ihnen zugrunde liegenden Stammwörtern zum anderen Male angeführt werden ${ }^{2}$. Von den einzelnen Wörtern $(1,4-8,13)$ sind die drei: porvari $(5)$, vaari $(7)$, valski $(7)$ in ihnen überhaupt nicht belegt; die übrigen erscheinen, wie folgt:

\begin{tabular}{|c|c|c|c|c|}
\hline PONTOPPIDAN & \multicolumn{2}{|c|}{ SCHRODERUS } & VRVoc. & Petraus \\
\hline 1. Lauvantaj [-ai] & (1) & $\ldots \ldots \ldots$ & Lauwantai & Lauwandai \\
\hline 2. Jauma & (4) & Sauma & $\ldots \ldots$ & $\ldots \ldots \ldots$ \\
\hline 3. nauta & (4) & Nauta & Nauta & $\ldots \ldots \ldots$ \\
\hline 4. parta & $(5)$ & Parta & Parta & $\ldots \ldots \ldots$ \\
\hline 5. pi $\int \mathrm{pa}$ & $(\tilde{5})$ & Pifpa & Pifpa & $\ldots \ldots \ldots$ \\
\hline 6. Tytär & (6) & Tytär & Tytär & $\ldots \ldots \ldots$ \\
\hline 7. vati & (7) & Fati & Fati & $\begin{array}{lll}\ldots & \ldots & \ldots\end{array}$ \\
\hline 8. vangi & $(7)$ & Fangi & $\ldots \ldots \ldots$ & $\ldots \ldots \ldots$ \\
\hline 9. kla $\int \mathrm{i}[\mathrm{cl}-]$ & (8) & $\mathrm{Cla} \int \mathrm{i} \sim \mathrm{G}$ & cla $\mathrm{i}$ & $\ldots \ldots \ldots$ \\
\hline 10. culda & $(8)$ & Culda & Culda & Culda \\
\hline 11. kynttila [-lä] & (13) & Kyntilä & Kyntilä & $\ldots \ldots \ldots$ \\
\hline
\end{tabular}

Von diesen Wörtern dürfen culda und klafi [cl-] aus den oben S. 94 f. erwähnten Gründen hier unberücksichtigt bleiben. Von den übriggeblieberen neun ist bei Petraus, wie wir sehen, nur ein einziges (Lauvantaj [-ai]) belegt, und auch dieses in abweichender Orthographie (Lauwandai); in VRVoc.

26 Näkemätöin 'LuJciofus', 27 Hambatoin 'Edentulus', 27 Parratoin 'Imberbis' usw.; einige auch bei Schroderus: S. 13 Kiriatoin 'Idiota', 57 Sarvitoin lechmä 'Vacca cornibus deftituta', 65 Alaftoin 'Nudus'; ebenso bei Petreus: Bl. I $3 \mathrm{~b}$ Ihminen wiatoin 'homo innocens', A $6 \mathrm{a}$ kelwotoin 'nauci', kijttämätöin 'ingratus', C 6a furutoinna (Essiv von Jurutoin): Hän maca Jurutoinna 'jacet Jecurus'.

1 Die betreffende Stelle lautet: "[Species Derivativorum] . . . Diminutiva, ut firjainen libellus, poicainen / filiolus, picainen / puellula, bárfåinen / buculus."

2 Es heisst bei ihm 1. c.: $¥ 2$. Diminutiva tam Nominalia, quàm verbalia, Rhyt[h]micæ compofitioni plurimum Jerviunt: Nominalia, ut Poica / filius, poicaimen / filiolus, finia / liber, firjanen / libellus, filmá / oculus, jilnı́inen / ocellus. Verbalia, ut: Lảbetån / lábettelen / mitto, autun ! nuttilen / juyo, firioitan / firivittelen / Jcribo, cutjon / catjelen / video.» 
fehlen von ihnen zwei (Jauma und vangi) und drei (Lauvantaj [-ai], vati und kynttila [-lä]) sind orthographisch abweichend (Lauwantai, Fati und Kyntilä); bei Schroperus fehlt eines [Lauvantaj [-ai]), und drei (vati, vangi und kynttila [-lä]) sind wiederum orthographisch abweichend (Fati, Fangi und Kyntilä). Im ganzen hätte Poxtoppidan somit aus Petræus nur zwei Diminutiva (Kirjainen und poicainen) nebst den Stammwörtern (kirja und poica), aus VRVoc. vier Wörter (nauta, parta, pifpa und Tytär) und aus Schroderus fünf (sauma und die soeben genannten) für sein Werk gewinnen können. Die Anknüpfungspunkte sind, wie man sieht, sehr gering. Und auch diese erweisen sich bei einer näheren Betrachtung als hinfällig. Es fragt sich nämlich, warum sollten aus PETreus eben Kirjainen und poicainen nebst den Stammwörtern kirja und poica entlehnt sein und nicht zugleich die bei ihm ebenfalls gebuchten pijcainen, härkäinen und filmäinen (s. oben S. 97 Fussnoten $1-2$ die Zitate aus PETRæus); und woher stammen andrerseits bei Pontoppidas die weiteren zwei Diminutiva nebst den Stammwörtern: Linduinen von lindu und veidzinen von veidzi? Ferner, warum sollten aus den anderen zwei Quellen oder aus einer von ihnen, in diesem Fall aus Schroderus, nur solche Wörter übernommen sein, die nach der derzeitigen Orthographie nichts Charakteristisches bieten ( (auma, nauta usw.), nicht aber zugleich Fangi, Fati, Kyntilä (= vangi, vati, kynttila [-lä] bei PontopPIDAN)? Es ist daher einleuchtend, dass weder Petreus noch Schroderus (bzw. VRVoc.) als Quellen bei PontopPIDaN in Betracht kommen können. Die Wörter Jauma, nauta, parta, pifpa und Tytär könnten sehr wohl, wie oben S. 95 bei einer anderen Gelegenheit hervorgehoben wurde, ebenfalls aus CRUGERUs stammen; natürlich auch Kirjainen von kirja und poicainen von poica. Offenbar hat PoNTOPPIDAN die soeben erwähnten drei Schriften gar nicht gekannt. Andernfalls hätte er möglicherweise auch die im zweiten Zitat aus Soterus [Bureus] (Auszug 9) enthaltenen Mes in mies, Warmo in waimo (genauer: VVarmo in vvaimo) und Aelehin in eläin korrigiert, denn diese Wörter liegen in allen diesen drei Schriften vor. t'brigens finden die zwei ersten sich bei Schroperus in 
richtiger Gestalt (mies, waimo) auch in der Vorrede ("Ad Lectorem") zu seinem Lexicon; Schroderus hat die sich auf das Finnische beziehende Stelle unmittelbar von Bureus übernommen, dabei Waimo als waimo richtig, und hat seinerseits als guter Kenner des Finnischen ${ }^{1}$ Mes in mies (nicht aber Allehin in eläin) korrigiert (s. o. S. 83 Fussnote 2). Sehr wahrscheinlich waren alle diese Wörter auch bei CrugErus gebucht, doch war das wohl nicht genügend, um PonTopPIDAN von der Unrichtigkeit von Mes, Warmo und Aelehin zu überzeugen, oder aber, was wahrscheinlicher ist, er hat sich darüber keine Gedanken gemacht und hat sie genau so wiedergegeben, wie sie in seiner Quelle (Soterus [BuREus]) waren. Das darf man PONTOPPIDAN durchaus nicht zum Vorwurf machen, denn es gibt uns mehr Sicherheit, dass er bei den aus Crugerus stammenden Belegen ebenfalls getreu der Quelle gefolgt ist.

Ferner kann die Frage aufgeworfen werden, ob PontoppIDaN durch Lektüre finnischer Texte, z. B. der Bibelübersetzung von 1642, Material für seine Grammatik gesammelt hat, wie es z. B. hinsichtlich des Griechischen und des Deutschen der Fall war (s. S. 89 Fussnote 2). Nun ist es schon an sich unwahrscheinlich, dass er wegen des Finnischen sich so viel Mühe gemacht hätte, weil dieses für seine Zwecke nebensächlich war; es wäre für ihn auch keine leichte Aufgabe, wenn nicht unmöglich gewesen, auf diesem Wege die zwei Ableitungsgruppen zusammenzubringen. ${ }^{2}$ Diese sowie die bei

I Schroderus hielt sich im Jahre 1636 von Januar bis November in Oulu (Uleåborg) auf und befasste sich u. a. mit dem Finnischen, wobei ihm der dortige Pfarrer Marcus Pauli Biörneburgensis als Sprachmeister diente, s. E. N. Setälä Kirjailija-albumi, Porvoo 1898, S. 309 f., Bengt Hesselman Ericus Johannis Schroderus Upsaliensis Dictionarium quadrilingue Suedicum Germanicum Latinum Græcum (Cod. Thott 2166 4:o) med en inledning och ett alfabetiskt register över de svenska orden jämte tillägg ur Lexicon Latino-Scondicum 1637 och Janua Linguarum 1640, Uppsala 1929, S. XIV f. und Derselbe Ericus Schroderus Ubsal. Lexicon Latino-Scondicum 1637. Utgivet med alfabetiska register över de svenska och de finska orden, Uppsala 1941, S. IV $\mathrm{f}$.

2 Zur Probe habe ich in der Bibelübersetzung von 1642 das 1. Buch Moses und das Matthäusevangelium durchgesehen und habe dort keines von 
ihm vorliegenden Sätze dürften wohl nur einer Grammatik entnommen sein, wie S. 93 hervorgehoben; beachte besonders die Diminutiva nebst ihren Stammwörtern: Linduinen 'avicula' von lindu 'avis', Kirjainen 'libellus' von kirja 'liber' usw. und die Sätze mit beigefügten Erklärungen ${ }^{1}$ : cuinga-s Janot? pro cuinga finä Janot 'qvid [quomodo] tu dicis?' und cungas menet? pro cunga finä menet? 'qvorfum tu vadis?'. Für diese Sätze kommt sicher, wie es ohne weiteres klar ist, keine andere Quelle in Betracht, desgleichen für das Sprichwort Tänäpän culda huomena mulda 'I dag guld, i morgen muld'. Wenn Poxtoppidax durch Lektüre dennoch etwas erworben hätte, dann einzelne Wörter, doch käme das aber in der Orthographie zum Vorschein, und er hätte wohl die Quelle angeführt wie in anderen ähnlichen Fällen (vgl. S. 89 Fussnote 2). Ebenso unwahrscheinlich ist, dass Pontoppionax eine weitere fi. handschriftliche Grammatik bzw. ein handschriftliches Wörterverzeichnis benutzt hätte; er hätte das erwähnt, wie er Crugerus' handschriftliche Grammatik genannt hat, oder aber es käme wieder in der Orthographie zum Vorschein. Nun ist die Orthographie aller dieser finnischen Belege bei Pontoppidan, wie schon gesagt, einheitlich; die wenigen Ausnahmen erklären sich meistens als Schreib- bzw. Druckfehler oder, wie in ein paar übrigen Fällen, aus Inkonsequenzen der derzeitigen Orthographie. Inkonsequenzen finden sich übrigens in noch höherem Maasse in PEtræus' Grammatik, vgl. $\S \tau, 3 \mathrm{~b}$.

In Anbetracht aller obigen Ausführungen muss man zum Resultat kommen, dass Pontoppidax für das Finnische nur

den in Frage stehenden Diminutiva (poicainen usw.) und von der ganzen Gruppe überhaupt nur eines (Mos. 1 XV 9 hehcoinen 'junge Kuh') gefunden. Von den bei Poxtoppidax belegten Karitivadjektiva ist nur eines im Nominativ gebucht: Mos. 1 XI 2 und Matth. XXII 24 lapjitoin 'ohne Kinder, kinderlos'; ausser diesem, was für uns aber belanglos ist, sind belegt: Mos. 1 XI 30, XXV 21 hedelmätöin 'unfruchtbar', XXXII 10, Matth. XIX 26 mahdotoin 'unmöglich', Yatth. XXV 30 kelwotoin 'unnütz', XXV 43 alaftoin 'nackend' und XXVII 24 wiatoin 'unschuldig'.

${ }^{1}$ Die Erklärungen können unmöglich von Pontoppidax stammen, weil sie eine tiefere Kenntnis der Sprache voraussetzen. 
zwei Quellen benutzt hat, Soterus [Burets] und a $1 \mathrm{~s}$ H a u p t q u e 1 l e Crugerus.

6. Wir sind auch in der Lage, die Stichhaltigkeit dieser Schlussfolgerung an Hand anderwärtiger Angaben einigermassen zu überprüfen. CRt'Gerts' Grammatik ist ferner, wie schon $\S 2$ erwähnt (s. auch Auszüge 15-16 und 19 in $\S 4$ ), von Peder Syv (1631-1702) ${ }^{1}$, einem Zeitgenossen und Freund Pontoppidans, herangezogen worden, zweimal anonym und zum dritten Male mit Namensnennung des Verfassers. In seinen Nogle betenkninger om det Cimbriske Sprog ${ }^{2} 1663 \mathrm{~S}$. 30 berichtet Syv, dass das Finnische zwölf Kasus hat ("De Finner hafpe tolf [[̈ndelier = CaJus]", s. Auszug 15), und S. 32, dass es eine handschriftliche finnische Grammatik gibt ("Den Rydjifie Orammatife findes jo tryft $i$ beris eget jprog/men Dend Fimiffe haandifrefoen", s. Auszug 16). Ohne Zweifel ist jene Angabe aus dieser handschriftlichen Grammatik geschöpft. Und wer ihr Verfasser war, geht aus einer Bemerkung in seinem späteren sprachwissenschaftlichen Werk, Den Danske Sprog-Kunst eller Grammatica 1685, hervor. Dort wird S. 103 f. ausgeführt, dass im Finnischen sowie im Lappischen beim Verbum die singularischen und pluralischen Präsens- und Imperfektformen Ind. im Gegensatz dazu, wie einige es im Dänischen haben wollen, verschieden lauten 〈"It nogle giøre 2 arocerende og Ujuldfomme tio eens $\mathrm{i}$ Enfoldig og Mangfoldig Tal er mob anore Tungemals maneer (thi endogiaa de Barbariffe Finner/og Rapperne/fomne af bem/ giore forifel her paa)" >; er beruft sich hierbei hinsichtlich des Finnischen auf Crugerus' handschriftliche Grammatik ("Gram. Fin. MJe. Crugeri») und hinsichtlich des Lappischen

1 Über sein Leben und Wirken siehe N. M. Petersen Bidrag til den danske Literaturs IIistorie III, 2. Udgave, Kjøbenhavn 1868, S. 366 ff., R. Paulli in Carl S. Petersens og Vilhelm Andersens Illustreret dansk Litteraturhistorie I, København 1929, S. 881 ff., H. EhrencronMüller Forfatterlexikon omfattende Danmark, Norge og Island indtil 1814 VIII, Kobenhavn 1930, S. 135 ff. und Carl S. Petersen in Povl Exgelstofts Dansk biografisk Leksikon XXIII, Kobenhavn 1942, S. $237 \mathrm{ff}$.

2 "Cimbrisch» ist teils in der Bedeutung Nordisch, teils in dem weiteren Sinne Gotisch-Germanisch gebraucht. 
auf Schefferus' Lapponia (s. Auszug 19). Crugerus' Grammatik ist Syv durch Pontoppidan bekannt geworden, vgl. $\$ 3$. Crugerus war also für das Finnische sein Gewährsmann nicht nur in Nogle betenkninger 1663 (hier auch BurEus herangezogen, s. gleich unten), sondern noch in Den Danske SprogKunst 1685; erst später hat er Perreus' Grammatik, aber nur dem Namen nach gekannt, wie wir gleich sehen werden.

Sxv bietet uns aber noch mehr als das. In der Königlichen Bibliothek zu Kopenhagen findet sich ein interfoliiertes Exemplar seines zuerst genannten Werkes, Nogle betenkninger, mit Notizen von seiner Hand (Rostg. Saml. Nr. $478^{\circ}$ ). Es umfasst 495 , das Original dagegen $\mathrm{X}$ (unpaginierte) +200 Seiten. Im Folgenden wird dieses mit $A$, jenes mit $B$ bezeichnet. Syv hat offenbar eine erweiterte Auflage dieses Werkes geplant und von Zeit zu Zeit verschiedene Ergänzungen nebst Literaturangaben bzw. bloss ergänzende Literaturangaben eingetragen; vgl. hierzu auch Fr. WINkEL HoRN Peder Syv, Kjøbenhavn 1878, S. 179. Die letzten Seiten des B (459-76, 479-95) enthalten ein Literaturverzeichnis ohne direkte Beziehung zu dem Text, darunter u.a. (S. 479 ff.) ein kurzes Verzeichnis der sich auf die schwedische Philologie beziehenden Werke, als Folge einer mit dem Professor AxDREaS SPOLE, Upsala, 1680-81 geführten Korrespondenz. Die übrigen Büchertitel hat er, wie es scheint, teils ebenfalls durch Korrespondenz erfahren, teils bei der Lektüre aus verschiedenen Werken bzw. aus Katalogen ausgeschrieben, manche aber offenbar nur vom Hörensagen gekannt und so eingetragen (daher häufig ungenau). Die neuesten Bücher sind von den Jahren 1685 (S. 491), 1686 (S. 308) und 1687 (S. 250); die betreffenden Eintragungen sind natürlich etwas neueren Datums. Allem Anschein nach hat Srv seine Notizen während einer längeren Zeitspanne gemacht; möglicherweise hat er damit gleich nach dem Erscheinen seines Werkes begonnen und sie bis in die neunziger Jahre fortgesetzt. Uns interessieren natürlich nur diejenigen Werke bzw. Notizen, welche Bezug auf unsere Frage haben. Pontoppidans Grammatik, um damit zu beginnen, wird S. 145 erwähnt; die betreffende Eintragung gehört offenbar nicht zu den allerälte- 
sten. Bureus' Regni Sueciæ descriptio (s. $\$ 3$ ) ist schon in A, aber erst in dem Nachtrag (gemacht in der Zeit, als das Werk bereits im Druck war) S. 196 herangezogen worden: "De Finner hajpe iffe $\mathfrak{F}$. eller noget pord / fom beghnder af $\mathfrak{B}$. $\mathfrak{D}$. G. eller to medindende/ pam. A. Bureus Defer. Srec. 56 S. \&." (s. Auszug 18 in $\S 4$ ). Sie wird nach dem Werk des Soterus (hierüber in \$ 3) zitiert; die Seitenangabe ("56") ist ungenau und stimmt weder für die Auflage von 1631 noch für die von 1633. ${ }^{1}$ In $B$ ist Bureus, ebenfalls nach Soterus, mehrmals erwähnt worden: SS. $81,84,85,96,112,132,133,343$. Die Seitenangaben sind auch hier nicht immer genau; in den meisten Fällen, SS. 81, 112, 132, 133 und 343, stimmen sie aber zu der Auflage von 1633, die offenbar gleichfalls in den übrigen Fällen benutzt worden ist. Vielleicht ist SYV auch Soterus' Werk durch Pontoppidar wie die Grammatik von Crugerus bekannt geworden; wenn dies der Fall sein sollte, so hat Pontoppidan Sonerus ebenfalls in der Auflage von 1633 benutzt.

Die Epitome descriptionis Sueciæ, Gothiæ, Fenningiæ, et subjectarum provinciarum von MICHä̈L O. Wexionius (geadelt: Gyldenstolpe), Aboæ 1650, wo u. a. lib. III cap. IX von der fi. Sprache (»De Fennicâ Lingg.»), cap. $X$ von der Verwandtschaft des Finnischen mit dem Estnischen ("De Convenientiâ ling: Fennicæ ac ESthnicæ in Jpecien) und cap. XII von der lappischen Sprache ("De Lappicâ Jeu Lapponicâ lingg:") gehandelt wird, ist bei SYv in B dreimal eingetragen worden: S. 472 ("Gyldenftolpes Defcriptio Sveciæ Lavdatur"), 473 ("Michaël Wexionius Epitome Defcript: Svecix. Aboæ. 1650 8") und 474 ("Sveciæ, Gothiæ, Fenningiæ et Jubjectarum Provinciarum defcriptiones. Abox. 1650"); die Eintragung $S$. 473 ist offenbar in der Reihe die jüngste und die S. 472 die älteste. Mit Bezug auf den Text ist dieses zu seiner Zeit vorzügliche Werk (auch bei SYv S. 472 mit "Lavdatur" charakterisiert) nicht herangezogen worden, obwohl es viel-

1 Die in Frage stehende Notiz findet sich in Soterus' Werk in der Auflage von 1631 auf der Seite 57 und in der Auflage von 1633 auf der Seite 55 . 
fach für SYv von Nutzen gewesen wäre. In B S. 81 (Ergänzungen zum Kap. XVI, A S. 20) hat Syv mit Heranziehung verschiedener Quellen einige Bemerkungen über das Finnische, Estnische und Lappische (ferner über das Lettische und Russische) und ihre Beziehungen zueinander gemacht; hierfür wäre WExionius' Epitome eine gute Quelle gewesen. Offenbar hat Syv dieses Werk nur dem Titel nach gekannt. Dasselbe gilt auch von PeTraus' Lingux Finnica brevis institutio, Abox 1649, die in B S. 107 in einer Note zu der Bemerkung S. 106 (=A S. 32)"... men Deno Finnife [sc. Granmatife] haandfrefuen'" (s. o.) anonym und mit ungenauem Titel angeführt wird: nog tryfl. Inftitutio Lingvæ Finnonicæ. Aboæ, 1649. 8». Diese Eintragung hat Srv, wie es scheint, verhältnismässig spät gemacht, wahrscheinlich erst nach dem Erscheinen seiner Sprog-Kunst 1685, denn dort ist als Quelle für das Finnische nur die handschriftliche Grammatik des Crughrus angeführt (s. o.). Ericus SchroDERCs' Lexicon Latino-Scondicum 1637 ist bei Syv in A nicht erwähnt. In B S. 475 ist es zuerst, wie folgt, eingetragen worden: "Lexicon parrum Latino-Scondicum Erici ObJalien [is» (in der folgenden Zeile steht: "Biblia Finnonica, Fol. Stokholm, 1642»). Die Eintragung ist offenbar, der Schrift und der Tinte nach zu urteilen, eine der ältesten, und es liegt auf der Hand, dass SYV damals das Buch nicht vor sich gehabt hat (merke den ungenauen Titel und Autorennamen). Bedeutend später (die Schrift und die Tinte sind verschieden) ist zwischen den Zeilen über "Erici UbJalienfis" "Scröderi" [Schroderi] und unterhalb "Lexicon . . Erici» wieder »I. Svet. Germ. Finn. Holmiæ. 1637. 24» zugefügt worden. $\mathrm{Zu}$ derselben Zeit, nach der Schrift und nach der Tinte zu schliessen, sind SS. 81, 85 und 130 die auf dasselbe Werk zurückgehenden Notizen entstanden. Das Buch war dann sicher in Syvs Besitz.

Dunkel ist die Herkunft der Bemerkung über den Versbau der finnischen Volkslieder und über die Et.ymologie des Wortes Runoi in A S. 140 (= B S. 342): "De Finner have rimt / bejtaa-

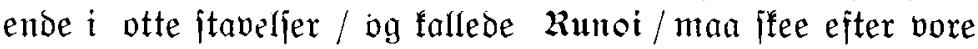
Ruter» (s. Auszug 17 in $§ 4$ ). Diese Bemerkung setzt die Kennt- 
nis von drei Quellen voraus: hinsichtlich der Gestalt und der Bedeutung des Wortes Runoi das soeben genannte Lexicon von Schroderus, wo es S. 41 gerade in dieser Gestalt vorliegt und 'Rhyt[h]mus, Rijm, der Reim' heisst, hinsichtlich des Versbans die Descriptio von Bureus, wo darüber folgendes steht: "R[h]ythmos praterea non à fimili vocum finitione, ut reliquæ gentes, fed à Jimili binarum ternarumque vocum initio obfervant, octonis ver $\int u m$ fyllabis claudentes", $\mathrm{s}$. SoTERUs Suecia 1633 S. $56^{1}$, und hinsichtlich der Etymologie des Wortes Wexionius' Epitome etc. lib. III cap. XIV, wo sie bei kurzer Bezugnahme auf die fi. Volkslieder angedeutet wird: "Dicebantur \& olim $\Re u n t$ / ad imitationem Runarum Sveo-Gothicarum." Syv hat zur Zeit der Niederschrift seiner Nogle betenkninger (A) weder Schroderus noch WexioNIUs gekannt, und Burecs (nach SoTERUs Suecia 1633) offenbar erst dann, als sein Werk im Druck war (s. o.); von ihm selbst kann also die in Frage stehende Bemerkung nicht ursprünglich herrühren, beachte in B S. 343 die dazu gehörende Notiz: "At A. Bureus p. 56, contrarium habet." Wahrscheinlich hat er die in Frage stehende Bemerkung durch Korresponden $z$ von seinen schwedischen Freunden, von denen er Nachrichten über die Literatur eingezogen hat (s. o.), vielleicht von Whxionius, gewonnen.

7. Henricus Crugerus u $\mathrm{n}$ d s e i n e G $\mathrm{r}$ a m mat i k. 1. Zunächst soll die Frage erörtert werden, wann die Grammatik von CRUgerus in PoxtopPidans Hände gelangt und wann sie geschrieben worden ist. Hierbei sind wir grösstenteils auf Rückschlüsse angewiesen. Poxtoppidan hat seine Grammatica Danica 1668 veröffentlicht, hat sie aber wenigstens zwanzig Jahre früher ausgearbeitet (s. § 3). Sie lag also in ihrer ersten Fassung bereits 1648 oder ein paar Jahre früher vor. $\mathrm{Ob}$ Pontoppidar schon zu jener Zeit, als er sie ausarbeitete, Crugerus' Grammatik in seinem Besitz gehabt und das daraus stammende Material in diese eingearbeitet hat, lässt

1 Syv hat, wie oben gesagt, Soterus' Werk in der Auflage von 1633 benutzt; die betreffende Stelle lautet in der Auflage von 1631 S. 58 ebenso. 
sich nicht mit Sicherheit ausmachen, da jene Handschrift verschollen ist. Die in der Königlichen Bibliothek zu Kopenhagen befindliche Handschrift (Thott $4638^{\circ}$ ) ist offenbar ein während der Umarbeitung entstandener Entwurf zur endgültigen Fassung des für den Druck bestimmten Manuskripts. In ihr ist das fi. Material überhaupt nicht angeführt, wie wohl in nur verhältnismässig wenigen Fällen auch das aus anderen fremden Sprachen. Von einem Entwurf kann man auch nicht viel anderes erwarten. Es galt Pontoppidan hierbei vor allem, die richtige Disposition zu finden, wie man das aus zahlreichen Zusätzen und besonders aus der Umgruppierung des Materials ersehen kann, und doch ist in ihm die Anordnung vielfach noch nicht die endgültige; der syntaktische Teil fehlt gänzlich, vgl. hierzu Bertelsen Danske Grammatikere VI S. 35 ff. Es ist aber sehr wahrscheinlich, dass Pontoppidan schon während der Ausarbeitung seiner Grammatik im Besitze der Grammatik von CRUGERUs war. Hätte er sich Ende der vierziger Jahre nach einer finnischen Grammatik erkundigt, so hätte er wahrscheinlich eher von der in Vorbereitung bzw. im Druck befindlichen Grammatik des Professors Eschillus Petreus als von der in Handschrift vorliegende $\lrcorner$ des Kaplans Henricus Crugerus gehört, und hätte er danach Anfang der fünfziger Jahre gesucht, so wäre er schon auf die gedruckte Linguœ Finnica brevis institutio 1649 des ersteren gestossen, die übrigens bereits in der 1650 erschienenen Epitome descriptionis Sueciæ etc. von WExIovius angeführt und somit in weiteren Kreisen bekannt geworden war. In beiden Fällen hätte er kaum seine diesbezüglichen Erkundigungen fortgesetzt. ${ }^{1}$ Falls es sich so verhält, befand

1 Durch den Umstand, dass Pontoppidan die isländische Grammatik von Jonas 1651 und die englische Grammatik von Wallis 1653 benutzt hat — diese während der Umarbeitung seiner Grammatik (s. $§ 3$ ) —, andrerseits aber die estnische Grammatik von Sta fr 1637 erwähnt, nicht aber zugleich oder statt dieser die von Gutslaff 1648 (Observationes grammaticæ circa linguam Esthonicam) und auch nicht die finnische von Petreus 1649, wird unsere oben ausgesprochene Annahme noch unterstützt. Pontoppidas hat also offenbar während der Ausarbeitung seines Werkes die finnische Grammatik von Crugerus in seinem Besitz gehabt und war von der Existenz der estnischen Gram- 
sich die finnische Grammatik von CrugErus um einige Jahre früher, sagen wir um 1645, schon in Pontoppidans Besitz. Die Grammatik selbst muss natürlich davor, etwa um 1640, geschrieben worden sein. In ein paar Punkten ist die Crugerus'sche Orthographie altertümlicher als die der Bibelübersetzung von 1642: bei Crugerus für $\bar{u}$ neben uu (zwei Belege) auch $\mathrm{w}$ (ein Beleg) und für $\delta$ neben dh (drei Belege) auch d (ein Beleg), in der Bibel von 1642 entsprechend uu (ausnahmsweise $u$ und v) und d, s. hierzu unten Punkt 3b. Daraus darf vielleicht, so gering das Material auch ist, gefolgert werden, dass CRUGERUs seine Grammatik früher verfasst hat, die Bibelübersetzung in die Öffentlichkeit trat und so allgemein bekannt wurde, vgl. auch $\$ 8$. Andrerseits ist aber zu beachten, dass Crugerus in orthographischen Fragen seine eigenen Wege ging und in manchen Punkten über seine Zeitgenossen hinausgekommen ist.

Im Anschluss hieran drängt sich die Frage auf, wie lange die Grammatik von Crugerus in Pontoppidans Besitz blieb, und was ihr weiteres Schicksal war. Poxtoppidan hat sie, wie wir wissen, für seine 1668 erschienene Grammatica Danica verwertet, und ferner hat sie Srv, durch PontopPIDars Vermittelung, in seinen Nogle betenkninger 1663 anonym erwähnt und aus ihr, wieder anonym, tine Angabe (über die Zahl der finnischen Kasus) mitgeteilt (s. §6). Anfang der sechziger Jahre war die CRUGERUs'sche Grammatik also offenbar noch in Pontoppidans Besitz. Pontoppidan starb 1678 (s. $\$ 3$ ), aber von Syv wird aus CRUGERUs in seiner 1685 ersehienenen Sprog-Kunst eine weitere Angabe (über das fi. Verbum), diesmal mit genauer Anführung der Quelle ("Gram. Fin. MJc. Crugeri»), mitgeteilt (s. § 6). Es fragt sich nun, ob Syv die beiden Angaben schon in der Zeit, als er

matik von STAнL in Kenntnis gesetzt und hat später nach weiteren Quellen dieser Sprachen nicht geforscht (nebenbei bemerkt, das Estnische ist in seinem Werk nicht angeführt, und es ist sehr wahrscheinlich, dass er die STaнlsche Grammatik selbst nicht gesehen hat, s. hierzu $\$ 8$ ). Anders war es mit dem Isländischen und Englischen; sie standen seiner Interessensphäre viel näher, besonders das erstere; übrigens wurde die Grammatik von Jovas in Kopenhagen gedruckt. 
seine Nogle betenkninger ausarbeitete, von PontoppId erhielt oder die zweite Angabe nebst der genauen Quellennennung etwas später, als dieser 1665 nach Koge übersiedelte und so sein Nachbar geworden war (s. § 3), oder ob die CRUGERUs'sche Grammatik nach der Vollendung bzw. nach dem Erscheinen von Pontoppidans Grammatik sogar in seinen Besitz überging. In dem zweiten Fall wäre die Grammatik von Crugerus um 1665 noch in Pontoppidans Besitz gewesen. Das Manuskript von Crugerus kann indessen weder in PontopPIdaxs noch Syvs handschriftlichem Nachlass aufgespürt werden. Es besteht noch eine Möglichkeit, nämlich die, dass sie von PoxtopPIDAx nach der Vollendung seiner Grammatik Ende der sechziger Jahre dem Verfasser zurückgeschickt wurde. Wie natürlich auch diese Annahme erscheinen mag, ist über Crugerus' Grammatik in Finnland nichts bekannt geworden (vgl. $\$ 8$ ). Wie es sich ferner damit verhält, dass die Grammatik von CRUGERUs Anfang des folgenden Jahrhunderts von LeıBviz genannt wird (s. $\S 2$ ), s. $\$ 8$.

2. 'Utber Crugerus' Leben wissen wir sehr wenig. Durch Pontoppldan erfahren wir, dass er ein Aboensis war, d.h. dass er in Turku ( $\$$ bo) oder in dessen nächster Umgebung geboren bzw. aufgewachsen war. ${ }^{1}$ Darauf weisen auch einige Elemente in seiner Grammatik hin (vgl. § 8); desgleichen der Wortlaut des aus ihr stammenden Zitats (s. Auszug 3 in $\S 4$ ), beachte darin die Ausdrücke: "Unica extat noftratium dictio ab F initium habens jabherma hallon / qram Tavajtenfes baoherma pronunciant. In lingra Finnica rarisfima à duabus confonantibus incipientia extant rocabula. Tavaftenfibus à CR hæc pauciffima extant, ut crappu nola lignea,.... His Aboen $\int e s$ \& in ejusdem finibus habitantes qvedam alia addunt, ut pleicu creta, ... .»; sein Ausgangspunkt ist, wie man danach schliessen kann, der Turkuer Dialekt (die in Turku und in dessen nächster Umgebung übliche Sprache) ${ }^{2}$, der

1 Mit Rücksicht darauf kann die Frage aufgeworfen werden, ob er nicht ein Verwandter bzw. Nachkomme (Enkel?) des 1591 in Turku gestorbenen Hexricus JohanNis Crugerus (s. §2) war.

2 Der Turkuer Dialekt zu Agricolas Zeit, Mitte des 16. Jh., wird von RAPOLA SKKH I SS. $34-36,323$ f. und VKS S. 21 als ein Misch- 
Hämeer Dialekt, dialectus Tavastensium, wird lediglich zum Vergleich herangezogen.

C. H. Strandierg $\AA$ bo stifts herdaminne I, $\AA$ bo 1832 , S. 113 f. bietet einige weitere Daten (vgl. \$ 2). Laut diesen war Crugerts 1643-52 Kaplan zu Naantali (Nådendal) und zugleich in Raisio (Reso), war fermer Respondens auf der Synode 1664 und hiess auch Cruciger (S. 113: "Af Nådendals... Kapellaner: . . Simon Clementis, 1627. Henricus Crugerus, 1643-52. Sigfridus Jacobi, 1669. Desse alle synas varit gemensamme Kaplaner för Nådendal och Reso.»; S. 114: "Reso Annexa, redan 1305 inrättad. Kapellaner:... Simon Clementis, tecknad of vanföre under Nådendal för 1627. Henricus Crugerus, eller Cruciger, likadeles ibid. för 1643 och 1652. Var Respondens vid Prestmötet 1664»). Wo CRUGerus nach dem Jahre 1652 und im Jahre 1664 angestellt war und was hierauf aus ihm wurde, geht aus unserer Quelle nicht hervor. Falls Henricus Crugerus mit Henricus Johannis, Finmo, identisch sein sollte, der am 22. Sept. 1636 in die Matrikel der Universitet Upsala eingetragen wurde, s. A. Axperssox Uppsala Universitets Matrikel S. 75 in Upsala Universitets Årsskrift 1902 und K. GrotenfeLT Suomalaiset yljoppilaat ulkomaan yliopist oissa ennen v. 1640. II (mit kurzen biograph. Angaben) in Hist. Ark. XVII, Helsinki 1902, S. 310, so hat er in Upsala studiert. Zeitlich stimmt das einwandfrei. In demselben Jahre wurden an der Universität Upsala noch mehrere andere Finnen immatrikuliert (allgemein wurden die Finnen mit "Finno" bzw. "Finlandus" oder nach Landschaften, Städten und Kirchspielen "Nylandius", "Viburgensis", "Aboensis", "Ijoensis» usw. bezeichnet), so u. a. am 21. Mai ANDREas Johaxis, Finno, am 29. Okt. Abrahames Abrahami, Finno, und am 18. Nov. Ericus Laurentil Loctouius, s. Andersson I. c. SS. 74, 76 und Grotenfelt 1. c. S. 309 f. Der erste von ihnen, mit dem später beigelegten Familiennamen Axpreas Johanis Keckoxits, wurde in Upsala 1642

dialekt charakterisiert, im Grunde Südwestfinnisch mit Hämeer Einschlag. Zu Crugerus' Zeit, hundert Jahre später, dürften die Verhält: nisse naturgemäss nicht viel anders gewesen sein. 
Magister, in demselben Jahre Schulrektor in Pori (Björneborg), 1659 Pfarrer in Huittinen und starb 1675, s. GrotenFEL'T l. c. S. 309; der zweite, später als ABRaham Kollavius, studierte in Upsala bis 1640, nachher in Turk $\mathrm{n}$, wo er 1643 Magister wurde, stellte um 1648 eine Übersetzung des schwedischen Gesetzbuches her (1926 von Professor M. Rapola herausgegeben), wirkte später als Ersatzrichter und als Vizelandrichter und starb 1667, s. Grotenfelt l. c. S. 310 und M. R[APO]LA in Kansallinen elämäkerrasto III, Porvoo 1930, S. 201; der dritte, Ericus Laurextir Loctounus, wurde 1638 Kaplan zu Lohtaja, 1647 Pfarrer daselbst und starb 1687, s. Grotenfelt 1. c. S. 310. Unser Henricus Johannis, über dessen spätere Lebensverhältnisse GrotexfELT nichts zu berichten weiss, konnte demnach sehr gut unter dem Namen Hexricus Crugercs (bzw. Cruciger) 1643 als Kaplan zu Naantali und Raisio auftauchen. Unter den zu jener Zeit sowohl im Auslande als in Turku (Åbo, seit der Gründung der Universität 1640) studierenden Finnen findet sich, soweit bekannt (s. Grotenfelt Suomalaiset ylioppilaat etc. in Hist. Ark. XIII S. 96 ff. und XVII S. 277 ff. mit Register und S. 387 f. Nachtrag und LAGUs Album studiosorum Academix Aboensis MDCXL-MDCCCXXVII in Skrifter utgifna af Svenska Literatursällskapet i Finland XI, $1-3,4-6,7$ mit Register, Helsingfors 1891, 1895, 1906), kein anderer Henricus, der für unseren Fall in Betracht käme. Unter der Voraussetzung, dass der 1636 in Upsala immatrikulierte Henricus Johannis, Finno, mit dem später auftauchenden Henricus Crugerus Aboensis identisch ist, können vielleicht die sprachlichen Interessen von AвRahamus AвRAнamr, des späteren Gesetzübersetzers ABRAham Kollanius, ihre Erklärung finden; sie könnten durch seinen Studienkameraden HexrICUs Johannis, des späteren Henricus Crugerus, aufgeschürt sein, wie auch umgekehrt die grammatischen Interessen des Henricus Johaxis durch den ersteren. Ferner könnte in diesem Fall besser verstanden werden, dass die handschriftliche Grammatik von Crugerus nach Dänemark wanderte; man kann sich nämlich denken, dass Crugerus sie schon in Upsala in Angriff genommen hat, was dort natürlich bekannt 
sein musste, und durch seine schwedischen Bekannten konnte Pontoppidax davon wiederum erfahren und sich nachher die Handschrift ausgebeten haben; die Tatsache, dass die Grammatik von Crugerus als Manuskript in die Hände Pontoppidans gekommen ist, steht ja fest, es fragt sich nur, auf welchem Wege Pontoppidas von ihrer Existenz gehört hat.

3. a) Über den äusseren Lebensgang des Henricus CRUGERUs sind wir also sehr dürftig unterrichtet. Auch seine Grammatik kennen wir nur nach einzelnen Bruchstücken. Glücklicherweise haben wir unter diesen durch Pontoppidans Vermittelung einen Abschnitt im ursprünglichen Wortlaut des Verfassers (s. Auszug 3 in $\S 4$ und vgl. $\S 5$ ). Daraus ersehen wir, dass Crugerus sein Werk, wie es zu seiner Zeit üblich war, lateinisch abgefasst hat; doch hat er bei einigen Wörtern, je nachdem es ihm zweckmässig erschien, bald fi. Synonyma angeführt 〈"... truski (Jammaco) ranunculus, ... prijmi (murfina) tempus jentandi,...»>, bald neben der lateinischen Übersetzung ergänzend noch eine schwedische hinzu-

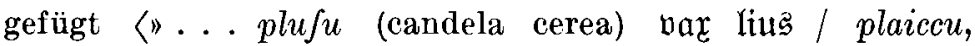
(bleina) macula, ... $\rangle$, oder aber, wenn im Lateinischen ein entsprechender Ausdruck fehlte bzw. ihm unbekannt war, allein die schwedische Übersetzung gegeben ("... fabherma hallon / . . práami opflag / ..m). An das letzte Verfahren werden wir gleich unten zu denken haben. Ausser diesem Zitat, das uns noch aus anderen Rücksichten wichtig ist (s. § 5 und hier unter (), hat Pontoppidan aus Crugerus ferner zwei Formengruppen, wie es scheint, in extenso angeführt, nämlich die Diminutiva auf -inen: Linduinen 'avicula' von lindu 'avis' usw. (s. Auszug 10 in \$ 4) und die Karitivadjektiva auf -toin, -töin: Neuvötoin [-vot-] 'raadløs', lapfitoin 'barnløs', rahatoin 'pengeløs', voimatoin 'mactesløs' usw. (s. Auszug 11 in $\S 4$ ). In dem letzteren Fall sind die fi. Adjektiva bei CRUGERUs offenbar mit schwedischen Übersetzungen angeführt worden, weil sie im Lateinischen zumeist periphrastisch oder durch Zusammensetzungen mit dem Verneinungspräfix inausgedrückt werden müssen (so Neuvotoin 'consilii inops', lapfitoin 'orbus, liberis orbus oder orbatus, liberis carens', 
rahatoin 'carens pecuniis', voimatoin 'iners, infirmus, imbecillus, vi carens, debilis, languidus' usw.), im Schwedischen aber durch Zusammensetzungen auf -lös (im heutigen Schwedischen 'rådlös', 'barnlös', 'penninglös', 'maktlös' usw.; in ihnen nähert sich -lös einem Suffix ebenso wie dän. -løs, d. -los und engl. -less) treffend wiedergegeben werden können. ${ }^{1}$ So hätte dann Pontoppidan seinerseits an die Stelle der schwedischen Utbersetzungen die dänischen gesetzt ('raadløs', 'barnløs', 'pengeløs', 'mactesløs' usw.). Dasselbe dürfte auch von dem Sprichwort Tänäpän culda huomena mulda 'I dag guld, i morgen muld' (s. Auszug 8 in $\$ 4$ ) gelten, das Crugerus wahrscheinlich mit schw. Übersetzung bot, die dann PontopPIDAN durch die dänische ersetzte.

Bei Abfassung der Grammatik übernahm Henricus Crugerus im grossen und ganzen natürlich die Anordnung der lateinischen Grammatiker seiner Zeit. Die derzeitige lateinische Grammatik bestand in der Regel aus vier Hauptteilen: Orthographia, Prosodia, Etymologia und Syntax, s. z. B. G. J. Vossius Latina grammatica (von mir benutzt die Auflage von 1631, Lugduni Bat.) und Ph. Melaxchthon Parva grammatica Latina (von mir benutzt die dänische Auflage, Hafniæ 1610). Ob Crugerus' Grammatik ebenfalls aus den vier oder, mit Auslassung der Prosodia (vgl. unten), aus drei Teilen bestanden hat, lässt sich nicht ausmachen (Pontoppidans Grammatik enthält drei Teile, indem die Prosodia in ihr fehlt, s. § 3). Es kann auch nicht immer festgestellt werden, welchen Teilen der Crugerus'schen Grammatik die bei Pontoppidan vorliegenden Bruchstücke entnommen sind. Das hier eingangs erwähnte Zitat stammt sicher aus der Orthographia. Wenn dieser über den Anlaut handelnde Abschnitt ursprünglich (bei CRUGerus) länger gewesen ist (s. hier unter c), so stammen die in den Auszügen 5,7 und 8 (s. $\S 4$ ) enthaltenen fi. Belege (und auch das Sprichwort Tänäpän culda huomena mulda, vgl. § 5)

1 Hierbei sei darauf hingewiesen, dass Vhál Grammatica Fennica, Aboæ 1733, S. 36 sich in gleichem Fall ebenso des Schwedischen bedient hat: rahatoin 'penningelös', waratoin 'medellös' und taitamatoin 'olärd, fåwitjk, obefkedelig'. 
von ebendort. Die beiden Formengruppen stammen ohne Zweifel aus der Etymologia; in diesem Teil der lateinischen Grammatik sind die Derivativa in einem besonderen Kapitel untergebracht, s. Vossius S. 75 ff. (»De Derivativis») und Melanchthon S. 38 ff. ("De Specie nominum); es handelt sich um die Scheidung der Nomina in primitiva und derivativa); so auch bei PoNTOPPIDAN S. 198 ff. ("Species [Nominum]") ${ }^{1}$ und noch bei Vhatel Gramm. Fenn. S. 31 ff. "De Specie Nominum»). ${ }^{2}$ Die kurze Bemerkung über die Verwendung der Lokaladverbien ulos 'hinaus' und ylös 'hinauf' (s. Auszug 14 in $\S 4$ ) stammt sehr wahrscheinlich aus der Syntax (vgl. §5). Somit kann mit mehr oder weniger Sicherheit behauptet werden, dass Crugerus' Grammatik mindestens aus drei Hauptteilen bestanden hat: Orthographia, Etymologia und Syntax.

Nach diesen Bemerkungen allgemeiner Art wollen wir nun an die Grammatik des Henricus Crugerus näher herantreten und sehen, was sie uns eigentlich bietet, und welche Auffassung wir uns auf Grund der durch Poxtoppidax und SYV übermittelten Bruchstücke von ilır bilden können.

b) Ort ho graphi e. Alphabetisch geordnet haben wir es im ganzen mit folgenden 70 Wörtern zu tun, wobei einige von ihnen mehr als einmal bzw. in mehr als einer Form vorliegen (die Ziffern in den runden Klammern beziehen sich auf die Auszüge in $\S 4$ und die eckigen Klammern enthalten meine Berichtigungen bzw. Ergänzungen wie im Obigen):

1 Doch sind bei ihm hier auch mehrere Komposita, die in dem mit "Figura" (bezieht sich auf einfache und zusammengesetzte Wörter) betitelten Kapitel S. 181 f. behandelt werden müssten, mit herangezogen worden.

2 Dass bei Petraus kelwotoin 'nauci' und kijttämätöin 'ingratus' als Komposita in dem Kap. "De Figura Nominum' (Bl. A 6a) angeführt sind, kann nur im Hinblick auf die lat. Grammatik verstanden werden; Petraus hat, sich mechanisch an das Schema der lat. Grammatik anschliessend, die fi. Karitivadjektiva gleich den lat. Komposita wie indoctus, ineptus, insipiens, impius usw. (s. Vossius S. 6 f. und MeLA:снтноN S. 37 f.) aufgefasst; dasselbe gilt von Martixius, s. bei ihm S. $25 \mathrm{f}$. 
1. fadherma $\sim$ vadherma 'hallon' (3)

2. huomena 'i morgen [cras]' (8), s. Nr. 60

3. Isätöin 'faderløs'

4. caappi 'Jkåp' (3)

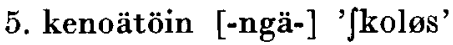
(11)

6. kirja 'liber', Dimin. Kirjainen 'libellus' (10)

7. klafi [cl-] 'glas' $(3,8)$

8. koli [co-] 'fkål' (3)

9. coulu 'Jkola' (3)

10. craaccu 'fupellex culin.' (3)

11. crappu 'nola lignea' (3)

12. crapu 'cancer' (3)

13. cratti ']ar (3)

14. crencu [krenccu] 'sedile' (3)

15. krijni 'fkrijn' (3)

16. crwhu 'fovea' (3)

17. cuinga 'qvid [quomodo]' (2) cuinga-s 'qvid tu' (2), s. Nr. 49

18. culda 'guld' (8), s. Nr. 60

19. cunga 'qvorfum' (2) cungas 'qvorfum tu' (2), s. Nr. 49

20. küütto [cuut-] 'Jkwta' (3)

21. kynttila [-lä] 'candela' (13)

22. lapfitoin 'barnløs' (11)

23. Lauvantaj [-ai] 'Dies Sat.' (1)

24. leivätöin 'brøedløs' (11)

25. lindu 'avis', Dimin. Linduinen 'avicula' (10)

26. Menen ['ich gehe'] (14), menet ['du gehst'] (2),
Mene! ['geh!'] (14), s. Nr.

Nr. 49,61

27. mulda 'muld' (8), s. Nr. 60

28. murkina ['jentaculum'] (3) 29. nauta 'bos' (4)

30. Neuvötoin [-vot-] 'raadløs' (11)

31. Noufen, noufen, Noufe!:

NouJen ylös ['ich stehe auf'] usw. (14), s. Nr. 69

32. Paidhatoin 'Skjorteløs' (11)

33. parta 'barba' (5)

34. peili 'fpegel' (3)

35. pelli 'fpield' (3)

36. pifpa 'Bifp' (5)

37. plaiccu 'macula' (3)

38. pleicu 'creta' (3)

39. plufu 'candela cerea' (3)

40. poica 'puer', Dimin.

poicainen 'puerulus' (10)

41. porme ftari 'Bårgme ftare'

42. porvari 'civis' $(3,5)$

43. prijmi 'tempus jentandi'

44. präämi 'opflag' (3)

45. rahatoin 'pengeløs' (11)

46. Jammaco 'ranunculus' (3)

47. Janot 'dicis' (2), s. Nr. 49

48. Sauma 'Jutura' (4)

49. Jinä, -s: cuinga-s Janot? pro cuinga finä Janot! 'qvid [quomodo] tu dicis?', cungas menet? pro cunga

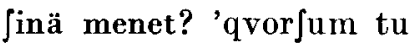
vadis?' (2)

50. Synnitöin 'Syndesios' (11) 
51. taalari 'dalar' (3)

52. trontti 'caulis oleris diffecti' (3)

53. truski 'ranunculus'

54. tuoli 'Stool' (3)

55. Tuomari 'domare'

56. Tuomio 'doom' (3)

57. tuoppi 'Stoop' (3)

58. tuudi [-dhi?] 'ftuud' (3)

59. Tytär 'dotter' (6)

60. Tänäpän 'I dag [hodie]':

Tänäpän culda huomena mulda'I dag guld, i morgen muld' (8)

61. ulos 'ud [hinaus, heraus, aus]': Menen ulos \& ulos menen ['ich gehe hinaus'],
Mene ulos! 'gak ud! [geh hinaus!]' (14)

62. vaari 'faar' (7) vadherma 'hallon' (3), s. Nr. 1

63. valski 'fal $\int k$ ' (7)

64. vangi 'fange' (7)

65. vati 'faat' (7)

66. veidzi 'culter', Dimin. veidzinen 'cultellus' (10)

67. vixi 'fix' (3)

68. voimatoin 'mactesløs' (11) 69. ylös 'op [hinauf, herauf, auf]': ylös noufen \& NouJen ylös ['ich stehe auf'], Noufe ylös! 'Stat op! [steh auf!]' (14)

70. aititöin [äi-] 'moderløs' (11)

Indem im Folgenden eine Übersicht über die Crugerus'sche Orthographie gegeben wird, werden dabei vor allem die Bibelübersetzung von 1642, die Gesetzübersetzung von Kollanius (einem Studienkamerad von Crugerus?, s. hier oben Punkt 2) 1648 (?) und die Grammatik von Petraus 1649 zum Vergleich herangezogen. Die Bibelübersetzung wurde von einem 1638 eingesetzten Ausschuss, bestehend aus Æschillus PETræus (nachmaligem Professor und Bischof) als Präses, Henricus J. Hoffman Maschoënsis, Martinus Strodius (nachmaligem Professor) und Gregorius MatTh ex FavoriNus Pijkensis hergestellt ${ }^{1}$. Bei der Verfassung der Grammatik waren dem Petraus von den Obengenannten Martivus Stodius und Gregorius Favorinus behilflich. ${ }^{2}$ Demnach sollte sie hinsichtlich der Orthographie der Bibelübersetzung

1 Siehe z. B. Niılo Ikola Ensimmäisen suomalaisen raamatun historiaa in Turun sivistyshistoriaa (= Turun Historiallisen Yhdistyksen julkaisuja II), Turku 1927, s. 47 und RApola VKS S. 24 ff.

2 Siehe Vorwort zu der Grammatik. 
gleich sein. Das ist jedoch nicht immer der Fall, wie wir sehen werden.

Die $\mathrm{kurzen} \mathrm{Vokale} \mathrm{sind} \mathrm{mit} \mathrm{je} \mathrm{einem} \mathrm{Zeichen} \mathrm{wie-}$ dergegeben (die Ausnahmen erklären sich als Schreib- bzw. Druckf(ehler);

für a steht a: fadherma, crappu, crapu, culda usw.;

" $\ddot{a}$ " a ${ }^{1}$ : Tänäpän, Isätöin, leivätöin, Jinä usw.;

" 0 " o: pormejtari, porvari, ulos usw.;

" $\ddot{\partial}$ " $\ddot{o}^{2}:$ ylös (dreimal belegt);

" $u$ " u: ulos, mulda, murkina, coulu, crapu usw.;

" $\ddot{u}$ " y: ylös, kynttila [-lä], Jynnitöin und Tytär;

" $e$ " $\mathrm{e}$ Menen, fadherma, Noufen usw.;

" $i$ " $\mathrm{i}$ : lindu, kirja, lapfitoin, cratti usw.

Im allgemeinen verhält es sich damit ebenso in der Bibel von 1642 〈früber z. B. für $u$ bei AgRICola u (uu), v, w, wu und o und noch bei Sorolainen $u, v$, w und o , s. Rapola SKKH I S. 68; desgleichen bei KolLaxius, s. RAPOLA AbrKK S. 14 .

Hinsichtlich der la nge $\mathrm{n} \mathrm{Vokale}$ ist das vorliegende Material knapp; nur mangelhaft sind wir über einige von ihnen und lediglich in der ersten Silbe unterrichtet;

für $\bar{a}$ steht aa: caappi, craaccu, taalari und vaari;

" $\vec{a} \quad$ ää ${ }^{3}$ präämi (der einzige Beleg);

1 Genauer: an zwei Stellen in Kursiv gedruckten Wörtern "ä»: "/inä" (2mal) (s. Auszug 2 in \$ 4) und "Tänäpän" (s. Auszug 8), an einer Stelle in einem in Antiqua gebrachten Wort »ä»: "Tytär» (s. Auszug 6), aber an einer anderen Stelle, ebenfalls in Antiqua stehenden Wörtern, aus Fraktur entlehntes "å»: "Isátóin», "kenoátoin [-ngá-] und vleivátỏin" (s. Auszug 11; daselhst vorliegendes vaititéin" ist folglich in máititơin" zu korrigieren), an einer weiteren Stelle in einem ebenfalls in Antiqua stehenden Wort »a» statt »ä» bzw. »å»: »Kynttila [-lä bzw. - lạ]» (s. Auszug 13); beachte auch "práámi" oder (?) "prååmi" (s. Auszug 3) mit sián" oder (?) viå inmitten des in Kursiv gedruckten Wortes; offenbar besass die Druckerei nicht genug Typen für $\ddot{a}$ in Kursiv- und Antiquaschrift.

${ }^{2}$ Genauer: "on, nur an einer Stelle in einem in Kursiv stehenden Wort (3mal): "yliss (s. Auszug 14); zu beachten ist, dass für ö als erste Komponente des Diphthongs $\ddot{o} i$ in den in Antiqua gedruckten Wörtern (s. Auszug 11) ebenfalls "ị" steht: "Isáto̊in", "leivátoin" usw.

3 Genauer: yái» oder (?) ฉåån, s. oben die Fussnote zu ï. 
für $\bar{u}$ steht uu und $\mathbf{w}^{1}$ : tuudi [-dhi?], küütto [cuutto] und crwhu;

" $\bar{i}$ " ij: krijni und prijmi;

" $\overline{0}$ o: koli [co-] (der einzige Beleg).

Doch kann schon anf Grund dieses Wenigen vermutet werden, dass die langen Vokale bei Crugerus in der ersten Silbe im grossen und ganzen gleich geschrieben waren wie in der Bibel von 1642. In dieser werden sie im Gegensatz zu der früheren Vielfältigkeit (z. B. für $\bar{u}$ bei AGRICOLA w, uu, u, v, vu und wu s. OJansuU MAgrK S. 8 sowie die LMÄH II S. 155 ff. angeführten Beispiele und bei Sorolansex uu, $w$, bisweilen $v$ und ausnahmsweise vu, s. PETAxder Esitys piispa Eerikki Sorolaisen Postillan kielestä s. $\tau$ in Suomi III, 6, Helsinki 1893, und die bei OJAxsuU LMÄH II s. 160 ff. angeführten Beispiele) ziemlich konsequent mit Doppelschreibung bezeichnet, ausser dass für $\bar{i}$, abweichend von diesem Prinzip, wie vielfach früher ij steht, s. RAPOLA SKKH I S. 71; nur ausnahmsweise wird in ihr z. B. für $\vec{u}$ neben dem allgemein üblichen uu auch $u$ und $v$ verwendet: Mos. 2 I 8 uji (= uusi 'neu'), Matth. XXVI 29 Akk. Sg. vden, XXVII 60 Illat. Sg. vteen, IX 17 Illat. Pı. vfijn. Bei PETr æus findet sich in diesem Fall neben dem allgemeinen uu: Bl. C 5a, 8a puulla 'ligno' (Abl. instr.), C 4b, 8a puufta 'ex ligno', D 2 b cuulla 'andire' usw., ziemlich häufig auch $w$ und ausnahmsweise $u$ : C 4a Swrembi 'major', fwrin 'maximus', D 1b jwrinens 'radicitus' usw. (vgl. bei C'Rugerus crwhu), C ib jurexi (= juureksi, Translat. von juuri 'radix'); bei Kollanius für $\bar{u}$ neben dem allgemeinen uu auch $u$ und $w$, betreffs der Bezeichnung der anderen Längen verhält es sich bei ihm annähernd ebenso wie in der Bibel von 1642, s. RAPoLa l. e. und ausführlicher AbrKK S. $15 \mathrm{f}$.

Bei den D i p h th o n g e n, soweit sie belegt sind, herrscht wie bei den kurzen Vokalen eine strenge Folgerichtigkeit (in Lauvantaj ist -aj statt -ai und in aititöin ai- statt äi- als Schreib- bzw. Druckfehler aufzufassen):

$1 \mathbf{w}$ ist ein doppeltes $\mathbf{v}$; mit diesem wurde früher $u$ häufig bezeichnet, so z. B. noch bei Sorolaines, s. o. 
für añ steht au: Lauvantaj [-ai], nauta und fauma;

"on " ou: coulu, Noufen und NouJe!;

" eu " eu: Neuvötoin [-vot-] (der einzige Beleg);

" $a i$ " ai: Paidhatoin, plaiccu, poicainen und Lauvan-

taj [-ai];

" $\ddot{a} i$ ai [äi] ${ }^{1}$ : aititöin [äi-] (der einzige Beleg);

" $o i$ " oi: poica, poicainen, lapfitoin, Paidhatoin usw.;

" $\ddot{0} \dot{q}$ " öi ${ }^{2}$ : Isätöin, kenoätöin [-ngä-], leivätöin usw.;

" $u i$ " ui: cuinga, cuinga-s und Linduinen;

\ei " ei: leivätöin, pleicu, veidzi und veidzinen;

" $u g$ " uo: huomena, tuoli, Tuomari, Tuomio und tuoppi.

Ebenso verhält es sich mit ihnen in der Bibel von 1642 und bei Kollanius, s. Rapola AbrKK S. 16.

Über die $\mathrm{k}$ u r z e $\mathbf{n} \mathbf{K}$ on s o n a n $\mathbf{t}$ e n gestattet das vorliegende Material einen recht guten Überblick. Die Verhältnisse sind hier nach der Natur der Dinge komplizierter.

Für $k$ steht: a) vor de $n$ hinteren Vokale n c: caappi, coulu, craaccu, pleicu, poica, poicainen, Jammaco usw.; k- statt c- in koli und küütto [cuutto] beruht auf einem Schreib- bzw. Druckfehler, in klaji dagegen wahrscheinlich auf einem Schreibfehler (s. §5); b) v or d e n vorder e V o k a l e n k: kenoätöin [-ngä-], kirja, Kirjainen, krijni, kynttila [-lä], murkina, truski, valski; ausnahmsweise c- statt k- in crencu [krenccu], infolge einer inkonsequenten Schreibung oder auf einem Schreib-bzw. Druckfehler beruhend; c) nach n (genauer $\eta$ ) aber in beiden Fällen g: cuinga, cunga, vangi. Ebenso in der Bibel von 1642, s. RAPOLA SKKH I S. 68, und im grossen und ganzen bei Kollanius, s. Rapola l. e. S. 69 und AbrKK S. 16.

Für $t$ steht: a) im An- und Auslaut t: taalari, trontti, tuoli, menet, Janot usw.; desgleichen im Inlaut nach kurzen Vokalen (die Stellung nach langen Vokalen ist nicht belegt), Diphthongen und nach $r$ : Tytär, vati, Isätöin, nauta, aititöin

1 Siehe oben die Fussnote zu ä.

2 Genauer: "ói, s. o. die Fussnote zu ö. 
[äi-]1, parta usw.; b) im Inlaut nach $l$ und $n$ aber d: culda, mulda, lindu und Linduinen (abweichend davon das Kompositum Lauvantaj (-ai] mit $t$ nach $n$ ). ${ }^{2}$ Ebenso in der Bibel von 1642 , so $\mathrm{z}$. B. Mos. 1 I 11 puut 'Bäume', V 3 Jata '100', VII 12 yötä (Part. Sg. von yö 'Nacht'), I 2 autia 'leer', III 20 Äiti 'Mutter', 2 II 8 Akk. Sg. äitin, 1 II 10 wirta 'Strom', II 12 culda 'Gold', IV 7 Jyndi 'Sünde', s. auch RAPoLA SKKH I SS. 68, 80 ff.; bei Petrasus Tabella neben Culda 'Aurum' und Luondo 'Natura' auch Wirda 'Fluvius', letzteres wohl auf einem Schreib- bzw. Druckfehler beruhend statt Wirta, vgl.

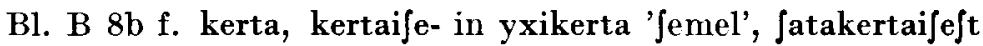

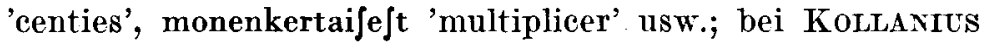
sind die Verhältnisse etwas komplizierter, s. hierüber RAPoLA AbrKK S. $16 \mathrm{f}$.

Für $p$ steht p: Paidhatoin, parta, peili, poica, pifpa, crapu, Tänäpän, lapfitoin usw. Ebenso in der Bibel von 1642: Mos. $1 \mathrm{XV} 2$ poica, lapfitoin, IV 14 tänäpän, XIX 3 leipiä (Part. Pl. von leipä 'Brot') usw. und im allgemeinen bei KoLLanIUS, s. RAPola AbrKK S. 17. Der Fall nach $m$ ist bei CrugerU

1 Das Karitivadjektiv aititöin [äi-] 'moderlos' (von äiti 'Mutter') mit t (starke Stufe) nach der ersten Silbe (vgl. Paidhatoin 'Skjorteløs' von paita 'Hemd') findet sich ferner in derselben Gestalt (äititöin) bei Flor. 63 und Jusl. Lex. (dagegen bei Lönnr. Lex. äiditön und als weniger gebräuchlich äititöin). Es ist hierbei zu beachten, dass das Stammwort äiti in der alten Schriftsprache und u. a. in den südwestlichen bzw. westlichen Dialekten ohne Stufenwechsel (immer starkstufig), also äiti Gen. äitin, erscheint; so auch in VRVoc. 66, bei PETra us Bl. A 4a und Jusl. Lex. (dagegen bei Lönrr. Lex. äiti Gen. äidin und als weniger gebräuchlich äitin), s. hierüber OJANsuU LMÄH I S. 203 f., RAPOLA KSi-Dift. SS. 72 ff., 80 f., AbrKK S. 38 (mit Literatur) und SKKH I S. 132.

2 Falls es sich hierbei nicht um einen Schreib- bzw. Druckfehler oder um eine inkonsequente Orthographie handelt, so haben wir es mit einer etymologischen Schreibung zu tun. Vgl. bei Petraus Bl. D 8a Lauwandai 'dies Saturni', Perjandai 'dies Veneris', Sunundai [Sunnun-] 'dies Dominicus', Manandai [Maanan-] 'dies Lunæ' mit -dai nach $n$ einerseits und Tijftai 'dies Martis', Tuor ttai 'dies Jovis' mit -tai nach $s$ andrerseits; bei Just. Lex. inkonsequent Lauwandai, Perjandai mit -dai, dagegen Sunnuntai, Maanantai (merke auch Heluntai 'pentecofte, pingeshelg') mit -tai gleich wie in Tijstai, Tuorftai. Zu den Komposita auf -tai s. auch RAPOLA SKKH I S. 152 f. 
nicht belegt; in dieser Stellung wurde zu seiner Zeit $p$ durch b bezeichnet (vgl. -ng- und -nd-), s. RAPOLA SKKH I S. 68.

Für $s$ steht im An- und Inlaut $\int$, im Auslaut s: Jammaco,

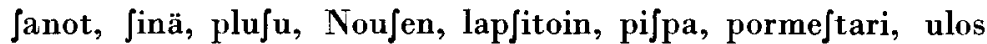
usw. (inkonsequent oder auf einem Schreib- bzw. Druckfehler beruhend -s- in Isätöin). So auch in der Bibel von 1642: Mos. 2 I 10 fota 'Krieg', I 8 ufi 'neu', II 19 käjiftä (Elat. Pl. von käsi 'Hand'), II 13 ulos usw.; desgleichen bei Kollanius, 8. RAPOLA AbrKK SS. 11 und 17. Beachte besonders bei Crugerus (oder rührt es von Pontoppidan her?) in Kursivschrift im Inlaut s vor $k$ : truski und valski (s. Auszüge 3 und 7 in $\S 4)$.

Für $\delta$ steht dh: fadherma $\sim$ Tav. vadherma und Paidhatoin; auch d: tuudi, falls dieses nicht infolge eines Schreib- bzw. Druckfehlers für tuudhi steht. In der alten Schriftsprache bis 1642 wird dieser Laut mit $d h$ oder $d$ bezeichnet, in der Bibel von 1642 mit d, s. Rapola SKKH I S. 88 f.; bei Petraus 1649 wieder beide Zeichen, häufiger jedoch d: Tabella Sade 'Pluvia', [Kä]den, Gen. von Käli 'Manus', [Cuu]den, Gen. von Cuufi 'Sex', Bl. C 3a edemmä 'ulterius' usw., andrerseits C 3a edhes 'ante', C 3b Jydhän 'cor', A 5a, C 5a pidhembi 'longior' usw.; bei Kollanius in der Regel dh, s. Rapola AbrKK S. 17.

Für $h$ steht h: rahatoin und crwhu;

" $f$ " $\mathrm{f}$ : fadherma (der einzige Beleg);

" $\eta$ n: cuinga, cunga, vangi usw.;

"n " n: huomena, krijni, Menen usw.;

) $m$ " $\mathbf{m}$ : Menen, huomena, Tuomari usw.;

" $l \gg \mathrm{l}$ : lindu, mulda, peili usw.;

"r $" r:$ rahatoin, truski, vaari usw.;

" $\underset{i}{ }$ " j: kirja und Kirjainen;

" $v$ v: vaari, vadherma, veidzi, porvari usw.

Von diesen Lauten sind von grösserem Interesse nur $f$ und $v$ (mit den übrigen verhält es sich ebenso in der Bibel von 1642 und im grossen und ganzen bei Kollanius). Nach Crugerus gibt es im Finnichens (im Dialekt von Turku) nur ein Wort mit $f$ : fadherma (s. Auszug 3 in $\S 4$ ). Für $v$, das bei CrUGErus bzw. Pontoppidan nicht nur in Kursiv und Antiqua, son- 
dern auch in Fraktur mit $\mathbf{v}$ bezeichnet wird, steht in der Bibel von 1642 und in der Regel bei Kollanius w, s. RAPOLA SKKH I S. 68 und AbrKK S. 18. Aber z. B. schon Hemmingius Henrici in Masco Vanhain Suomen maan Pijjpain / ja Kircon Esimieften Latinan kielised laulud ... Stockholm 1616, Olaus Elimaus Evangeliumit ia Epiftolat. . . Stockholm 1618, 2. Aufl. 1622, IACobus Henrici Yxi Christillinen Saarna, Pidhetty Turusa ... ab Isaaco Rothovio ... nytt Somexi cäätty ... Stockholm 1634 und Bertuli Hordel Passio, Stockholm 1636, haben v.

Über die anlautenden $k, t, p$ und $f \mathrm{~s}$. hier noch unter $\mathrm{c}$. Anstelle des ts der heutigen fi. Schriftsprache steht dz: veidzi und veidzinen. In der älteren Schriftsprache z. B. bei AGRICoLA allgemein tz, seltener $d z$, bei JAAkKo FinNo umgekehrt, bei SorolaINen meistens tz und in der Bibel von 1642 in der Regel dz, s. RAPola SKKH I 89 ff.; bei PETRæus wieder beide Zeichen: Tabella Neidzy 'Virgo', Bl. A 1b Ruotzi 'Svecia', A 6b Ruotzalainen 'Svecus', A 7b itze 'ipse', A 8a Idze id.,

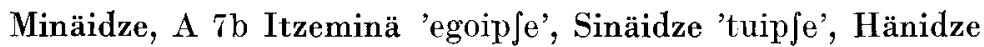
'illeipfe' usw.; abweichend davon bei Kollanius ziemlich konsequent hdh, aber auch häufig $\mathrm{dh}$, s. hierzu RAPOLA AbrKK SS. 5 ff., 18 und SKKH I S. 93.

Von den Ge minatkons o n a $\mathrm{n}$ t e n sind nur $k k, t t$, $p p, l l$ und $m m$ belegt. Für $k l i$ steht vor den hinteren Vokalen die Stellung vor den vorderen Vokalen ist nicht belegt nach langem Vokalelement cc $^{1}$ und nach $\eta$ (nur ein Beleg) c: craaccu, plaiccu und crencu; mit Rücksicht auf die Bezeichnung des $t t$ nach $n$ mit tt (dafür gibt es zwei Belege) lässt sich denken, dass crencu infolge eines Schreib- bzw. Druckfehlers für crenccu oder richtiger für krenccu steht. $t$ ist, auch nach $n$, wie soeben bemerkt, mit tt bezeichnet: cratti, cüütto [cuutto], kynttila [-lä] und trontti; $p p$ mit pp (die Stellung nach $m$ ist nicht belegt): crappu, caappi und tuoppi; $l l$ mit ll: pelli (der einzige Beleg); $m m$ mit mm: Jammaco (der einzige Beleg). In

I Diese Schreibweise ist schon vorher von Agricola benutzt worden, bei dem $k k$ neben dem allgemeinen ck und den weniger häufigen $\mathbf{c h}$, c und $\mathbf{k}$ ab und zu auch durch cc wiedergegeben wird: Cuccainen 'Blume', Miecca 'Schwert' usw., s. OJansuu MAgrK S. 24. 
der Bibel von 1642 sind $k k, t t, p p, l l$ und $m m$ in den gleichen Fällen mit ck, tt bzw. (nach $n$ ) t, pp, ll und $\mathbf{m m}$ wiedergegeben, z. B. Mos. 1 I 2 lijckui 'schwebte', VII 14 caicki 'allerlei', Apostelgesch. XXVII 40 Anckurit (Akk. Pl.) 'Anker'; Matth. II 21 otti 'er nahm', Mos. 1 V 4 Jijtti 'er erzeugte', Matth. V 15 kyntilä 'Licht': kyntiläjalcaan (Illat. Sg.) 'auf den [LichtFuss =] Leuchter', Part. Sg. kyntilätä, Mos. 1 XXXVIII 17 panti 'Pfand'; Matth. XXIV 32 Oppicat! 'Lernet!', (nach Streng NRLS S. 241 f.) Stuoppi (auch Stopi: Part. Sg. Stopia) 'Stoof'; Mos. 1 XLI 35 tulla 'kommen'; Mos. 2 VIII 6, 13 Jammacot (N்om. Pl.) 'Frösche', VIII 12 Jammackoin (Gen. Pl.); vgl RAPOLA SKKH I SS. 68, 83 f. und VKS S. 27. Im grossen und ganzen ebenso bei Kollanius, s. Rapola AbrKK S. $18 \mathrm{f}$.

Die Konsonantenverbindungen, soweit belegt, sind schon meistens im Zusammenhang mit Einzelund Geminatkonsonanten mitberücksichtigt worden; -lt-, -rt-, $-n t-, \quad-p s-,-s p-$, -ntt- usw. sind mit -ld-, -rt-, -nd-, -pJ-, -fp-, -ntt- usw. wiedergegeben. - Über die anlautenden $k l$, $p l$, $p r$ und $t r$ s. unter c. - Es bleibt nur noch hinzuzufügen, dass - $k s$ - mit -x- bezeichnet wird: vixi (der einzige Beleg); ebenso in der alten Schriftsprache, die Bibel von 1642 mitgerechnet, und noch eine geraume Zeit nachher; erst Anfang des 19. Jh. setzt sich dafür -ks- durch und schliesslich auch in der Bibel, in der Ausgabe von 1853, s. RAPoLA SKKH I S. 68 und 79.

Wie wir gesehen haben, steht die CRUGERUs'sche Orthographie im allgemeinen auf derselben Stufe wie die der Bibel von 1642. In der Bezeichnung des $\delta$ mit dh, allerdings auch (?) mit $\mathrm{d}$, und des $\bar{u}$ neben uu mit $\mathbf{w}$ weicht sie von dieser ab und schliesst sich näher an die ältere Schreibung an, wenn auch noch in der Zeit nach 1642 dh und w (z. B. bei Petrasus) gebraucht wurden. In einigen Punkten steht uns Crugerus aber näher, und zwar in der Bezeichnung des $v$ mit $\mathrm{v}$, des $k k$ mit cc (im Prinzip der Doppelschreibung) und des $t t$ mit tt auch nach $n$.

c) L a u t l e h re (Anlaut). In der alten fi. Schriftsprache werden die jüngeren germanischen (schw.) Lehnwörter mit ur- 
spr. $b$-, $d$-, $g$ - und $f-$, die im Finnischen, da sie hier von Haus aus fehlten, durch $p$-, $t$-, $k$ - und $v$ - (seltener $p$-) ersetzt wurden, im Anschluss an das Schwedische, also etymologisierend, häufig ebenfalls mit b- usw. (bei AGRICola jedoch ab und zu mit p-, t-, k- und w-) geschrieben, so z. B. borwari (bei AGRICOLA Borghari und Porghari), dalari, glafi und fangi (auch ein Paar ältere germ. Entlehnungen mischte man in diese ein: tuomari und tuomita mit Stamm tuomi-, wovon auf fi. Boden die Ableitung tuomio; sie werden als duomari oder domari usw. geschrieben). Ebenso in den ältesten Wörterbüchern; in Juscenius' Lex. 1745 aber schon z. B. Daalleri und talari, Fangi und wangi. ReNvall führt in seinem Lex. 1823-26 noch eine Reihe Wörter mit b-, d-, g- und f- an, hebt aber dabei hervor, dass sie mit $p$ - usw. gesprochen werden und dass von jenen nur, und zwar in sehr geringem Umfang $f$ in dem unter dem schw. Einfluss stehenden Küstengebiet, besonders aber im Turkuer (Aboer) Dialekt üblich ist, s. SS. $26,28,42$ und 40 (So heisst es bei ihm IS. 40 über $f$ : "Sonus f pure Finnis est ignotus: quare idem in initio vocabulorum peregrinorum, eivitate Finnica donatorum, a nostratibus plerisque ut $\mathfrak{w}$, rarius ut $\mathfrak{p}$ (ff in media voce sæpe ut $\mathfrak{h} \mathfrak{w}$ ), a paucissimis vero maritimis, Suetizantibus, max. Aboënsibus ut $\mathfrak{f}$ effertur» $\rangle$. Von den Wörtern mit b. usw. sind mehrere auch in LönNRots Lex. aufgenommen aus dem Grunde, weil sie in der Literatur so vorliegen, s. I SS. 51, 53, 86 und 84. Vgl. s. vv. porme $\int t a r i$, porvari, Tuomari, tuomio, taalari usw. $\S 4$ in den Fussnoten zu den Auszügen 3, 5, 7, 8 und s. hierzu RApola SKKH I S. 96 ff. Crugerus liess sich nicht von dem herrschenden Brauch irre führen und hielt sich allein an die gesprochene Sprache. Es heisst bei ihm hierüber - diese Stelle seiner Grammatik ist durch PontopPIDANs Vermittelung erhalten (s. Auszug 3 in $\S 4$ ) - folgendermassen: "Nulla vernacula dictio incipit ab his literis B, D, G, F, Z, ab his enim initium habentes à Svecis funt in ufum traducta.

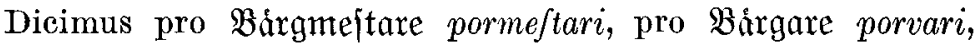
pro Domare Tuomari, pro dont Tuomio, pro balar taalari, pro glas 7 la $f i$ [cl-], pro fix vixi [vixi]. Unica extat noftratium dictio ab $\mathbf{F}$ initium habens fadherma hallon / qvam Tavajten- 
Ses vabherma pronunciant.» Somit haben wir über den Anlaut dieser Wörter eine direkte Nachricht ans der Mitte des 17. Jh. Was man bisher mit Rücksicht auf die Dialekte und auf Grund der schwankenden Schreibung bei AGRICola (s. o.) gefolgert hat (s. Rapola l. c. SS. 48 f., 96 ff.), wird damit bestätigt. $\mathrm{Zu}$ AGricolas Zeiten (hundert Jahre früher) dürften die Verhältnisse nicht viel anders gewesen sein.

In anderen jüngeren germanischen (schw.) Lehnwörtern, in denen mit urspr. Konsonantenverbindungen im Anlaut, sind diese in den südwestlichen bzw. in westfinnischen Dialekten vielfach erhalten geblieben (so $k r$-, $p l$-, $p r$ - usw.) bzw. der fi. Aussprache angepasst worden (z. B. $g l$ - durch $k l$-ersetzt), oder aber in gewissen Fällen vereinfacht worden (z. B. $s k$ - und $s t^{-}>k$ - und $t$-). In der alten Schriftsprache und auch in den ältesten Wörterbüchern werden sie wiederum häufig hinsichtlich des Anlauts wie in den Quellenwörtern geschrieben. Vgl. s. rv. klaji, cratti, craaccu, crwhu, crencu [krenccu], pleicu, truski, plufu, crapu, prijmi, präämi, trontti, tuoppi, tuoli usw. $\$ 4$ in den Fussnoten zu dem Auszug 3 und vgl. hierzu auch OJaxsue LMÄH I SS. 9 f., 18 ff. und Rapola 1. c. SS. 96, 98 ff. Auch über diese Lehnwort gruppe gibt uns CRUGERUs Auskunft, wobei er wieder auf Dialektunterschiede eingeht. In der Fortsetzung des Abschnittes über den Anlaut (s. Auszug 3 in §4) lesen wir folgendes: "In lingva Finnica rarisfima à duabus confonantibus incipientia extant vocabula. Tavaftenfibus à CR hæc pauciffima extant, ut crappu nola lignea, cratti lar, craaccu Jupellex culinaris, crwhu fovea circa fornacem conver $\int i$ cineris, crencu [krenccu] sedile uni Jedenti. His Aboen $\int e s \&$ in ejusdem finibus habitantes qvædam alia addunt, ut pleicu creta, truski (Jammaco) ranunculus, plufu (candela cerea) vax liłı / plaiccu, (bleinta) macula, crapu cancer, prijmi (murfina) tempus jentandi, príámi opjlag/ trontti caulis oleris de $\int$ eeti. Laicorum vitium est nativum in dictionibus à duabus confonantibus incipientibus pronunciandis omittere priorem confonantem, ut dicant pro Sfov fov/pro ङlagh lagh / pro @lár lár / pro Spinna pinna. Sic in Jeqventibus ufitatis dictionibus $\mathrm{S}$ feqventi confona abforbetur propria tamen terminali litera resercata, ut pro Stopp tuoppi/pro Stool tuoli / pro jfola coulu/pro jfál foli [co-]/pro jfrota 


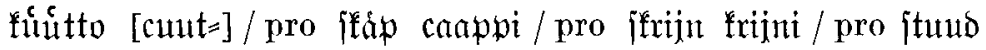
tuubi [=obji?] / pro ipielo pelli / pro ipegel peili." Inhaltlich gehören hierher, genauer gesagt, zum ersten Teil dieses Abschnittes (s. S. 123) die fi. Belege in den Auszügen 5 (»Finni pro B ufurpant $P$, ut dicant \& Jeribant pro Borvari porvari Bárgare / Borger / eivis; pro barta parta bart / barba; pro Bifpa pifpa Bifp \&c."), 7 ("Qvoniam Finni literam f rejiciunt, illamq́ve vocabulis à Svecis mutuò acceptis excludunt, cognatumq́ve $\mathfrak{v}$ a fjumunt, pronunciant pro faar vaari, pro faat vati, pro fange vangi, pro jalfił valski.») und 8 ("Finni, qrum $G$ non admittant, ut dictiones incipiat, pro gla ji dicunt kilafi [cl-], pro gulda culda. Tänäpän culda huomena mulda. $\mathfrak{\Im}$ bag guld / $i$ morgen muldo.»). Es ist daher möglich, dass der Abschnitt über den Anlant bei Crugkerus etwas länger gewesen ist, oder dass z. B. ihm noch eine Anmerkung beigefügt worden war, wo diese Belege angeführt waren (zu porvari und klafi vgl. auch § 5). Wie dem auch sei, wird der Anlaut bei CRUGerus viel ausführlicher behandelt, als dies bei seinen Nachfolgern der Fall ist. Petrets befasst sich damit ganz kurz und berücksichtigt nur die mit Konsonantengruppen anlautenden Wörter: Bl. A 1a »Paucæ dictiones incipientes à duabus confonantibus, ut: Sraacu / inftrumentum culinare, cui lebetes imponuntur ....) (es folgen einige onomatopoetische bzw. deskriptive Wörter). Etwas mehr bei Martisius: Bl. A $1 \mathrm{~b} \| \mathrm{F}$. \& $Q$. in lingvâ finnicâ non inveniuntur, ni ji fortè in vocibus, quæ peregrinæ Junt" und $A$ 2b "I. Ix PRIxcIPIo nullam dictionem B. D. \& G. inchoant, nifi tantum in iis, quæ peregrinæ Junt; ut: Duvntari / Dontare / Judex, \&c. In medio vero \& fine hoc omnino faciunt. II. Dictiones à duabus Confonantibus incipientes, nullas agnofeunt finnones." Bei VHase steht hierüber nur folgendes: S. 2 "Lite$\operatorname{ras} \mathfrak{b} / \mathfrak{g} / \mathfrak{b} / \mathfrak{f} /$ naturales Fenni, ut Sawoni, ignorant \& in motione excludunt...."

d) Formenle hre. De klination. Aus Srvs Nogle betenkninger S. 30 (s. Auszug 15 in $\S 4$ und vgl. hierzu $\S 6$ ) haben wir eine kurze, aber desto wichtigere Mitteilung, nämlich die, dass Crugerus in seiner Grammatik für das Finnische zwölf Kasus angeführt hat; um welche Kasus es sich handelt und wie ihre Benennungen lauten, ist leider nicht ermittelt 
worden. In der deskriptiven fi. Grammatik werden heute fünfzehn Kasus unterschieden, s. SEтÄLÄ Suomen kielioppi, 13. Auflage, Helsinki 1941, $\S 75$ ff. So von käsi (mit -si $<{ }^{*}$-ti $<$ *-te) 'Hand' im Sg.: 1. Nominativ käsi, 2. Akkusativ käden (mit $-\mathbf{n}<{ }^{*}$-m) oder, aus syntaktischen Gründen, käsi (= Nom.), 3. Genitiv käden (mit urspr. -n), 4. Essiv kätenä, 5. Partitiv kättä (= kät-tä mit konsonantischem Stamm), 6. Translativ kädeksi, 7. Inessiv kädessä, 8. Elativ kädestä, 9. Illativ käteen (<kätehen <*kätezen), 10. Adessiv kädellä, 11. Allativ kädelle, 12. Ablativ kädeltä, 13. Abessiv kädettä, 14. Instruktiv (Instrumental) käsin (eigentlich die Pluralform; die Singularform heisst käden und tritt in den Wendungen wie hän veti $k$ a h d e n $k$ ä $d$ e $n$ 'er zog mi t b e id e n H ä n d e n' auf, vgl. jalan < *jal $\gamma$ an von jalka 'Fuss': hän tuli jalan 'er kam zu Fuss', Pl. jaloin: lapset juoksevat paljain jaloin 'die Kinder laufen [mit blos sen F ü s s e n=] barfüssig’1, 15. Komitativ käsine- (gilt zugleich pluralisch und wird stets mit Possessivsuffixen gebraucht: käsineni, -si usw. 'mit meiner Hand, meinen Händen, deiner Hand, deinen Händen' usw.); im Pl.: Nom. kädet, Akk. = Nom., Gen. käsien oder kätten, Ess. käsinä, Part. käsiä, Translat. käsiksi, Iness. käsissä, Elat. käsistä, Illat. käsiin, Adess. käsillä, Allat. käsille, Ablat. käsiltä, Abess. käsittä, Instr. käsin, Kom. käsine- (s. Sg.). Wenn wir von dem Akk., der im Sg. mit dem Gen. lautlich zusammengefallen ist bzw. dem Nom. gleichlautet wie immer im Pl., und von dem in engem Umfang gebrauchten Abess. absehen und ferner den Instr. und Kom., die gewisse Ähnlichkeit haben, als eins rechnen, wie es von den älteren Grammatikern bei VHAEL (s. unten) und voN BEcKER geschehen ist ${ }^{2}$, so zählen wir auch

1 Der Instr. ist im Finnischen schon starr geworden, wie man sich an den von Setälä Suomen kielen lauseoppi, 12. Auflage, Helsinki $1942, \S 67$ angeführten Beispielen überzeugen kann.

2 Übrigens herrscht allgemein die Auffassung, dass der Instr. und der Kom. ursprünglich ein Kasus mit der Endung -ine gewesen sind, jedoch mit Unrecht; s. hierzu Verf. Die Possessivsuffixe in den uralischen Sprachen I (= MSFOu. LIV) S. $227 \mathrm{ff}$., vgl. auch Ravila FUF XXIII S. 47. 
nicht mehr als zwölf Kasus: 1. Nom., 2. Gen., 3. Ess., 4. Part., 5. Translat., 6. Iness., 7. Elat., 8. Illat., 9. Adess., 10. Allat., 11. Ablat., 12. Instr.-Kom. Crugerus mag etwa diese, oder aber die meisten von ihnen angeführt haben, vgi. gleich unten die Auffassung der fi. Kasus bei Petraus und Vhate. Unter dem von Crugerus stammenden Belegmaterial sind lediglich zwei bzw. drei adverbiell erstarrte Essivformen vorhanden: Tänäpän $(<<$ tänäpäivänä = tä-nä + päivä-nä) 'hodie' und huomena $(<$ huomenna $=$ huomen-na) 'cras'1, ferner eine komprimierte Illativform cunga (= kunka < kuhunka = ku-hun-ka; ku- ist Stamm, -hun Illativendung und -ka eine enklitische Partikel) 'quorJum'2 und ein Instr.-adverbium von demselben Pronominalstamm (ku-: kuka 'wer; welcher') und mit derselben enkl. Partikel cuinga (= kuinka) 'quomodo'. In Petræus' Linguæ Finnicœ brevis institutio 1649 sind nach dem Muster der lateinischen Grammatik nur sechs Kasus angeführt, darunter der Vokativ, der im Fi. keine eigene Form hat: B1. A 2b "CaJus fex: Nominativus, Genitivus, Dativus, Accufativus, Vocativus, Ablativus." Doch musste Pexraus dabei gleich die zu eng gesetzten Schranken überschreiten, indem er für den Akk. Sg. zwei Endungen, desgleichen für den Nom. bzw. Akk. Pl. und für den Ablat. Sg. und Pl. sogar vier Endungen anführte, z. B. Bl. A 4 b f. Sg. Nom. Yö 'Nox', Gen. yön, Dat. [Allat.] yölle, Akk. [Akk., Part.] yön, yötä, Vok. [= Nom.] yö,

1 Tänäpän mit apokopiertem Endvokal und huomena mit -naus -nn- bei Crugerus stammen of fenbar aus dem Turkuer Dialekt. Der Schwund des Endvokals und die Kürzung des -nn- (nach langem Vokalement der ersten und) nach dem Vokal der zweiten Silbe sind südwestfinnische Lauterscheinungen, s. OJassu LMÄH I SS. 9, 155 f., II S. 146 f. und Rapola SKKII I SS. 322 ff. (S. 325 tenepen bei AGRIcola, Tänäpän bei Sorolainen und tänäpän in der Bibel von 1642 angeführt), 208 ff. (S. 210 f. Homena bei Agricola und huomena bei Sorolainen angeführt); vgl, auch RApola ESRK in Suomen kansan Raamattu SS. 35-37, wo die in der Bibel von 1642 vorliegenden tänäpän und huomena als südwestfinnische Formen bezeichnet werden.

2 Mit Rücksicht darauf, dass cunga bei den alten südwestfinnischen Autoren öfters belegt ist, muss dieses bei Crugerus wohl aus dem Turkuer Dialekt stammen, vgl. oben S. 68 Fussnote 2. 


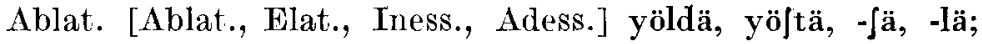
Pl. Nom. [Nom., Part.] Yöt, öitä, Gen. öitten, Iat. [Allat.] öille, Akk. [Akk. (= Nom.), Part.] yöt, öitä, Vok. [= Nom.]

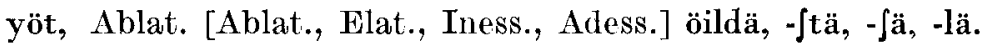
Mehrere Kasus sind somit trotzdem unerwähnt geblieben. In der Syntax, Bl. C 3b ff., kommen jedoch die wichtigsten von diesen in einem oder in dem anderen Zusammenhang zur Sprache. So wird der Ess., dessen Endung -na, -nä Bl. A 2a als enkl. Partikel aufgefasst wird, $\mathrm{C} 6$ unter dem Nom. angeführt: Hän maca [= makaa] Jurutoinna 'jacet Jecurus' usw., C $8 b$ aber (in temporalem Gebrauch) unter dem Ablat.: Näinä

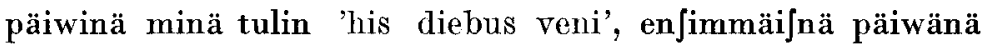
hän tuli 'primo die ille venit' (die anderen Beispiele sind Adessive, darunter ein Inessiv); der Translat. wird C 6a unter dem Nom. genannt ("Etiam nuncupandi verba, \& quæ jimilem vim habent, utrinque Nominativum adfeifcunt, ubi pofterior Nominativus in $\mathfrak{X} \mathfrak{\Im} /$ terminatur»): Hän on walittu Cuningaxi 'electus eft Rex' usw., desgleichen C ra ("Quibusdam verbis additur Dativus perfonam fignificans, cum Nominativo commodum vel incommodum (ignificanten): Se on minulle hywäxi 'eft mihi commodo' usw., dagegen $\mathrm{C} 7 \mathrm{~b}$ unter dem Akk.

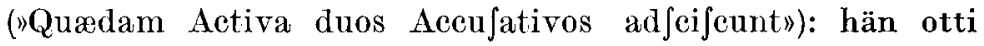
duomarixens minun 'fumpfit me judicem' usw.; der Illat. steht D 1. unter dem Akk. ("Oppidorum, Regionum, peculiarium locorum \& negotiorum nomina ponuntur in Accufativo cum Quæftio eft per Quo»): Hän meni Turcuhun 'ivit Abogiam' usw. (unter den Beispielen auch Allative: meni maalle 'ivit rus' usw.), desgleichen C 4 ("Reus, \& quæ huic affinia

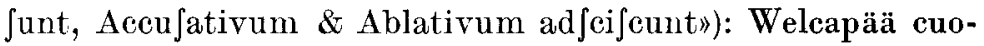
lemahan 'obnoxius mortis' (die übrigen Beispiele sind Elative), $\mathrm{C} 6 \mathrm{~b}$ ("Verbis æftimandi junguntur Aceufativi»): Paljohongos fitä pidhät? 'Quanti hoc æetimas?', colmehen markahan 'tribus marcis' usw. (unter den Beispielen auch Partitive) und $\mathrm{C} 8 \mathrm{~b}$ ("Ad quæftionem quamdiu refpondetur per AccuJativum»): monehen wuotehen 'per multos annos' (die anderen Beispiele sind Akkusative, darunter ein Nom.). ${ }^{1}$

1 Vgl. hierzu auch AHLQvist Bidrag till Finska språkforskningens historia före Porthan S. 9 und 12 ff. 
Auch die übrigen Kasus sind gebucht: D 3 a einige Instr.-formen des sogen. II. Infinitivs: iftui lukein kirja [= kirjaa] 'Jedit legens librum', iftui Jyödhen marjoja 'Jedit commedens [!] grana' usw. (freilich auch eine Anzahl der Instr.-Adverbien in dem Kap. über die Adverbien B 7b ff.), D 5b ein Abess.: Miehet ['ohne Mann'] und C 1b ein Kom.: jwrinens 'radicitus'; sie sind aber als Kasus nicht erkannt. Wie wir sehen, stand PETRaus der fi. Deklination ganz hilflos gegenüber. Er hat zwar im ganzen, allerdings den für das Finnische überflüssigen Vokativ (s. o.) nicht mitgezählt, neun bzw. zwölf Kasus als solche angeführt - in der Formenlehre neun: Nom., Akk., Gen., Part., Iness., Elat., Adess., Allat. und Ablat., in der Syntax noch drei: Ess., Trans. und Illat. (der erste auch schon in der Formenlehre erwähnt, s. o.), hat aber ihr wahres Wesen nicht erfasst und sie alle in das Prokrustesbett der fünf lat. Kasus (Nom., Gen., Dat., Akk. und Ablat.) gezwungen. Keinen Fortschritt in dieser Hinsicht bedeutet MatThias Martinius' Hodegus Finnicus, Holmiæ 1689, s. Bll. A 4b f., A 6a ff., E 3a ff. (S. 78 ff.; der erste Bogen ist unpaginiert). Dieser ist eigentlich eine neue Auflage der PETraus'schen Grammatik, nur mit zahlreicheren und besser gewählten Beispielen; genauer hierüber AHLQVIST Bidrag etc. S. 22 ff. und V. TaRKIAINEN Virittäjä 1927 S. 1 ff.

Selbst wenn unter den zwölf Kasus in Crugerus' Grammatik der Vokativ miteinbegriffen sein sollte, ist sie hierin der Grammatik seines Zeitgenossen Petræus und der vierzig Jahre später erschienenen Grammatik des MaRTIxius weit überlegen. Es kann natürlich, und zwar mit Recht, gefragt werden, ob man auf die blosse übernittelte Zahl der Kasus hin ein derartiges Urteil fällen darf. Doch muss man sich daran erinnern, dass Crugerus auch in anderen Fällen im Vergleich mit seinen beiden Nachfolgern oder richtiger mit Petraus allein - Martinius' Hodegus ist, wie soeben bemerkt, kein selbständiges Werk - einen viel schärferen und klareren Blick verrät, ferner eine Selbständigkeit, die bei diesem fehlt (s. z. B. unter $\mathbf{b}$ und $\mathbf{c}$ ). Daher ist es ganz erwartungsgemäss, dass unser Verfasser auch hierbei vorurteilsfrei an die Sache ging und die fi. Deklination mehr oder weniger im rechten Licht dar- 
stellte. Ardrerseits hat man keinen Anlass anzunehmen, dass Syv etwa die Nachricht von den zwölf Kasus in CrugeRC's' Grammatik ungenau übermittelt hätte. Wir haben bei SyV einen anderen Fall ganz ähnlichen Charakters, wo die fremden Ausführungen zwar ebenfalls kurz, aber richtig wiedergegeben sind. Er hat in dem interfoliierten Exemplar seiner Nogle betenkninger etc. - dieses oben $\S 6$ mit $B$, das Original mit A bezeichnet - S. 103 der Stelle gegenüber, wo sich S. 102 (= A S. 30) die Nachricht von den zwölf fi. Kasus findet: "De Finner hafue tolí [CaJus]", eine folgende Bemerkung hinsichtlich des Polnischen gemacht: "obe $\mathfrak{B o l a f f e r}$ 8. fom

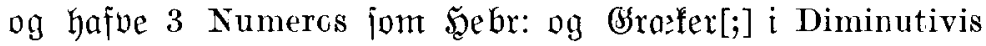
ere be meget rige og lnffelige." In B S. 107 der Stelle gegenüber, wo S. $106(=$ A S. 32) als Quelle für das Finnische eine handschriftliche Grammatik (die ron CRUGerus, s. §6) angegeben wird, wird als Quelle für das Polnische die Grammatik von Jerkyis Roterus erwähnt: " Polffe Grammatife Jerem: Roteri. Brejlaw. 1616" (erste Auflage). ${ }^{1}$ In diesem Werk (von mir benutzt die Auflage von 1680, Breslau): Schlüssel zur Polnischen und Deutschen Sprache, werden in der Tat Bl. E $3 \mathrm{a}$ ff. acht Kasus angeführt ${ }^{2}$, E $2 \mathrm{~b}$ drei Numeri (der Hinweis

1 JAGIC Istorija slavjanskoj filologii (= Enciklopedija slavjanskoj filologii I), Sanktpeterburg 1910, S. 53, nimmt an, dass die 1. Auflage der Roterus'schen Grammatik von 1638 sei; gesehen hat er selbst die 1646 in Danzig erschienene Auflage; ferner existiert nach ihm eine Auflage von 1687. Die Jahreszahl 1616 dürfte jedoch richtig sein, denn in Adencras Mithridates oder allgemeine Sprachenkunde, 2. Theil, Berlin 1809, S. 665 wird dieses Werk unter demselben Jahre angeführt: »Jer. Roter's Schlüssel zur Polnischen und Teutschen Sprache. Bresl. 1616, 8.) $\mathrm{N}$ a c h t r a g. Nachdem das Obige geschrieben war, bin ich in der Lage gewesen, Karol Estreichers Bibljografja polska (Bdd. XXIIIXXXII hsg. von $S t$ a $n$ islaw Estreicher) zu benutzen, wo Bd. XXVI, Krakow 1915, S. 388 f. genaue Angaben (mit Literatur) über Jeremias Roterus' Werk geboten werden: Schlüssel zur Polnischen und Teutschen Sprach, Breslaw 1616; 2. Auflage Bresslaw 1638, 3. Aufl. Danzig 1646, 's. Aufl. Breslau 1680, 5. Aufl. Dantzig 1687 und 6. Aufl. Breslau 1706.

2 Also ein Kasus mehr als das Polnische hat, vgl. z. B. A. Melllet et H. de Willman-Grabowska Grammaire de la langue polonaise, Paris 1921, S. $31 \mathrm{ff}$. 
auf des Hebräische und Griechische rührt von SYV her) und H 8 wird von den Dininutiva u.a. gesagt: "Sึ Deu Diminutivis jins bie Poblen jehr glücflelig uno auch reich /..."

Vorausgesetzt, dass CRUGERts mit den zwölf Kasus im allgemeinen das Richtige getroffen hat, was wahrscheinlich ist (vgl. oben), wird sein Werk hierin erst von der dritten im Druck erschienenen fi. Grammatik, der Grammatica Fennica. von BARTHOLDUS VHAEL, Abox 1733, mit ihren vierzehn Kasus übertroffen. Immerhin wird von VHAEL der Vokativ mitangeführt, dagegen nicht der Akk. Sg. auf -n (er ist in dem mit ihm oleichlantenden Gen. miteinbegriffen), desgleichen der Akk. Pl. (dieser ist in dem mit ihm identischen Nom. Pl. miteinbegriffen), ${ }^{1}$ und ferner sind der Instr. und Kom. unter der gemeinsamen Benennung „Inftructivus vel Defcriptivus» zusammengefasst. So haben wir nach VHaEL S. 6 ff. z. B. von Cala 'pifcis' im Sg.: 1. Nominativus Cala, 2. Genitivus Calan, 3. Dativus [Allat.] Calalle, 4. Accufativus [Part.] Calaa, 5. Vocativus ( $=$ Nom.] Cala, 6. Ablativus [Elat.] Calalta, 7. Locativus [Iness.] CalaJa, 8. Mediativus [Adess.] Calalla, 9. Privativus [Ablat.] Calalta, 10. Negativus [Abess.] Calatta, 11. Factivus vel Mutativus [Translat.] Calaxi, 12. Nuncupativus [Ess.] calana, 13. Penetrativus [Illat.] calahan, 14. Inftruetivus vel Defcriptivus [Instr.-Kom.] caloin 'fifke-wijs', warcain 'inftar furis, furtin', partoines 'cum barba tua'; Pl. Nom. calat, Gen. calain, Jat. caloille usw.

Von den P r o no mi na ist belegt das Personalpronomen der 2. P. Sg. Jinä sowie das aus dessen unbetonter Parallelform sä über enklitisch suffigiertes -sä, -sa (je nach dem, ob an ein vorder- oder hintervokalisches Wort angehängt) entstandene apokopierte -s: cuinga-s Janot? pro cuinga Jinä Janot?

1 Vgl. hierzu Vhael S. 9 f., wo über den Akk. folgendes steht: "Quantum ad Accuiatioum, nota hic \& Jemper, duplicem eum effe; (a) Partialem; täi lcipä̆ / comedit de pane, hon ôt af britct; löi mieltä/percuffit virum, llug munten. ( $\beta$ ) Totalem: jöi leiwan / totum comedit panem, ăt ofw ct beit bris: lëi mieben fcil. cudliari / percu/fit sirum ad necem ujque, j. e. trucidavit, flog mumen ibiäl. Partialis in hac opella ubique exprimitur. Totalis vero cum Genitivo, quoad terminationem convenit in fingulari; in plurali autem cum Nominativo; ubi partialis eft lequiä / miebiä; totalis leiwät / miehet." 
'qvid [quomodo] tu dicis?' und cungas menet? pro cunga Jinä menet? 'qrorfum tu vadis?' (s. Auszug 2 in $\S 4$ ). In der alten finnischen Schriftsprache sind die Formen mit dem enklitischen Anschluss -s sehr häufig und werden immer in bezug auf die 2. P. Sg. verwendet; so z. B. bei AGRICola (nach OJANsUU LM ̈̈H I S. 179 und Pronom. S. 61) NT Matth. VII 5 catzo cuingas wlofotaifit 'siehe zu, wie du ausziehest', XXV 24 cuhungas edh kyluenyt '[wohin $=$ ] wo du nicht gesät hast', Joh. I 19 Cucas olet? 'Wer bist du?', XIII 36 eppes [=etpäs] voi minua nyt Jeurata 'du kannst jetzt mir nicht folgen' usw. (in der Bibel von 1642 lauten der zweite und dritte Satz wie folgt: cuhungas et kylwänyt und cucas olet?); ferner (nach OJansuu Pronom. S. 61) bei Fixno Ettäs 'Dass du' und bei Hemmink quins edh 'wie du nicht', Niins 'So du', Ettes 'Dass du' usw. Beachte auch in VRVoc. FPColl. Bl. K 7a Cuingas Jitä teet? 'Quomodo hoc facis?', $\mathrm{K}$ 8a Cuingas finä woit elä? 'Ut tu autem vales?' (Cuingas mit pleonastisch hinzugesetztem Pronomen Jinä), I 6a Cungas nyt menet? 'Quo tu nunc abis?' usw., bei Petreus B1. D 5b cungas? 'quorfum tu?', C $7 \mathrm{~b}$ Petari tules tennä [tänne]! 'adesdum Petre!', Martivius S. 85 Petari, vel Peckoi tules tänne!, $93 \mathrm{Cu}$ ftas tulet? 'unde vadis?' sä $>-s a ̈,-s a>-s$ ist ein südwestfinnischer Entwicklungsprozess, s. OJansct LM̈̈H I S. 179 f., Pronom. S. 60 ff. und RAPOLA SKKH I SS. 186, 236, 322-25, ESRK in Suomen kansan Raamattu S. 36 f., VKS S. 39; folglich stammen cuinga-s und cungas bei CRUGERUs wieder aus dem Turkuer Dialekt. In den heutigen südwestlichen Dialekten ist die Bedeutung des Enklitikons -s schon verdunkelt, s. OJANSUU LMÄH I S. 179; desgleichen in der heutigen fi. Schriftsprache, s. SETäLä Suomen kielen lauseoppi ${ }^{12}$ S. 126 (\$125 IV).

In der 1. P. Sg. ist auf die gleiche Weise aus dem unbetonten mä, einer Parallelform von minä 'ich', über enklitisches -mä, -ma im Südwestfinnischen ein apokopiertes -m entstanden, das dort ferner zu -n wurde, s. OJAxsuU LMÄH I S. 180 f., II SS. 127 Fussnote 1, 144 f., Pronom. S. 59 f. und RAPOLA SKKH I SS. 242, 322-25, ESRK in Suomen kansan Raamattu S. 36 f., VKS S. 39. Das -n ist in der alten fi. Schriftsprache von Anfang an belegt, bei weitem aber nicht so hänfig 
wie -s: AgRICola (nach OJansuU LM S. 60) NT Luc. XI 24 Mine palaian iellens minun Hone Jeni i o $\int \mathrm{t}$ a $\mathrm{n}$ vloflexin 'Ich will wieder in mein Haus zurückkehren, vo n wo i ch ausging'; bei Hемmiski neben -n: ettän 'dass ich' usw., einige male auch -m: Sittäm 'sitten mä, dann ich' usw., s. OJañsuU LMäH I S. 180, Pronom. S. 59 f. und RAPOLA SKKH I S. 242.1

Es fragt sich nun, was mit "pro" bei CRugercs: cuinga-s Janot? pro cuinga Jinä Janot? und cungas menet? pro cunga Jinä menet? gemeint ist; ob es etwa in dem Sinne zu verstehen ist, dass cuinga-s und cungas soviel wie cuinga finä und cunga Sinä bedeuten ${ }^{2}$, oder aber, dass in jenen Formen das -s aus finä entstanden ist. Mit Rücksicht darauf, in welchem Zusammenhang cuinga-s und cungas bei PonTopPIDAN angeführt sind (s. Auszug 2 in $\S 4$ ), liegt es klar auf der Hand, dass CruGERUs -s als aus Jinä entstanden aufgefasst hat; er ist also der heutigen Deutung des Anschluss -s nahe gekommen, vgl. oben. Die heutige Auffassung von -s findet sich schon bei vor BECKER, indem er es Finsk Gr. S. 161 (vgl. SS. 8 f. und 74 f.) von -sa, -sä ableitet.

Ferner ist bei Crugerus der Pronominalstamm ku- in

1 Die enklitischen Formen -mä, -ma und -sä, -sa sind von den älteren Grammatikern gebucht bei VHAEL S. 43: «na / ï (ma/in / fi vocalis major adfit) contracte ufurpantur pro minä/ jinä», voN BECk E R Finsk Gram-

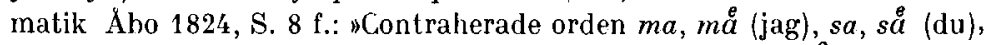
nyttjas af grundfinnarne blott e f $\mathrm{t}$ e $\mathrm{r}$ något annat ord, năstan såsom anhangs particklar eller suffixer och hafva derföre ingen tonisk accent", vgl. daselbst SS. 74 f., 161 und Renvall Finsk Språklära, Åbo 1840, SS. 76 f., 119. Einige Beispiele nach Renvalu Lex.; jottama lyön 'quod si ferio, quid quod cædo', emmä oder emma $<$ en $\div$ mä oder + ma) 'non ego' essä (< et + sä) oder etsäs (mit pleonastisch angehängtem -s nach -sä) 'non tu'.

"Die Verwendung von "pro" in diesem Sinne findet sich offenbar bei ReNvall Lex. I (1823) S. 40, wo folgendes steht: "ettán ut ego (pro

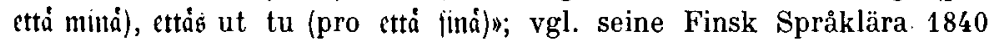
S. 81 (vgl. auch S. 119), wo er -n und -s (in ettän, ettäs usw.) nicht mit den Personalpronomina der 1. und 2. P. Sg. minä und Jinä verbindet, sondern sie eine Art von Personalsuffixen bzw. unvollständige Personalsuffixe nennt (S. 81: "ett slags personal Suffixer» und S. 119: "ofullständiga Personal-Suffixer»). 
einer Illativ- und in einer Instr.form belegt: cunga und cuinga, s. 0 .

Von den Ver b a 1 f or me $n$ sind nur die 1. und 2. P. Sg. Ind. Präs. sowie die 2. P. Sg. Imper. belegt: Menen ['ich gehe'], Noufen (ylös) ['ich stehe (auf)'], menet ['du gehst'], Janot ['du sagst'], Mene! ['geh!'], Noufe (ylös)! ['steh (auf)!'] (s. Auszüge 2 und 14 in $\$ 4$ ). Sie stammen, wie es scheint, teils (menet und fanot) aus der Laut- bzw. Formenlehre (Orthographia bzw. Etymologia), teils (Menen, NouJen usw.) aus dem Kapitel über die Abverbia in der Syntax, vgl. $\$ 5$ und hier oben unter a. Eine sich direkt auf das Verbum beziehende Angabe aus dem Werk unseres Verfassers ist durch SYv Den Danske Sprog-Kunst S. 103 f. (s. Auszug 19 in $\$ 4$ und vgl. \$ 6) übermittelt worden. I)iese Angabe ist jedoch sehr kurz, und wir können daraus nur soviel herauslesen, dass im Finnischen die singularischen und pluralischen Formen im Ind. Präs. und Imperf. verschieden lauten; leider sind dafür keine Beispiele angeführt.

Von den A d ve r b i e $n$ sind belegt: ein Modaladverbium cuinga 'quomodo', zwei Temporaladverbien Tänäpän 'hodie' und huomena 'cras', s. Auszüge 2 und 8 in $\$ 4$ und hier oben; ferner zwei Lokaladverbien (alte Lative auf -s) ulos 'hinaus' und ylös 'hinauf', s. Auszug 14.

Aus der W o r t b i ld u $\mathrm{ng}$ s $\mathrm{l}$ e $\mathrm{h}$ r e sind zwei Formengruppen trhalten, und zwar, wie es seheint, vollständig, s. Anfang dieses Punktes. Die eine bietet vier 1)iminutiva auf -inen nebst den Stammwörtem: "Qinduinen avicula, à lindu avis, Sirjainen libellus à firta liber, veiozinen cultellus à veiozi (ulter, poicainen puerulus à poica puer" (s. Auszug 10 in $\S 4$ ); die andere zehn Karitivadjektiva auf -toin, -töin: "Neuvotoin [-vot-] raables / lapfitoin barnles / rahatoin pengeles / voimatoin macteŝles / Paidhatoin Sfjorteles/Isátóin faberles / ai-

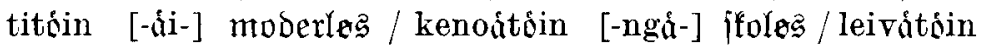
breedles / Jynnitón Sundesleśn (s. Auszug 11 in $\$$ 4). Die beiden Gruppen erscheinen in der in der alten Schriftsprache üblichen Form, vgl. RAPOLA SKKH I SS. $283 \mathrm{f}$. und 286. Von den Diminutiva hat Petrats, wie wir schon oben (\$5) gesehen haben, einen Beleg mehr, also im ganzen fünf (von die- 
sen zwei mit Crugercs gemeinsam): Bl. A $6 \mathrm{~b}$ kirjainen 'libellus', poicainen 'filiolus', pijcainen 'puellula' und härkäinen 'buculus', D 5b f. nochmals die zwei ersten nebst den Stammwörtern (Poica 'filius' und kirja 'liber') und ferner filmäinen 'ocellus' von filmä 'oculus'; von den Karitivadjektiven dagegen nur zwei: Bl. A 6a kelwotuin 'nauci' und kijttämätöin 'ingratus'. Bei Martixius finden sich von der ersteren Gruppe acht: S. 29 Calainen 'pi jciculus', Kirjainen 'libellus', Poicainen 'filiolus vel puellus', Pijcainen 'puellula', Neidzykäinen 'Virguncula'; S. 110 werden Kirjainen und Poicainen wiederum angeführt, dieses Mal mit den Stammwörtern, und ferner Silmäinen 'ocellus' von Silmä 'oculus', Leipäinen 'ett lijtet Bröd' von Leipä 'panis', weidzinen 'cultellus' von Weidzi 'culter'; von der zweiten Gruppe vier: Bl. B 5a f. Mautoin 'in Jipidus', Mahdotoin 'indignus', Kelwotoin 'inutilis', Kijttämätöin 'ingratus'. Bei VHAEL von den ersteren sieben: S. 32 f. ("Subftantiva \& adjectiva») wähäinen von wähä 'parvus', reikäinen von reikä 'foramen', lapfuinen und caunuinen oder (winterjecta fyllaba ca") lapfucainen und caunucainen von lapfi 'infans' und caunis 'pulcher', ferner (ta Comparativis») ifommainen 'majufculus' von ifo 'magnus'; von den letzteren wieder vier: lewotoin 'irrequietus' von lepo 'quies', rahatoin 'penningelös' von raha 'pecunia, penning', waratoin 'medellös' von wara 'penus, förråd' und taitamatoin 'olärd, fåwit jk, obefkedelig'. Die beiden Gruppen zusammengenommen, ist Crugerus, wie wir sehen, im Vergleich mit seinen Nachfolgern hierin ausführlicher. Ferner ist hierbei noch hervorzuheben, dass ein Teil der in der zweiten Gruppe bei Petraeus, Martinius und VhaEl belegten Derivativa von dem Verbalstamm (kijttämätöin und taitamatoin), bei CRUGERUs aber alle von dem Nominalstamm abgeleitet sind.

Dann ist bei Crugerus belegt ein Diminutivum auf -oi (oder genauer auf -k7\%oin): Jammaco mit -c- (schwache Stufe). In dieser Wortgruppe sind im heutigen Finnischen die schwachstufigen Formen belegt in den südwestlichen Dialekten, z. B. kuko < kukoi 'Hahn', sauko 'Fischotter', üäkö 'Fledermaus', neliko 'Viertelmass' (daneben auch die starkstufigen: kukko, nelikiko), s. OJANSUU LMÄH I S. 202, und in dem Unter- 
Satakunta-Dialekt: kukò, saịko, neliko usw., s. IKoLA ASMÄH I S. 291; die schwachstufigen Formen nebst erhaltenem - $i$ sind in der alten Schriftsprache und in den ältesten Wörterbüchern noch öfters belegt: SoRoLaINEx cukoi, VRVoc. 87 und Flor. 99 Saucoi, VRVoc. 80 Nelicoi usw. (dagegen z. B. VRVoc. 89 Cuckoi und VRVoc. 90 und FLoR. 102 Yöcköi mit erhaltenem - $i$, aber mit sekundärem starkem Stamm), s. hierüber RAPOLA KSi-Dift. S. 36 ff. und SKKH I $109 \mathrm{f}$.

e) In dem mit "Syntaxis Præpofitionum" betitelten Kapitel findet sich bei PontopPIDan eine kurze Notiz über die Verwendung der fi. Lokaladverbien ulos 'hinaus' und ylös 'hinauf': "Finnones dicunt Menen ulos \& ulos monen, ylós nou $\int e n \&$ Noufen ylós. Sed notandum hîc, qvòd verbis imperativi modi Præpofitiones potiùs poftponantur. Ut: §tat op / gaf $\mathfrak{u d} /$ løb hen / .... Ita Finnones: Mene ulos gaf ub/Noufe ylós itat op» (s. Auszug 14 in $\S 4$ ). Wie die betreffende Stelle in Crugerus' Grammatik gelautet hat, lässt sich nach ihrer freien Wiedergabe bei PoxtopPIdan nicht feststellen. Es lässt sich auch nicht genau sagen, welchem Teil der Crugerus'schen Grammatik diese Belege entnommen sind, ob der Syntax, wo sie bei PoNToppIdaN vorliegen (vgl. \$ 5), oder aber der Etymologia, wo sie in dem mit "De figuris verborum" oder ähnlich betitelten Kap. mit Rücksicht auf die Wendungen ulos menen und ylös nou Jen ebenso gut untergebracht sein könnten. In der derzeitigen lat. Grammatik handelt es sich in einem so betitelten Kap. um die Scheidung der Verba in simplicia und composita (letztere u. a. durch Zusammensetzung mit Präpositionen gebildet wie advenio, insideo usw.), s. Melanchthox Grammatica Latina S. 51 f. und Vossius Latina grammatica $S .145 \mathrm{f}$. und 163. So allerdings bei dem blindlings dem Schema der lat. Grammatik folgenden PETRAeUs: B1. B $2 \mathrm{~b}$ "De Figuris Verborum. Figure funt Dua: Simplex \& Compofita. Simplex, ut: 2 jtun / gradior, panen / colloco.

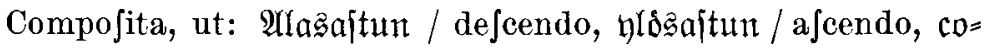
conpanen / compono"; natürlich ebenso bei dem unselbständigen Martinius, s. S. 43. Der präpositionale Gebrauch der lokalen und anderen Adverbien bzw. Postpositionen in der alten fi. Schriftsprache in den Wendungen wie ulos menen 
['ich gehe hinaus, exeo'], ylös noufen ['ich stehe auf, exsurgo'] (Crugerus), Alasaftun 'de fcendo', ylösaftun 'ajcendo' (Pé RAUs) usw. geht auf den fremden, vor allem den schw. Einfluss zurück, vgl. Renvall Lex. z. B. s. vv. u 1 os und y $\mathrm{l} \ddot{\mathrm{s}}$, ferner OJansuU MAgrK S. 180 f., RaPoLA SKKH I S. 31 , VKS S. 60 f. und Virittäjä 1942 S. 5 ff.

8. Zum Schluss sollen die obigen Auseindersetzungen über Crugkrus kurz zusammengefasst und um einige Bemerkungen erweitert werden.

An Hand des Abschnittes über den Anlaut und der zwei Ableitungsgruppen (s. $\S 7,3 \mathrm{c}$ und d) lässt sich vermuten, dass die Grammatik von CRUGERUs umfangreicher war als die von Petreus, Martinius und Vhael, dies natürlich unter der Voraussetzung, dass in jener die übrigen Teile in demselben Masse ausgearbeitet waren. Hervorzuheben sind CrugeRus ${ }^{*}$ Nachrichten über die Dialektunterschiede (s. $\S 7,3 \mathrm{c}$ ) und seine Deutung des Enklitikons -s aus finä 'tu' (s. $§ 7,3 \mathrm{~d}$ ), besonders aber die von ihm gegebene Regel über die Vereinfachung der Konsonantengruppen mit $s$-im Anlaut (s. Auszug 3 in $\S 4: " .$. Sic in feqventibus ufitatis dictionibus $\mathbf{S}$ feqventi confona abforbetur propria tamen terminali litera refercata, ut pro Stoop tuoppi / . ..m); das verleiht seiner Grammatik einen wissenschaftlichen Anstrich. Beachte auch die konstruierten Formen Borvari, barta, Bijpa, glaji und gulda (s. Auszüge 5 und 8 in $\S 4$ : "... Finni pro $B$ ujurpant $P$, ut dicant \& Jeribant pro Borvari porcari Bárgare / Borger / civis; pro barta parta bart / barba; pro Bijpa pifpa Biip \&c." und "Finni, qvum G non admittant, ut dictiones incipiat, pro glafi dicunt $k l a f i$, pro gulda culda*); vielleicht stammen diese jedoch von Pontoppidan her, der auch in anderen Fällen (s. z. B. seine Gramm. Danica S. 30) Formen konstruiert.

Lexikalisch liefert Crugerus rinige Wörter (alles schw. Lehnwörter), die im Finnischen meines Wissens sonst bzw. nicht in der von ihm gegebenen Bedeutung gebucht sind: truski 'ranunculus', prijmi 'tempus jentandi [Frühstückszeit]' (Prijm bei Agricola ist eine literarische Entlehnung und hat die Bedeutung 'Prim, Morgengebet, Frühmesse') und tuudi 
[-dhi?] 'ftuub' ['stolpe, stod' usw.], die im Turkuer ( $\$$ boer) Dialekt zu seiner Zeit offenbar gebraucht wurden.

Von Pontoppidan wird Crugerus als Aboensis bezeichnet. Von den Wörtern und Formen, die aus dem Turkuer (Aboer) Dialekt stammen bzw. stammen können, sind bei ihm belegt fadherma 'hallon' mit $f$ - $(s, \S 7,3 c)$, Tänäpän 'hodie' mit apokopiertem Endvokal (s. $\$ 7,3 d$ ), huomena 'cras' mit - $n$ - aus -nn- (s. $\$ 7,3 \mathrm{~d})$, Jammaco 'ranunculus' mit -c- ( $=-k \cdot-$; schwache Stufe) (s. § 7, 3d), aititöin [äi-] 'moderløs' mit -t- (starke Stufe) nach der ersten Silbe (s. $\S 7,3 \mathrm{~b})$, cunga (= kunka < kuhunka) 'qvorJum', cuinga-s 'qvid [quomodo] tu' und cungas. 'qvorfum tu' (s. $\S 7,3 d$ ). Von Crugerus selbst wird fadherma als ein im Turkuer Dialekt vosliegendes Wort bezeichnet (Tav. vadherma); ferner werden von ihm die folgenden Wörter mit $p l$-, tr-, $k r$ - und $p r$ - ausdrücklich als solche charakterisiert: pleicu 'creta', truski 'ranunculus', plufu 'candela cerea', plaiccu 'macula', crapu 'cancer', prijmi 'tempus jentandi', präämi 'opflag' und trontti 'caulis oleris

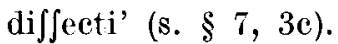

Crugercs hat natürlich die finnische Literatur, die zu seiner Zeit existierte und damals schon eine hundertjährige Tradition hatte, gut gekannt. Z. B. werden die Diminutiva auf -inen: Linduinen, Kirjainen usw. sowie die Karitivadjektiva auf -toin, -töin: Neuvötoin [-vot-], lapfitoin usw. von ihm so geschrieben, wie es seit AGRICoLA in der Literatur allgemein gebräuchlich war (s. $\S 7,3 d$ ); dasselbe gilt von den meisten anderen Wörtern. Er liess sich aber nicht immer von der schriftlichen Tradition Ieiten. In einigen Fällen war für ihn die gesprochene Sprache massgebend. So in der Schreibung der Lehnwörter (s. § $7,3 \mathrm{c}$ ) und so in den orthographischen Fragen (s. $\S 7,3 \mathrm{~b}$ ). Es kann nicht genau bestimmt werden, wann seine Grammatik abgefasst ist. Oben $(\S 7,1)$ wurden die Jahre um 1640 als approximative Zeit ihres Entstehens angenommen. War sie vor oder nach dem Erscheinen der Bibelübersetzung von 1642 fertiggestellt? In dem letzteren Fall lieferte die Bibel dem Crugerus einen wertvollen Stoff; in den meisten Punkten stimmt seine Orthographie mit der der Bibel überein (s. $\S 7,3 b$ ). Auch in dem ersteren Fall dürften ihm als Aboen- 
sis die in Turku ( $\$$ bo) hinsichtlich der finnischen Orthographie herrschenden Anschaumgen nicht unbekannt gewesen sein. Doch übertraf er in der Orthographie seine Zeitgenossen und wirkt in einigen Punkten moderner.

Crugerus hat sehr wahrscheinlich keinen Vorgänger gehabt (vgl. \$1). Er konnte sich nur das Wenige zugute machen, was Burets in seiner Descriptio (s. \$§ 3 und 4) über das Finnische geschrieben hat. Sicher hat er das gekannt und auch benutzt, denn seine Ausführungen über den Anlaut der fi. Wörter klingen sehr an diejenigen des Btrets an (s. Auszug 3 in $\$ 4$ ). Andrerseits entsteht die Frage, ob Crugercs' Grammatik von seinen Nachfolgern benutzt worden ist. Eigentlich kommt hierbei nur PETRÆus, der Anfang der vierziger Jahre dazu Gelegenheit gehabt hätte, in Betracht. Die Anklänge bei beiden Autoren sind aber zu gering, um diese Frage im positiven Sinne zu beantworten. PETR Aus hat zwei Diminutiva kirjainen 'libellus' und poicainen 'filiolus' nebst ihren Stammwörtern, die auch bei CRUGERUs belegt sind ( $\$$. $\$ 5$ und $7,3 \mathrm{~d}$ ); dann ist das Wort cratti bei beiden gleich mit 'lar' übersetzt. Das ist fast alles. Und das kann auf Zufall beruhen. Immerhin ist es sehr wahrscheinlich, dass PETreus die Grammatik von Crugerus gesehen hat; wenigstens muss er von ihrer Existenz gehört haben, und das dürfte ihm den Anstoss gegeben haben, selbst eine Grammatik abzufassen. Später wanderte die handschriftliche Grammatik des CrcGerc's nach Dänemark und verschwand aus dem finnischen Gesichtskreis. Sie wird in keinem finnischen Werk erwähnt, auch nicht in Rexvalls Do signis relationum nominalium in lingua Fennica, Aboæ 1815-17, S. 8 f., wo mehrere Handschriften aufgezählt werdell.

Im Anschluss an das Vorige taucht von selbst die Frage auf, warum die CrcGercs'sche Grammatik nicht im Druck erschienen ist. Existierte doch in Turku seit dem Anfang der vierziger Jahre eine Druckerei (Drucke ab 1643, s. Pippixg Förteckning öfver i tryck utgifna skrifter på Finska - Luettelo Suomeksi präntätyistä kirjoista, Helsingfors $1856-57$, S. 17), und ausserdem könnte sie in Stockholm veröffentlicht worden sein wie viele fimnische Werke vor- und nachher. 
Hat doch Crugerus seine Grammatik mit der $\Lambda$ bsicht geschrieben, dass sie im Druck erschiene. Warum ist das nicht geschehen? Die Gründe dafür können verschiedene sein. Das Werk von Crugerus ist, wie es scheint, ziemlich umfangreich gewesen, jedenfalls umfangreicher als $z$. B. die Grammatik von PeTrel's (s. $\S 7,3 \mathrm{c}$ und d). Das könnte ein Grund gewesen sein; die Druckmöglichkeiten waren damals beschränkt. Ferner konnte der Grund der sein, dass die Crcgerus'sche Orthographie von der damals üblichen zu stark abwich (-cc-, -ntt- und $\mathbf{v}$ statt des damals üblichen -ck-, -nt- und $w$, das ist, was wir wissen, s. $\S 7,3 b$ ) und dass er hinsichtlich der Schreibung der Lehnwörter seine eigene Anschauungen hatte (bei ihm z. B. porvari, vangi und tuoppi statt borwari, fangi und stuoppi oder stopi, s. $\S 7,3 c$ ), oder dass er zu behaupten wagte, es gäbe im Finnischen zwölf Kasus, nicht aber sechs wie der im Banne der lateinischen Grammatik stehende Petreus in seiner Linguæ Finnica brevis institutio nachher lehrte. Das war Grund genug. Es ist hierbei an einen nicht ganz unähnlichen Fall anderthalb Jahrhunderte später zu denken. 1810 bewarb sich der Dichter (später auch als Grammatiker bekannt) JACOB JUDÉN (JAAKKo JUTEINI) um einen finnischen Übersetzerposten in dem neugegründeten Regierungskonseil, wurde jedoch abgewiesen, weil er sich nicht bestimmen liess, von seiner Schreibweise ks und ts zugunsten des damals üblichen $\mathrm{x}$ und $\mathrm{tz}$ abzuweichen, s. J. Krour Suomalaisen kirjallisuuden vaiheet, Helsinki 1897, S. 204 f. Schliesslich bzw. ausserdem könnte der Grund der sein, dass der Professor (später Bischof) Petræus eine finnische Grammatik in Vorbereitung hatte, die 1649 im Druck erschien. Wie es sich mit den Gründen auch verhalten mag, die Grammatik von Crugerus ist nicht gedruckt worden. Da die Wege zu seinem Ziel, sein Werk gedruckt zu sehen, verlegt waren, so konnte der Verfasser desto leichter von ihm Abschied nehmen und es nach Dänemark schicken, vielleicht auch in der Hoffnung, dass es dort veröffentlicht werde.

Dann entsteht noch eine Frage, nämlich die, ob LEIBxiz die Crugerus'sche Grammatik in seinen Händen gehabt hat, wie SETäLÄ Lisiä suom.-ugr. kielentutk. historiaan in Suomi 
III, 5 S. 238 f. denkt (s. § 2). Im Lichte der neuen Angaben über ihr Schicksal ist dies indessen unwahrscheinlich, wenigstens braucht es nicht der Fall gewesen zu sein. Pontoppidax hat die Grammatik von Crugerus etwa ab 1645 in seinem Besitz gehabt und für seine Zwecke verwertet (s. \$§ 2, 4 und $7,1)$ und hat daraus Srv für dessen 1663 erschienene Nogle betenkninger eine Angabe mitgeteilt (s. $\S 6$ ); wie lange sie nachher in Poxtoppidars Besitz blieb und ob sie späterhin in Syvs Hände überging (von $\mathrm{SYV}$ wird sie ferner in seiner 1685 erschienenen Sprog-Kunst angeführt), oder ob sie dem Autor zurückgeschickt wurde, lässt sich nicht feststellen (s. § 7, 1). Pontoppidan, Syv und aller Wahrscheinlichkeit nach auch Crugerus waren schon gestorben (Poxtoppidan 1678, Syv 1702; Crugerus' Todesjahr ist unbekannt), als Leibniz seinen von SETÄLÄ l. c. S. 237 erwähnten Aufsatz niederschrieb, wo unser Verfasser angeführt wird. Unter diesen Umständen ist es schwer verständlich, wie die Grammatik von Crugerus in Leibniz' Hände gelangen sollte. Aus dem Aufsatz LEIBNIz' hat SETÄLÄ I. c. S. 238 den oben $\S 2$ angeführten Auszug gemacht: „Grammaticas nostras recensituris fortasse non erunt prætereundi Grammatici linguarum vicinarum. - - - quibus addiderim Finnicam Henrici Crugeri Aboensis, $L i$ vonicam vel fortasse potius Estonicam Henrici Stahlii et Henrici Goesekenii - - - - Leider hat SETÄLÄ diese Stelle nicht vollständig wiedergegeben; offenbar eine ganze Reihe der Grammatiker "linguarum vicinarum" ist dabei ausgelassen worden (mit $--\ldots$ bezeichnet), unter diesen, wie man annehmen muss, PonTopPIDAN mit seiner Grammatica Danica, ein zu jener Zeit hervorragendes Werk, das von einem sich einigermassen für die skandinavischen Sprachen Interessierenden kaum übersehen werden konnte, und das LEIBNIZ sicher gekannt hat. ${ }^{1}$ Einmal im Besitz dieses Werkes brauchte

1 Vgl. Leibitil Otium llanoveranum sive Miscellanea, hsg. von J. Fr. F e 11 e rus, Leipzig 1718, S. 158, wo folgendes steht: "Otto Sperlingius, Confiliarius \& Profe ffor regius Itafniæ, mifit ad me linguæ Danicæ hiftoriam elegantem, \& qua varia nos docet ad Orbem Septentrionalem Jpectantia.* Cinter "linguæ Danicæ hiftoria» kann wohl nur Pontoppinans Grammatica Danica gemeint sein. Mit Otto Spent.re- 
IseIBniz darin nichts weiter als die Præefatio zu lesen, um auf ein langes Verzeichnis der Grammatiker zu stossen, darunter auf STAHL und CRUGERUS: "Grammaticam... Livonicam [jeripfit] Henricus Stahl, ... ac Finnicam Henricus Crugerus Aboensis..." (s. §3). Es ist sehr wahrscheinlich, dass Leibniz diesen Passus aus Pontoppidan übernommen und in seinen Aufsatz eingefügt hat, allerdings mit einer Berichtigung hinsichtlich der STAHLschen Grammatik (s. gleich unten). Die Zusammenhänge dürfen somit etwa folgendermassen skizziert werden. LeIbxiz' soeben erwähnter Aufsatz bietet $u$. a. E r g än z u n g e n zu ECCARdus' Historia studii etymologici linguæ Germanicæ 1711 (s. $§ 2$ ), worin der Verfasser sich im Kap. XXI und Kap. XXII mit den Werken über die skand. Sprachen befasst und im Anschluss daran (Kap. XXII) mit denen über das Finnische, Estnische und Lappische. Pontoppidans Grammatik wird dabei (Kap. XXI), merkwürdig genug, nicht erwähnt, wohl aber z. B. Jonas' Grammatica Islandica rudimenta 1651; von den damals im Druck erschienenen zwei finnischen Grammatiken (PETRaEU' Institutio 1649 und MartinrUs' Hodegus 1689) und vier estnischen (StaHLs Anführung 1637, Gutslaffs Observationens 1648, GösekenIUs' Manuductio 1660 und Hoknusgis Grammatica 1693) werden nur die Petraus'sche und die GösEk ExIts'sche genannt. In seinem oben erwähnten Aufsatz hat nun LEIBNiz u. a. — so muss man denken - die von Eccardus übersehene Grammatica Danica PoxtoppIDANs ergänzend angeführt und an Hand dieser, genauer deren Profatio, ferner die finnische Grammatik von HENRIcus Crugerus Aboensis und die estnische von Hexricus STAHL. Hinsichtlich der finnischen Grammatik ist hervorzuheben, dass der Name des Verfassers bei ihm genau so wie bei

gius (1634-1715; s. H. Ehrencron-Müller Forfatterlexikon VII, Kabenhavn 1929, S. 445 ff.) stand LeiBNiz 1699 bis 1706 im Briefwechsel betreffs der nordischen Völker und Sprachen, s. EDuard BodemanN Der Briefwechsel des Gottfried Wilhelm Leibniz in der Königlichen öffentlichen Bibliothek zu Hannover, Hannover 1889, S. 307 f. Es mag noch hinzugefügt werden, dass LEIBNiz an den skand. Sprachen sehr interessiert war, vgl. \%. l3. seine Collectanea etymologica I S. 272 f. 
Pontoppidan erscheint. Ferner: hätte Lembntz Crugenus' Grammatik in seinen Händen gehabt, so hätte er, wie er es in anderen ähnlichen Fällen tat, noch hinzugefügt, dass sie ein Manuskript war; bei Pontoppidax wird dieser Umstand nicht in der Præfatio, sondern in der eigentlichen Grammatik S. 59 erwähnt ("Grammatica Finnica manuferipta", s. Auszug 3 in $\$$ 4), was der Aufmerksamkeit LEIBxiz' offenbar entgangen ist. Dass Leibriz hierbei Pontoppidan als Quelle gedient hat, sehen wir nicht weniger deutlich daran, wie STAHLs estnische Grammatik von ihm angeführt wird. Doch verhält es sich mit dieser ein wenig anders. Pontoppidax hat sie zwar in der Profatio zu seiner Grammatik erwähnt (merke: bei ihm "[Grammatica] Livonica"), hat aber aus ihr keinen Beleg mitgeteilt, und es ist offenbar, dass er sie selbst nicht gesehen, ja sogar nicht mal ihren genaueren Titel ("Anführung zu der Estnischen Sprach») gekannt hat (vgl.oben S. 106 Fussnote); wäre dies der Fall gewesen, so hätte er sie auch richtig als "Grammatica] Estonica" und nicht als "[Grammatica] Livonica" angeführt. ${ }^{1}$ LEIBxiz war sich dessen bewusst, dass das Livische (lingua Livonica) eine besondere Sprache war (vgl. z. B. SETÄLÄ l. c. S. 239 f.) ${ }^{2}$, und war andrerseits davon unterrichtet (durch seine weite Korrespondenz oder z. B. an Hand Wexioxius' Epitome ete. lib. III cap. $\mathrm{X}$, die er sehr wahrscheinlich gekannt hat), dass die Stahlsche eine estnische Grammatik war. So fügt e er bei der Übernahme des Pox-

1 Pontopidan hat die Nachricht über die Stahlsche Grammatik offenbar durch Korrespondenz erhalten. Sein Gewährsmann, wer es auch gewesen sein mag, ist dabei ungenau verfahren, indem er aus der geographischen Gesammtbezeichnung "Livonia» (zu jener Zeit Liv- und Estland umfassend, s. z. B. Soterus [Bureus] Suecia 1633 S. 66 ff. und Adam Olearius Offt begehrte Beschreibung der Newen orientalischen Reise, Schleswig 1647, S. 87) das Adjektiv "Livonica" (Grammatica Livonica) im Sinne "Estonica" bildete.

2 SeтӓLӓ führt 1. c. S. 240 aus dem Aufsatz Leıвniz' eine Stelle an, wo das deutlich zutage tritt: "- - 7. Finnonica (cum Lapponica et cognata Estonica). 8. Livonica propriè dicta, quæ in paucis superest locis, si modo ab aliis satis diversa est, de qvo dubito cum specimina desint. - - - 10. Hungarica (qvæ nulli magis qvam Finnonicæ accedit)." 
TopPIDANschen Textes auf seine gewöhnliche Art eine milde Berichtigung bei: "Lironicam vel fortasse potius Estonicam"; andernfalls hätte er einfach "Estonicam" geschrieben. Ausser der Strahlschen Grammatik (STAHL bei ihm latinisiert STAHLIUS wie bei WexIoNius) führte er die bei Eccardus schon erwähnte (diesmal also dessen Angabe nicht nur ergänzend, sondern zugleich wiederholend) Grammatik von HenrICUs Gösekeñus an.

Über die Lebensverhältnisse des Hexricus Crugerus sind wir also, wie aus dem Obigen hervorgeht, sehr spärlich unterrichtet. Auch aus seiner Grammatik, besitzen wir nur einzelne Bruchstücke, die aber trotzdem hinreichend sind, um uns von ihr eine ungefähre Vorstellung zu schaffen und CRUGERUs selbst als Grammatiker in groben Zügen charakterisieren zu können. Er erscheint uns in sehr günstigem Licht. Er war ein selbständiger und vorurteilsfreier Geist. Seine Wahrnehmungen fussten auf unmittelbaren Beobachtungen der gesprochenen Sprache. Die finnische Schriftsprache war in jener Zeit in rascher Entwicklung begriffen und machte mit der 1642 erschienenen Bibelübersetzung einen mächtigen Schritt vorwärts; die orthographischen Fragen standen im Vordergrund. Auch in diesem Punkt übertraf er seine Zeitgenossen.

JuLIUs Mark.

\footnotetext{
Abkürzungen.

AbrKK = MARTti Rapola Äännehistoriallinen tutkimus Abraham Kollaniuksen lainsuomennosten kielestä, Suomi V, 5, Helsinki 1928.

ASMÄH = NiLLo IкоLA Ala-Satakunnan murteen äännehistoria I, Annales Universitatis Fennicae Aboensis B III, 1, Turku 1925.

DALIN = A. F. DALIN Ordbok öfver svenska språket I-II, Stockholm 1850-53.

DEWb. ${ }^{11}=$ Friedrich KLuge Etymologisches Wörterbuch der deutschen Sprache, 11. Auflage bearbeitet von W. $\mathrm{Kra}$ u e und A. Gö t z e, Berlin 1934.

ESRK = MARTtr RAPOLA Ensimmäisen suomalaisen Raamatun kieli, Suomen kansan Raamattu, Helsinki 1942.
} 
EWb. ${ }^{2}=$ FERdinand WiedemanN Ehstnisch-deutsches Wörterbuch, 2. vermehrte Auflage, redigirt von $J$ a c o b H u r t, St. Petersburg 1893.

FBB = Vilн. ThомsеN Beröringer mellem de finske og de baltiske (litauisk-lettiske) Sprog, Kobenhavn 1890.

Flor. $\quad$ Henricus M. Florinus Nomenclatura rerum brevissima Latino-Sveco-Finnonica, 2. Auflage, Aboæ 1683.

FPColl. = Formulæ puerilium colloquiorum, s. VRVoc.

FUF $\quad=$ Finnisch-Ugrische Forschungen, Helsinki 1901-.

GEWb. ${ }^{3}=$ Sigismund Feist Vergleichendes Wörterbuch der gotischen Sprache, 3. neubearbeitete und vermehrte Auflage des Etymol. Wb. d. got. Sprache, Leiden 1939.

Jusl. $\quad=$ Daniel Juslenius Suomalaisen Sana-Lugun Coetus Fennici lexici tentamen — Finsk Orda-Boks Försök, Stockholm 1745.

KSi-Dift. = MARTT RAPOLA Kantasuomalaiset pääpainottomain tavujen $i$-loppuiset diftongit suomen murteissa, Suomi IV, 17, Helsinki 1919-20.

I.MÄHI = HEIKKI OJANSUU Suomen lounaismurteiden äännehistoria I (Vokaalioppi), Suomi III, 19, Helsinki 1901; II (Konsonantit), Suomi IV, 2, Helsinki 1903.

LönnR. = Eirias Lönnot Suomalais-Ruotsalainen Sanakirja Finskt-Svenskt Lexikon I-II, Helsinki-Helsingfors 1874-80; Suppl. hsg. von A. H. K a ll i o 1886.

MAgrK = Heıкк Ojansuu Mikael Agricolan kielestä, Suomi IV, 7, Helsinki 1909.

MSFOu. = Mémoires de la Société Finno-Ougrienne, Helsinki 1890.

NDEWb. $\quad=$ H.S. Falk und AlF Torp Norwegisch-dänisches etymologisches wörterbuch I-II, Heidelberg 1910-11.

NNEOb. = ALF Torp Nynorsk etymologisk ordbok, Kristiania 1919.

NRLS = H. J. Streng Nuoremmat ruotsalaiset lainasanat vanhemmassa suomen kirjakielessä, Helsinki 1915.

NyK = Nyelvtudományi Közlemények, Budapest 1862-.

Petreus = Aschillus Petraus Linguæ Finnicæ brevis institutio, Aboæ 1649.

Pronom. = Heıккі OJansuU Itämerensuomalaisten kielten pronominioppia, Annales Universitatis Fennicae Aboensis B I, 3, Turku 1922.

Renv. = Gustayus Renvall Suomalainen Sana-Kirja - Lexicon linguæ Finnicæ I-II, Aboæ 1823-1826.

Rietz = Johan Ernst Rietz Svenskt dialekt-lexikon, Lund 1867. 
SAOb. $\quad=$ Ordbok öfver svenska språket, utgifven af Svenska Akademien, Lund 1898-..

Schrod. = Ericus Schroderus Ubsal. Lexicon Latino-Scondicum, quo quatuor celebriores totius Europæi linguæ atque Idiomata orbis, scilicet Latinum, Suecicum, Germanicum \& Venedicum seu Finnonicum ... proponuntur; IIolmiæ 1637. Von mir b?nutzt der Facsimile-Abdruck, hsg. von B engt Hes selman mit "Utgivarens

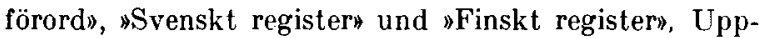
sala 1941.

SKKHI = MartTi Rapola Suomen kirjakielen historia pääpiirteittäin I, Helsinki 1933.

Sö̀nRw. = K. F. Söperwall Ordbok öfver svenska medeltidsspråket I-II L Lund 1884-1918.

SvEOb. ${ }^{2}=$ EloF Hellquist Svensk etymologisk ordbok I-II, 2. Auflage, Lund 1939.

Vend. = Herman Vendell Ordbok över de östsvenska dialekterna, Helsingfors 1904-07.

Verz. = E. N. SET̈̈LA Biobliographisches verzeichnis der in der literatur behandelten älteren germanischen bestandteile in den ostseefinnischen sprachen, FUF XIII, Helsingfors 1912-13.

Vkí = Martti Rapola Vanha kirjasuomi, Helsinki 1945.

VRVoc. = [ANonymus] Variarum rerum vocabula Latina, cum Svetica et Finnonica interpretatione, Holmiæ 1644. Als Anhang (mit fortlaufender Druckbogennumeration, aber unpaginiert): Formulæ puerilium colloquiorum, Stockholmiæ 1644. 